\title{
Economic evaluation of change in clinical practice : methods for informing decisions about guidelines and implementation strategies
}

Citation for published version (APA):

Hoomans, T. (2008). Economic evaluation of change in clinical practice : methods for informing decisions about guidelines and implementation strategies. [Doctoral Thesis, Maastricht University]. Universitaire Pers Maastricht. https://doi.org/10.26481/dis.20081017th

Document status and date:

Published: 01/01/2008

DOI:

10.26481/dis.20081017th

Document Version:

Publisher's PDF, also known as Version of record

Please check the document version of this publication:

- A submitted manuscript is the version of the article upon submission and before peer-review. There can be important differences between the submitted version and the official published version of record.

People interested in the research are advised to contact the author for the final version of the publication, or visit the DOI to the publisher's website.

- The final author version and the galley proof are versions of the publication after peer review.

- The final published version features the final layout of the paper including the volume, issue and page numbers.

Link to publication

\footnotetext{
General rights rights.

- You may freely distribute the URL identifying the publication in the public portal. please follow below link for the End User Agreement:

www.umlib.nl/taverne-license

Take down policy

If you believe that this document breaches copyright please contact us at:

repository@maastrichtuniversity.nl

providing details and we will investigate your claim.
}

Copyright and moral rights for the publications made accessible in the public portal are retained by the authors and/or other copyright owners and it is a condition of accessing publications that users recognise and abide by the legal requirements associated with these

- Users may download and print one copy of any publication from the public portal for the purpose of private study or research.

- You may not further distribute the material or use it for any profit-making activity or commercial gain

If the publication is distributed under the terms of Article 25fa of the Dutch Copyright Act, indicated by the "Taverne" license above, 
Economic Evaluation of Change in Clinical Practice:

Methods for Informing Decisions about Guidelines and Implementation Strategies 
Print: Datawyse / Universitaire Pers Maastricht Cover design and lay-out: Ties Hoomans

Copyright (C) 2008 Ties Hoomans, the Netherlands ISBN 9789052787626 


\title{
Economic Evaluation of Change in Clinical Practice: Methods for Informing Decisions about Guidelines and Implementation Strategies
}

\author{
Dissertation \\ to obtain the degree of Doctor \\ at the Maastricht University, \\ on the authority of the Rector Magnificus, Prof. dr. G.P.M.F. Mols, \\ in accordance with the decision of the Board of Deans, \\ to be defended in public \\ on Friday 17 October 2008 at 12.00 hours
}

by

Ties Hoomans

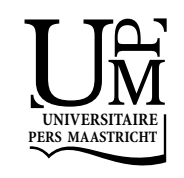


Supervisor

Prof. dr. J.L. Severens

Co-supervisors

Dr. A.J.H.A. Ament

Dr. S.M.A.A. Evers

\section{Assessment Committee}

Prof. dr. J.A.M. Maarse (Chairman)

Prof. dr. A.H. Briggs (University of Glasgow)

Prof. dr. R.P. Grol

Prof. dr. J.A. Knottnerus

Prof. dr. F.H. Rutten (Erasmus University Rotterdam) 
aan $\operatorname{pap}^{\dagger}$ en mam, lieke en onne 



\section{Contents}

Chapter 1 General introduction 9

Chapter 2 Methodological quality of economic evaluations of guideline implementation into clinical practice: a systematic review of empiric studies

Chapter 3 Value for money in changing clinical practice: should decisions about guidelines and implementation strategies be made sequentially or simultaneously?

Chapter 4 Implementing guidelines to change clinical practice: how much to invest and what is the value?

Chapter 5 Modelling the value for money of changing clinical practice: a stochastic application in diabetes care

Chapter 6 Value of information and value of implementation: application of an analytic framework to inform resource allocation decisions in metastatic hormone-refractory prostate cancer

Chapter 7 General discussion

Summary

Samenvatting

Acknowledgements

Curriculum vitae 

I General Introduction 
10 Chapter 1 


\section{I.I Introduction}

Economic evaluations are increasingly being used by decision makers to form considerable judgement about whether implementing guidelines to change clinical practice is likely to be worthwhile [1]. Clinical guidelines are regarded as a vehicle for translating research evidence and bring it into daily practice, for improving patient care and containing costs [2]. Despite the evident benefits of guidelines, health care professionals and patients may not adhere to guideline recommendations [3]. Resources need to be committed to implementation strategies to change adherence to clinical guidance [4-7]. In the face of suboptimal practice, decision makers need not only to decide about whether to adopt guidelines but also to determine whether it is worth ensuring their implementation [8,9]. Moreover, as these decisions are inevitably undertaken in a context of uncertainty concerning the costs and effects of both guidance and its implementation, it is important to decide whether to fund additional research to reduce decision uncertainty $[10,11]$. Given the limited resources available for practice change, decision makers need to carefully consider resource allocation between guideline adoption, strategy adoption and research funding. Economic evaluations seek to inform these decisions, and can be defined as comparative analyses of two or more alternative uses of resources in terms of their costs and consequences [12].

The growing prominence of economic evaluation as a basis for decision making about resource allocation for guideline implementation to change clinical practice has led to an increased scrutiny of studies and their methods $[12,13]$. That is, for the evaluations to provide decision makers with useful and reliable information, they should follow methodological guidance. The established methods and guidelines [12,14-18] provide guidance on data collection, decision analysis and interpretation of analytic results for economic evaluation of (standard) health care interventions or programmes, with the methodology for studying the efficiency of guideline implementation covering issues related to the design and statistics of implementation research [6,19-22] and to cost-effectiveness analysis of implementation strategies [8,23-26]. Given its nature and complexity, however, there remain important methodological challenges associated with exploring the economics of clinical practice change, like 'how to combine evidence on guidelines and strategies to determine the value for money of changing practice?', 'on the basis of what value should decisions about practice change be based?', and 'how to explore decision uncertainty and asses the worth of collecting more evidence?'. This thesis addresses these methodological challenges, and aims to advance analytic methods for economic evaluation of guideline implementation to change clinical practice.

This chapter first outlines the economics of clinical practice change. Next, the established methods for health economic evaluation and that for economic evaluation of 
change in clinical practice are discussed, addressing the methodological challenges in the latter. Finally, the aim and outline of the thesis are formulated.

\section{I.2 Economics of change in clinical practice}

\section{I.2.I Clinical guidelines}

As defined by the Institute of Medicine, clinical guidelines are 'systematically developed statements to assist health care professional and patient decisions about appropriate health care for specific clinical circumstances' [27]. Such guidelines have the potential to improve patient care and contain health care costs by promoting health care interventions of proven benefit and discouraging inefficient interventions [28,29]. With guidelines usually referring to a set of recommendations, covering several aspects of patient management (i.e. diagnosis, treatment or follow up of the disease or condition targeted), they may vary in their scope and length, and are often adapted to local situations [2,30,31]. Guideline recommendations may target various types of behaviour (e.g. prescribing, use of medication or general management) of individual professionals or multi-professional groups and/or individual patients or patient groups. Guidelines differ from quality concepts and assurance tools that are defined as 'authorative statements of (a) minimum levels of acceptable performance results, (b) excellent levels of performance or results, or (c) the range of acceptable performance or results' $[32,33]$ in that guidelines should be followed in most circumstances but allow for some flexibility in clinical use [34].

Whilst guideline development has become more and more formalised and institutionalised, there is no widely accepted way to incorporate economic considerations into guidelines [7,35]. Determining whether a clinical guideline represents an efficient use of resources basically involves consideration of both the effects and costs of the guideline recommendations. Besides final patient outcomes or health related outcome measures, guideline effectiveness is commonly established in terms of clinical outcome measures (e.g. cholesterol level or blood glucose) and measures at the level of health care professionals (e.g. medication prescribing or treatment rate). Guideline costs may include the costs of developing the clinical guideline and the costs of health care provision. Guideline development costs may include time costs of staff attending development meetings and research costs, and may exceed half a million euros [3]. Health care provision costs, such as the costs for medication or treatment, are a consequence of patient management following guideline recommendations.

\subsubsection{Non-adherence to guideline recommendations}

Studies in Western countries suggest that $30-40 \%$ of patients do not receive care according to evidence-based insights, and $20-25 \%$ of care provided is not needed or potentially harmful [2,36-38]. Non-adherence to clinical guidance may be caused by a 
variety of factors [39-44]. These factors can relate to individual health care professionals and patients (e.g. knowledge and competence, attitudes and opinions or motivation for change), to the social setting (peers and culture) and the system (organisation and structure, financial resources and reimbursements) [2]. Suboptimal adherence to care standards can not only have adverse medical and legal consequences [45] but also has economic impact, reducing the efficiency of health care provision in terms of health gain and resources forgone $[9,46,47]$. Efficiency losses may amount to several millions of euros on annual basis at national level $[48,49]$.

To encourage professionals and patients to use clinical guidance in daily practice, the development of evidence-based guidelines must be complemented by well developed, well executed and sustained implementation programmes $[2,3,50]$. Implementation involves identifying and assisting in overcoming the barriers to the use of the knowledge obtained from a tailored message [28]. It is a more active process than diffusion and dissemination, in that it uses not only the message itself but also organisational and behavioural tools that are sensitive to constraints and opportunities of identified professionals and patients in identified settings [28]. Most theories on implementation of research evidence in clinical practice emphasise the importance of developing good knowledge and understanding of the nature and complexity of behaviour and behavioural change, its important moderators, the important modifiable mediators of behaviour (e.g. knowledge and attitudes), and the impact of interventions to change these $[2,37]$.

\section{I.2.3 Implementation strategies}

Implementation strategies aim to change the adherence by health care professionals and patients to evidence-based clinical guidance [5,51]. Such strategies are more and more tailored to local situations, and may be targeted at single health care professionals (or patients) or multi-professional (or multi-patient) groups. Implementation strategies are usually classified according to a taxonomy of professional, organisational, regulatory and financial interventions that was developed by the Cochrane Effective Professional and Organisational Change (EPOC) [1], and may be either single faceted or multifaceted (i.e. combining two or more strategies). Frequently used (combinations of) strategies include educational materials and meetings, outreach visits, audit and feedback, and reminders [1,37].

Whether implementation strategies can be defined as 'good value for money' depends on both its effectiveness in changing adherence to evidence-based clinical guidelines and the cost of implementation [6,8]. An indication of the effected change in behaviour may be obtained from the direct comparison of provided care with guided care, non-objective measures like self-report data, surrogates for guideline adherence (e.g. the number of diagnostic tests or amount of treatments provided) or (intermediate) patient outcomes. Given the complexity and dynamism of behavioural change, it 
may be relevant to consider patterns of change, such as the duration of implementation effects, potential learning effects, and minimum or maximum adherence rates. Implementation costs may include the costs for developing and executing implementation strategies [7]. Examples of strategy development costs are time costs of staff attending development meetings, expenses on training outreach visitors and software development costs. The execution costs of implementation strategies may involve media costs and opportunity costs of health care professionals and patients attending educational meetings or receiving outreach visitors, and often vary with the format, intensity and degree of implementation activities as well as the number of professionals or patients targeted [6,9]. The overall budget impact of national implementation programmes may range from (much) less than a million euros [52-54] to multiple millions of euros [5557], with implementation strategies costing between a few euros and several thousands of euros per health care professional targeted.

\section{I.3 Methods for health economic evaluation}

\section{I.3.I Basics of health economic evaluation}

Economic evaluation in health care can be defined as the comparison of alternative interventions and programmes in terms of their costs and consequences [12], and there are basically two (complementary) approaches to this $[12,13]$ : trials and models. Trialbased studies (e.g. randomised controlled trials (RCTs) or quasi-experimental designs) are considered the primary source for generating unbiased estimates of the baseline risk, relative treatment effect, health related measures and resource use between the options being compared [14]. In modelling studies, all available data from a wide range of sources (e.g. trials, observational designs and expert opinions) are brought to bear on fully specified decision problems for a defined population and context [58]. Coupling decision models with evidence synthesis, particularly undertaken using Bayesian methods, allows decision makers to explore the uncertainty surrounding the economic evidence of all options being considered and the expected value of conducting further research $[10,14,58]$.

For the explicit comparison of the costs and consequences of health care interventions or programmes, there are four basic forms of economic evaluation [12,59]: costminimisation, cost-effectiveness, cost-utility and cost-benefit analysis. These forms differ in the way consequences are included (i.e. respectively, costs only, clinical or health outcomes, disability-adjusted life-years (DALYs) or quality-adjusted life-years (QALYs), and monetary values or net benefit). In order to address efficiency from the wider viewpoint of society (i.e. allocative efficiency) and overcome problems of ratio statistics in handling decision uncertainty, as is the case in cost-effectiveness and cost-utility analysis, a net benefit approach (i.e. assigning monetary values to health outcomes) is often considered more appropriate for the economic comparison of health care inter- 
ventions or programmes [60-65]. Within this approach, (variance in) economic data can be handled on a single dimension, allowing the use of routine statistical procedures (e.g. standard regression techniques), the consideration of scaling effects of health care interventions or programmes and the estimation of confidence limits or acceptability curves.

\section{I.3.2 Methodological guidance for health economic evaluation}

Methodological guidance for (standard) health economic evaluation covers three broad areas [12,13,66], including: (1) evaluative design; (2) data collection; and (3) data analysis and interpretation of results. Guidelines for the (1) design of economic evaluations concern among others the form of evaluation, the analytic perspective and the time horizon of analysis. Following guidelines for (2) data collection, it is important that all relevant costs and effects are identified, and that these are measured accurately and valued credibly. Methodological guidelines for (3) data analysis and interpretation of results concern the discounting of costs and effects, the reporting and interpretation of incremental and sensitivity analyses, and the use of data modelling. Given the growing prominence of modelling studies in exploring health economics, standards of quality and validity for decision analysis and decision modelling are set, covering issues such as model structure, data input and model consistency or validity [67-71].

Essentially, the methods and guidelines for economic evaluation of (standard) health care interventions or programmes provide guidance on how to structure the decision problem; how to characterise the decision uncertainty; and how to interpret the results of analysis so that decisions about technology adoption and research funding can be made in agreement with both the objectives (i.e. maximise health gain) and constraints (i.e. limited resources) on health care service delivery [10].

\section{I.4 Methods for economic evaluation of change in clinical practice}

The evaluation of the value for money of guideline implementation to change clinical practice is in several ways different from (standard) health economic evaluation. First of all, in that the breadth of costs and consequences that could be considered is wider. That is, determining whether the implementation of a clinical guideline is worthwhile involves determining whether the guidance represents an efficient use of resources and establishing the resource implications of ensuring health care professionals and patients to adhere to the guideline $[6,8,9]$. In addition, there are several methodological issues related to empiric study design and statistics, and decision modelling and evidence synthesis (see below). 


\section{I.4.I Empiric study design and statistics}

In order to collect useful and reliable economic evidence for deciding on clinical practice change, complex, large-scale trials often are recommended [1]. Evidently, (cluster) RCTs generate unbiased estimates of the relative baseline measures, (health and behaviour) effects and resource use between the options (alternative guidelines, alternative implementation strategies) being compared [58]. Nonetheless, such trials are often deemed infeasible or undesirable owing to statistical issues relating to power, conduct and analysis of studies [6,19-22,72-74].

Avoiding the risk of contamination in patient RCTs, cluster RCTs, with patients clustered at the level of the professional or organisation, are increasingly being used for guideline implementation studies. Such trials (e.g. factorial or balanced incomplete block designs), however, might require considerable sample sizes, with associated recruitment issues. Additionally, designing and planning of clustered trials need careful consideration to the unit of randomisation, the choice of the primary outcomes (i.e. in terms of both effectiveness and efficiency), the information on intracluster correlation coefficients (based on the relationship of the between-cluster to within-cluster variance) and the inclusion of baseline measurements [21]. The analysis and interpretation of CRCT evidence also require an adequate choice of the unit of analysis (i.e. patient or cluster) and the application of appropriate analytic techniques to account for clustering, using adjustments to simple statistical tests or advanced statistical methods (e.g. hierarchical or multilevel modelling). To provide robust information, such trials can be time-consuming and expensive [21].

Although quasi-experimental designs (e.g. (controlled) before and after studies and time series designs) to study the economics of changing practice are useful when there are political, practical or ethical barriers to conducting (randomised) experiments [2], such studies introduce potential systematic bias to internal validity and external validity (or generalisability) and their results should be interpreted with caution [21].

\section{I.4.2 Decision modelling and evidence synthesis}

Modelling seems to provide a useful framework to overcome biases such as research inefficiency, evidence synthesis and decision analysis in economic evaluation of change in clinical practice $[6,8,75,76]$. In effect, several decision models were presented for exploring the cost-effectiveness of implementation strategies by combining the findings on the costs and effects of implementation with economic evidence on the health care technologies for which enhanced adherence is being promoted [23-26]. These models adopt a simplified approach to modelling the economics of guidance implementation, reporting patient-level cost-effectiveness ratios summarised for implementation strategies. Nonetheless, the use of decision models 'fed with synthesised evidence' is not necessarily restricted to cost-effectiveness studies - other forms of economic evaluation, 
varying in their purpose and complexity, might be of better use (e.g. cost-utility or costbenefit analysis) [14].

Combining decision modelling and evidence synthesis (e.g. within a net benefit framework) offers a means of relating economic data on both clinical guidance and implementation strategies from a variety of sources (rather than relying on a single study) to the specific decision problem in case of suboptimal practice, facilitating the extrapolation and generalisation of evidence to the specific clinical setting (i.e. reflecting patterns in varying localities, diseases, treatments, and professional and patient behaviour (over time)). It helps decision makers to identify optimal combinations of guidelines and strategies to change clinical practice under conditions of uncertainty, and can contribute to the process of setting research priorities. Evidently, for modelbased evaluations to be valuable for decision makers, adequate disclosure of the data input and modelling assumptions need to provided, e.g. concerning the transferability of empiric findings [6,25] or the potential selection bias between the target and study population [23].

\section{I.5 Methodological challenges in economic evaluation of change in clinical practice}

The increasing importance of incorporating economic considerations when deciding about changing clinical practice has led to an increase in the number of evaluative studies $[1,37,51,77-79]$. Nonetheless, the number of economic evaluations remains comparatively small given the quantity of studies evaluating solely the effectiveness of implementing clinical guidelines [1,3]. Moreover, there is no robust, generalisable evidence base to provide useful and reliable estimates of the likely value for money of implementation strategies and guideline implementation [1]. The lack of methodological rigour in economic appraisals of clinical practice change may not only result from the misuse or underuse of economic methodology, or poor reporting. Rather, this may well be due to biases in the methods and guidelines for guideline implementation evaluation. Although implementation research design and statistical issues are addressed frequently [6,19-22,72-74], methodological guidance for data collection and decision analysis need to be further developed, raising a variety of methodological challenges. Examples of these include: what are the relevant costs and effects that should be considered in economic evaluations of developing and implementing clinical guidelines, and how are these to be combined to adequately inform decision making about change in clinical practice? How to determine economic impact of non-adherence to cost-effective guidelines and the resource available for their implementation? How to examine the value for money of implementation strategies and that of guideline implementation to change clinical practice? How to quantify and explore (combined) uncertainty of clinical guidelines and implementation strategies, and assess the value of information in a con- 
text of implementation research? What is the use of evidence synthesis and decision models in exploring the economics of guideline implementation, and what is good modelling practice in this sense? How should the results of economic evaluations of clinical guidance, implementation strategies and clinical practice change be interpreted and used by decision makers to inform resource allocation decisions? Evidently, these methodological challenges should be addressed before the quality of evaluations of the value for money of guideline implementation to change clinical practice can be improved, and the resulting evidence can be used to inform health policy makers in setting priorities and allocating resources efficiently.

\section{I.6 Aim}

This thesis explores the economics of change in clinical practice. Its central aim is to advance methods, particularly considering the use of decision modelling and evidence synthesis, for economic evaluation of implementing clinical guidelines. The set of advanced methods is meant to provide decision makers methodological guidance in conducting evaluations, judging evidence and commissioning research to inform resource allocation decisions about changing practice under conditions of uncertainty concerning the economic evidence on clinical guidance and its implementation.

\subsection{Outline}

Chapter 2 reviews the use of economic appraisal in evaluations of guideline implementation to change clinical practice, verifying whether economic evaluations follow methodological guidance and discussing the evidence on the value for money of implementing clinical guidelines and the biases in economic methodology. Chapter 3 comprehensively illustrates that the approach to decision making about clinical practice change (i.e. whether decisions about the adoption of guidelines and implementation strategies are made sequentially or simultaneously) has important implications for the choices at hand and therefore on patient care and resource use. In Chapters 4 to 6, the use and practicality of decision modelling and evidence synthesis in informing resource allocation decisions about changing clinical practice are addressed. Chapter 4 presents a model for examining the scope of cost-effective clinical practice change, establishing the economic implications of non-adherence to guideline recommendations, the investment potential for guideline implementation and the value for money of implementation strategies. A total net benefit approach (i.e. assigning monetary values to health outcomes and combining evidence on guidance and its implementation with information on clinical practice) is suggested to overcome problems with the use of ratio analysis, e.g. when comparing multiple guidelines and multiple strategies across different 
clinical settings or when analysing decision uncertainty. Chapter 5 demonstrates the stochastic application of the model to inform resource allocation decisions in type 2 diabetes in primary care in The Netherlands. An integrated Bayesian approach to decision modelling and evidence synthesis is adopted for quantifying and exploring the uncertainty associated with decision making about change in Dutch diabetes practice. Using a (unified) Bayesian decision theoretic approach for establishing both the value of implementation and that of information, an analytic framework is applied in Chapter 6 to inform decision making about resource allocation to metastatic hormonerefractory prostate cancer in the United Kingdom. Chapter 7 presents the main findings and conclusions of this thesis and offers a general discussion, addressing some considerations related to the research and several recommendations for further investigation and decision making. 


\section{References}

1. Grimshaw JM, Thomas RE, et al. Effectiveness and efficiency of guideline dissemination and implementation strategies. Health Technol Assess 2004;8(6):iii-iv, 1-72.

2. Grol R, Wensing M, et al. Improving patient care: the implementation of change in clinical practice. London: Elsevier Limited; 2005.

3. Grol R, Buchan H. Clinical guidelines: what can we do to increase their use? Med J Aust 2006;185(6):301-2.

4. Feder G, Eccles M, et al. Clinical guidelines: using clinical guidelines. BMJ 1999;318(7185):728-30.

5. Freemantle N. Implementation strategies. Fam Pract 2000;17 Suppl 1:S7-10.

6. Mason J, Wood J, et al. Designing evaluations of interventions to change professional practice. J Health Serv Res Policy 1999;4(2):106-11.

7. McIntosh E. Economic evaluations of guideline implementation strategies. In: Thorsen T, Makela $\mathrm{M}$, editors. Changing professional practice: Theory and practice of clinical guidelines implementation. Copenhagen: Danish Institute for Health Services Research and Development; 1999.

8. Sculpher M. Evaluating the cost-effectiveness of interventions designed to increase the utilization of evidence-based guidelines. Fam Pract 2000;17 Suppl 1:S26-31.

9. Severens JL. Value for money of changing healthcare services? Economic evaluation of quality improvement. Qual Saf Health Care 2003;12(5):366-71.

10. Claxton K, Fenwick E, et al. Decision-making with uncertainty: the value of information. In: Jones AM, editor. Elgar Companion to Health Economics. Cheltenham: Elgar Publishing; 2006. p. 51425.

11. Sculpher M, Claxton K. Establishing the cost-effectiveness of new pharmaceuticals under conditions of uncertainty--when is there sufficient evidence? Value Health 2005;8(4):433-46.

12. Drummond MF, Sculpher MJ, et al. Methods for the economic evaluation of health care programmes. 3rd edition ed. Oxford: Oxford University Press; 2005.

13. Drummond M, Sculpher M. Common methodological flaws in economic evaluations. Med Care 2005;43(7 Suppl):5-14.

14. Briggs A, Sculpher M, Claxton K. Decision modelling for health economic evaluation. Oxford: Oxford University Outcomes; 2006.

15. Claxton KP, Sculpher MJ. Using value of information analysis to prioritise health research: some lessons from recent UK experience. Pharmacoeconomics 2006;24(11):1055-68.

16. Drummond M, McGuire A. Economic evaluation in health care: merging theory with practice. Oxford: Oxford University Press; 2001.

17. Gold MR, Siegel JE, et al. Cost-effectiveness in health and medicine. Oxford: Oxford University Press; 1996.

18. Hunink MGM, Glasziou PP, et al. Decision making in health and medicine : integrating evidence and values. Cambridge etc.: Cambridge University Press; 2001.

19. Campbell M, Fitzpatrick R, et al. Framework for design and evaluation of complex interventions to improve health. BMJ 2000;321(7262):694-6.

20. Campbell MK, Steen N, et al. Design and statistical issues in implementation research. In: Thorsen T, Makela M, editors. Changing professional practice: Theory and practice of clinical guidelines implementation. Copenhagen: Danish Institute for Health Services Research and Development; 1999.

21. Eccles M, Grimshaw J, et al. Experimental evaluations of change and improvement strategies. In: Grol R, Wensing M, Eccles M, editors. Improving patient care: the implementation of change in clinical practice: Elsevier Limited; 2005.

22. Grimshaw J, Campbell M, et al. Experimental and quasi-experimental designs for evaluating guideline implementation strategies. Fam Pract 2000;17 Suppl 1:S11-6. 
23. Gandjour A, Lauterbach KW. When is it worth introducing a quality improvement program? A mathematical model. Med Decis Making 2003;23(6):518-25.

24. Gandjour A, Lauterbach KW. How much does it cost to change the behavior of health professionals? A mathematical model and an application to academic detailing. Med Decis Making 2005;25(3):341-7.

25. Mason J, Freemantle N, et al. When is it cost-effective to change the behavior of health professionals? JAMA 2001;286(23):2988-92.

26. Mason JM, Freemantle N, et al. Specialist nurse-led clinics to improve control of hypertension and hyperlipidemia in diabetes: economic analysis of the SPLINT trial. Diabetes Care 2005;28(1):40-6.

27. Institute of Medicine Committee on Clinical Practice Guidelines. Guidelines for clinical practice: from development to use. National Academy Press. 1992.

28. Thorsen T, Makela M. Changing professional practice. Theory and practice of clinical guidelines implementation. Copenhagen: Danish Institute for Health Services Research; 1999.

29. Woolf SH, Grol R, et al. Clinical guidelines: potential benefits, limitations, and harms of clinical guidelines. BMJ 1999;318(7182):527-30.

30. Shekelle PG, Woolf SH, et al. Clinical guidelines: developing guidelines. BMJ 1999;318(7183):5936.

31. Verkerk K, Van Veenendaal H, et al. Considered judgement in evidence-based guideline development. Int J Qual Health Care 2006;18(5):365-9.

32. Grimshaw J, Russell I. Achieving health gain through clinical guidelines. I: Developing scientifically valid guidelines. Qual Health Care 1993;2(4):243-8.

33. Grimshaw JM, Russell IT. Achieving health gain through clinical guidelines II: Ensuring guidelines change medical practice. Quality in health care QHC 1994;3(1):45-52.

34. Eddy DM. Clinical decision making: from theory to practice. Practice policies - what are they? JAMA 1990;263(6):877-8, 80.

35. McIntosh E, Donaldson C, et al. Recent advances in the methods of cost-benefit analysis in healthcare. Matching the art to the science. Pharmacoeconomics 1999;15(4):357-67.

36. Grimshaw J, Eccles M, et al. Implementing clinical guidelines: current evidence and future implications. J Contin Educ Health Prof 2004;24 Suppl 1:S31-7.

37. Grol R, Grimshaw J. From best evidence to best practice: effective implementation of change in patients' care. Lancet 2003;362(9391):1225-30.

38. Schuster MA, McGlynn EA, et al. How good is the quality of health care in the United States? Milbank Q 1998;76(4):517-63, 09.

39. Cabana MD, Rand CS, et al. Why don't physicians follow clinical practice guidelines? A framework for improvement. JAMA 1999;282(15):1458-65.

40. Drummond $\mathrm{M}$, Weatherly $\mathrm{H}$. Implementing the findings of health technology assessments. If the CAT got out of the bag, can the TAIL wag the dog? Int J Technol Assess Health Care 2000;16(1):112.

41. Eccles M, Grimshaw J, et al. Changing the behavior of healthcare professionals: the use of theory in promoting the uptake of research findings. J Clin Epidemiol 2005;58(2):107-12.

42. Foy R, MacLennan G, et al. Attributes of clinical recommendations that influence change in practice following audit and feedback. J Clin Epidemiol 2002;55(7):717-22.

43. Grol R. Improving the quality of medical care: building bridges among professional pride, payer profit, and patient satisfaction. JAMA 2001;286(20):2578-85.

44. Shekelle P, Eccles MP, et al. When should clinical guidelines be updated? BMJ 2001;323(7305): 155-7.

45. Lobach DF, Hammond WE. Development and evaluation of a Computer-Assisted Management Protocol (CAMP): improved compliance with care guidelines for diabetes mellitus. Proc Annu Symp Comput Appl Med Care. 1994:787-91. 
46. Cleemput I, Kesteloot K. Economic implications of non-compliance in health care. Lancet 2002;359(9324):2129-30.

47. Cleemput I, Kesteloot K, et al. A review of the literature on the economics of noncompliance. Room for methodological improvement. Health Policy 2002;59(1):65-94.

48. Collins R, Fenwick E, et al. A systematic review and economic model of the clinical effectiveness and cost-effectiveness of docetaxel in combination with prednisone or prednisolone for the treatment of hormone-refractory metastatic prostate cancer. Health Technol Assess 2007;11(2):1-198.

49. Fenwick E, Claxton $\mathrm{K}$, et al. The value of implementation and the value of information: combined and uneven development. Med Decis Making 2008;28(1):21-32.

50. Lobach DF, Hammond WE. Computerized decision support based on a clinical practice guideline improves compliance with care standards. Am J Med 1997;102(1):89-98.

51. Grol R, Grimshaw J. Evidence-based implementation of evidence-based medicine. Jt Comm J Qual Improv 1999;25(10):503-13.

52. Foy R, Penney GC, et al. A randomised controlled trial of a tailored multifaceted strategy to promote implementation of a clinical guideline on induced abortion care. $\mathrm{Br} \mathrm{J}$ Obstet Gynaecol 2004;111(7):726.

53. Kaner EF, Lock CA, et al. A RCT of three training and support strategies to encourage implementation of screening and brief alcohol intervention by general practitioners. Br J Gen Pract 1999;49(446):699-703.

54. Lock CA, Kaner EF, et al. A randomized trial of three marketing strategies to disseminate a screening and brief alcohol intervention programme to general practitioners. Br J Gen Pract 1999;49(446):695-8.

55. Eccles MP, Whitty PM, et al. A pragmatic cluster randomised controlled trial of a Diabetes REcall And Management system: the DREAM trial. Implementation Science 2007;2:6.

56. Sullivan SD, Lee TA, et al. A multisite randomized trial of the effects of physician education and organizational change in chronic asthma care: cost-effectiveness analysis of the Pediatric Asthma Care Patient Outcomes Research Team II (PAC-PORT II). Arch Pediatr Adolesc Med 2005;159(5):428-34.

57. Verstappen $\mathrm{WH}$, van Merode F, et al. Comparing cost effects of two quality strategies to improve test ordering in primary care: a randomized trial. Int J Qual Health Care 2004;16(5):391-8.

58. Sculpher MJ, Claxton $\mathrm{K}$, et al. Whither trial-based economic evaluation for health care decision making? Health Econ 2006;15(7):677-87.

59. Fox-Rushby J, Cairns J. Economic evaluation. Berkshire: Open University Press; 2005.

60. Ament A, Baltussen R. The interpretation of results of economic evaluation: explicating the value of health. Health Econ 1997;6(6):625-35.

61. Briggs A, Fenn P. Confidence intervals or surfaces? Uncertainty on the cost-effectiveness plane. Health Econ 1998;7(8):723-40.

62. Stinnett AA, Mullahy J. Net health benefits: a new framework for the analysis of uncertainty in cost-effectiveness analysis. Med Decis Making 1998;18(2 Suppl):S68-80.

63. Willan A, Briggs A. Statistical analysis of cost-effectiveness data. West Sussex, England: John Wiley \& Sons Ltd; 2006.

64. Willan AR. Analysis, sample size, and power for estimating incremental net health benefit from clinical trial data. Control Clin Trials 2001;22(3):228-37.

65. Willan AR, Lin DY. Incremental net benefit in randomized clinical trials. Stat Med 2001;20(11):1563-74.

66. Evers S, Goossens M, et al. Criteria list for assessment of methodological quality of economic evaluations: Consensus on Health Economic Criteria. Int J Technol Assess Health Care 2005;21(2): 240-5. 
67. Anonymous. Decision analytic modelling in the economic evaluation of health technologies. A consensus statement. Consensus Conference on Guidelines on Economic Modelling in Health Technology Assessment. Pharmacoeconomics 2000;17(5):443-4.

68. Philips Z, Bojke L, et al. Good practice guidelines for decision-analytic modelling in health technology assessment: a review and consolidation of quality assessment. Pharmacoeconomics 2006;24(4): 355-71.

69. Philips Z, Ginnelly L, et al. Review of guidelines for good practice in decision-analytic modelling in health technology assessment. Health Technol Assess 2004;8(36):iii-iv, ix-xi, 1-158.

70. Sculpher M, Fenwick E, et al. Assessing quality in decision analytic cost-effectiveness models. A suggested framework and example of application. Pharmacoeconomics 2000;17(5):461-77.

71. Weinstein MC, O'Brien B, et al. Principles of good practice for decision analytic modeling in healthcare evaluation: report of the ISPOR Task Force on Good Research Practices--Modeling Studies. Value Health 2003;6(1):9-17.

72. Campbell MK, Mollison J, et al. Cluster trials in implementation research: estimation of intracluster correlation coefficients and sample size. Stat Med 2001;20(3):391-9.

73. Campbell MK, Mollison J, et al. Analysis of cluster randomized trials in primary care: a practical approach. Fam Pract 2000;17(2):192-6.

74. Campbell MK, Thomson S, et al. Sample size calculator for cluster randomized trials. Computers in biology and medicine 2004;34(2):113-25.

75. Brennan A, Akehurst R. Modelling in health economic evaluation. What is its place? What is its value? Pharmacoeconomics 2000;17(5):445-59.

76. Buxton MJ, Drummond MF, et al. Modelling in economic evaluation: an unavoidable fact of life. Health Econ 1997;6(3):217-27.

77. Foy R, Eccles MP, et al. What do we know about how to do audit and feedback? Pitfalls in applying evidence from a systematic review. BMC health services research ISE: 1472 6963. 2005;5:50.

78. Gilbody S, Whitty P, et al. Educational and organizational interventions to improve the management of depression in primary care: a systematic review. JAMA 2003;289(23):3145-51.

79. Jamtvedt G, Young JM, et al. Does telling people what they have been doing change what they do? A systematic review of the effects of audit and feedback. Qual Saf Health Care 2006;15(6):433-6. 



\section{Methodological Quality of Economic Evaluations of Guideline Implementation into Clinical Practice: A Systematic Review of Empiric Studies}

Ties Hoomans ${ }^{1}$, Silvia M.A.A. Evers' ${ }^{1}$, André J.H.A. Ament ${ }^{1}$, Mariette W.A. Hübben ${ }^{1}$, Trudy van der Weijden ${ }^{2}$, Jeremy M. Grimshaw ${ }^{3}$, Johan L. Severens ${ }^{1,4}$

${ }^{1}$ Department of Health Organisation, Policy and Economics, Maastricht University, the Netherlands; ${ }^{2}$ Centre for Quality of Care Research (WOK), Department of General Practice, Maastricht University, the Netherlands; ${ }^{3}$ Clinical Epidemiology Programme, Ottawa Health Research Institute, Canada; ${ }^{4}$ Department of Clinical Epidemiology and MTA, University Hospital Maastricht, the Netherlands

Value Health 2007;10(4):305-16 


\section{Abstract}

Despite the emphasis on efficiency of health care services delivery, there is an imperfect evidence base to inform decisions about whether and how to develop and implement guidelines into clinical practice. In general, studies evaluating the economics of guideline implementation lack methodological rigour. We conducted a systematic review of empiric studies to assess advances in the economic evaluations of guideline implementation.

The Cochrane Effective Professional and Organisational Change register and the MEDLINE were searched for English publications between January 1998 and July 2004 that reported objective effect measures and implementation costs. We extracted data on study characteristics, quality of study design, and economic methodology. It was assessed whether the economic evaluations followed methodological guidance.

We included 24 economic evaluations, involving 21 controlled trials and three interrupted time series designs. The studies involved varying settings, targeted professionals, targeted behaviours, clinical guidelines and implementation strategies. Overall, it was difficult to determine the quality of study designs owing to poor reporting. In addition, most economic evaluations were methodologically flawed: studies did not follow guidelines for evaluation design, data collection and data analysis.

The increasing importance of the value for money of providing health care seems to be reflected by an increase in empiric economic evaluations of guideline implementation. Because of the heterogeneity and poor methodological quality of these studies, however, the resulting evidence is still of limited use in decision making. There seems to be a need for more methodological guidance, especially in terms of data collection and data synthesis, to appropriately evaluate the economics of developing and implementing guidelines into clinical practice. 


\section{I Introduction}

Clinical guidelines have become an increasingly common element in health care. As defined by the Institute of Medicine, clinical guidelines are 'systematically developed statements to assist practitioner and patient decisions about appropriate health care for specific clinical circumstances' [1]. These guidelines have the potential to improve patient care by promoting efficient and discouraging inefficient health care interventions [2-4]. Despite evidence of their cost-effectiveness, guidelines do not translate automatically into clinical practice: patients and health care professionals may not adhere to guideline recommendations $[5,6]$. Implementation strategies such as the distribution of educational materials, outreach visits or financial incentives aim to change the behaviour (i.e. guideline adherence) of patients and professionals [7]. Nevertheless, these strategies are not themselves without costs. Since implementation efforts compete with other health care programmes for limited health care resources, it becomes increasingly important to determine whether implementing guidelines is worthwhile [8-11]. Notwithstanding current interest in guidelines, there is uncertainty about the most likely cost-effective way to develop and implement them into clinical practice [12-14].

Economic evaluations are used to inform appropriate decisions about whether and how to develop and implement clinical guidelines [15]. For economic evaluations to provide health policy makers with useful and reliable information, the evaluations should follow methodological guidelines. In an extensive review of empiric studies from 1966 to 1998, Grimshaw et al. evaluated the effectiveness and efficiency of different guideline implementation strategies [14]. On the basis of a quality assessment of study design and economic methodology, they concluded that the limited number of economic evaluations produced methodologically poor evidence on how best to use the limited resources for clinical practice change.

Given the growing literature on economic methodology in health care [9,15-18], we are interested into advances in the economic evaluation of guideline implementation. Therefore, we conducted a systematic review of empiric studies that evaluated the costs and effects of guideline implementation strategies published since 1998. Our aims were: (1) to identify empiric economic evaluations; (2) to assess the quality of empiric study design; and (3) to analyse the methods for economic evaluation. We verified whether the economic evaluations of guideline implementation followed methodological guidance. Following this, we discussed the evidence on the value for money of developing and implementing guidelines to change clinical practice, and addressed the potential biases in economic methodology literature to inform decision making. 


\subsection{Methods}

\subsubsection{Search strategy and inclusion criteria}

The Cochrane Effective Professional and Organisational Change (EPOC) Group specialised register [19] and the MEDLINE database were searched for English publications from January 1998 to July 2004. MEDLINE search terms were related to relevant study designs, guidelines and strategies, and economic data (based on the EPOC search strategy [19], having a sensitivity of $92.4 \%$ and precision of $18.5 \%$ ). Appendix 2.1 details the MEDLINE search strategy.

All titles and abstracts of the search results were independently screened by two reviewers (TH or $\mathrm{MH}$ and SE or AA or JS) to identify potentially relevant studies. The main criterion for study identification was sensitivity rather than specificity. Based on the full-text reading, two reviewers ( $\mathrm{TH}$ and $\mathrm{MH}$ ) then independently assessed the identified studies for eligibility for inclusion. In addition, the reference lists of included studies were checked. Any disagreements relating to study inclusion were resolved by consensus (TH, MH and JS).

We included all randomised controlled trials (RCTs), controlled clinical trials (CCTs), controlled before and after studies (CBAs) and interrupted time series designs (ITSs) that involved full economic evaluations of guideline implementation to change the behaviour of health care professionals. Studies were selected for inclusion whether or not the term guideline was explicitly mentioned. Studies were included only if they reported objective measures of health care professional and/or patient outcomes. Details of the above mentioned inclusion criteria have been described elsewhere [14,20]. Additionally, studies were considered full economic evaluations of guideline implementation only if they reported information on both the costs and effects of implementation strategies $[15,21]$.

\subsubsection{Data extraction and data analysis}

Two reviewers (TH and SE or AA or JS) independently extracted data on the study settings and participants, targeted behaviours, guidelines and strategies, quality of study design and methods for economic evaluation. Guideline implementation strategies were classified according to a taxonomy of professional, organisational, financial and regulatory strategies that was developed by the EPOC group [20]. The quality of study design was judged using Cochrane EPOC methodological quality criteria $[14,20]$, involving design aspects such as concealment of allocation and blinded or reliable assessment of outcomes. Finally, the methodological quality of the economic evaluations was assessed against the British Medical Journal (BMJ) guidelines for reviewers $[15,21]$.

The BMJ guidelines for economic evaluations cover three broad areas including: (1) economic evaluation design; (2) data collection; and (3) data analysis and interpreta- 
tion of results. Guidelines for the (1) design of economic evaluations concern among others the form of evaluation and the viewpoint of analysis. Following guidelines for (2) data collection, it was assessed whether all relevant costs and effects were identified, and whether these were measured accurately and valued credibly. Methodological guidelines for (3) data analysis and interpretation of results concern the discounting of costs and effects, the reporting and interpretation of incremental and sensitivity analyses, and the use of data modelling. If studies used models for data extrapolation or data synthesis, we verified whether the quality and validity of these models were assessed explicitly.

The economic evaluation of guideline implementation differs from standard health care technology assessment in that the breadth of costs and effects that could be considered is wider $[9,14,16]$. That is, if guideline implementation strategies are to be costeffective, it is a pre-requisite that the guidelines being promoted are cost-effective $[17,18]$. In terms of data collection for estimating the costs of guideline implementation, we therefore assessed to what extent the included studies considered guideline development costs, implementation strategy development costs, implementation strategy execution costs and health care provision costs. Regarding the collection of data for evaluating the effectiveness of guideline implementation, we verified whether studies measured practice change by patient outcomes and/or health care professional outcomes. Additionally, in studies that reported professional outcomes, it was assessed whether these outcomes were measures for health care professional behaviour in terms of adherence or surrogates of adherence to guideline recommendations.

Although there is a considerable range of potentially relevant costs and effects for guideline implementation evaluation, it may sometimes be legitimate to design an economic evaluation of a more limited scope $[9,14,17]$. First, the cost-effectiveness of a clinical guideline needs not be measured if the evidence base of the guideline recommendations is clear and transferable into the implementation setting $[10,17]$. That is, implementation trials may be limited to measuring the costs and effects of strategies to change the behaviour of health care professionals; the value for money of guideline implementation could then be evaluated by combining the findings of an implementation trial with the economic evidence on the guideline, e.g. by using data models $[10,17]$. Second, the viewpoint of the analysts determines which costs and effects are relevant $[9,15,16]$. For example, the costs of patient resources consumption or productivity losses need not be considered if the economic evaluation is undertaken from the perspective of a health care provider or providing institution. Nevertheless, a societal perspective would consider the full range of potential costs and effects of guideline implementation. Finally, some costs and effects need not be considered if it can be assumed that their inclusion will not change the policy decision to be informed [14]. If, however, the study (design) is of a more limited scope, the limitations should be justified explicitly and supported by appropriate evidence $[14,15]$. 
Any disagreements relating to data extraction were resolved by consensus (TH and $\mathrm{SE}$ or AA or JS). Complete review data extraction forms are available from the corresponding author. It was envisaged that the studies included would be too heterogeneous to be combined using a formal meta-analysis; therefore, a descriptive synthesis of the review results was undertaken. All data were entered in a MS Excel database.

\subsection{Results}

\subsection{Results of literature searches and screening of results}

The searches of the EPOC register and the MEDLINE database produced 579 and 2561 hits, respectively. All abstracts and titles were screened and 208 studies were initially identified as potentially relevant. On the basis of full-text assessments, we excluded 184 of these studies from our review. The main reasons for exclusion were: (1) study designs did not meet criteria for randomisation, control, or sufficiency of data points; (2) guideline implementation was not aimed at changing the behaviour of health care professionals but on changing patient behaviour; and (3) studies reported only health care provision costs or no cost data at all. In total, 29 articles [22-50] of 24 studies [22-24,26-33,35,36,38-41,43,45-50] yielding 35 separate comparisons were included in our review.

\subsubsection{Study characteristics}

Table 2.1 summarises the characteristics of all included studies. Eleven studies $(46 \%)$ were conducted in the United States [23,24,26,27,31,33,41,43,48-50], and seven $(29 \%)$ in the United Kingdom [22,28,29,36,38,45,47]. The most common setting was general practice or community-based $(50 \%)$. Four studies were conducted in a university (teaching) hospital $[22,40,49,50]$ and one study in a non-teaching or universityaffiliated hospital [45]. In the majority of studies (71\%), physicians were the target of guideline implementation. Most commonly involved clinical specialities included: general practice or family medicine, emergency medicine or intensive care, primary or community care, and hospital medicine. Seventy-nine percent of the studies targeted just one type of professional behaviour, most often prescribing. In the remaining studies $(21 \%)$, general management was most commonly targeted in combination with other types of professional behaviour.

Table 2.2 details the guidelines and strategies to implement them into clinical practice. The majority of studies aimed to improve patient management (63\%) [22,24,27$30,32,33,36,41,43,45-47,50]$, and in $50 \%$ of the studies [23,27-29,31-33,38,41,45,46, $50]$, the nature of desired change was an increase in established management. Only three studies initiated new patient management $[30,36,47]$. 
Table 2.I Overview of study characteristics

\begin{tabular}{|c|c|c|}
\hline Characteristic & Type & $\mathrm{n}(\%)$ \\
\hline \multirow[t]{3}{*}{ Country } & USA & II (46\%) \\
\hline & UK & $7(29 \%)$ \\
\hline & Other & $5(21 \%)$ \\
\hline \multirow[t]{4}{*}{ Setting of care } & General practice or community based & $12(50 \%)$ \\
\hline & Inpatient & $8(33 \%)$ \\
\hline & Outpatient & $3(13 \%)$ \\
\hline & Mixed & I (4\%) \\
\hline \multirow[t]{5}{*}{ Academic status } & University (teaching) hospital & $5(21 \%)$ \\
\hline & Non-teaching or university-affiliated & $2(8 \%)$ \\
\hline & Mixed & I (4\%) \\
\hline & Not clear & $4(17 \%)$ \\
\hline & Not relevant & $12(50 \%)$ \\
\hline \multirow[t]{4}{*}{ Medical profession } & Physicians & $17(7 \mid \%)$ \\
\hline & Physicians and nurses & $4(17 \%)$ \\
\hline & Nurses & I (4\%) \\
\hline & Other & $2(8 \%)$ \\
\hline \multirow[t]{7}{*}{ Clinical speciality } & General practice or family medicine & II (46\%) \\
\hline & Internal medicine & I (4\%) \\
\hline & Emergency medicine or intensive care & $4(17 \%)$ \\
\hline & Primary or community care & $4(17 \%)$ \\
\hline & Hospital medicine & $3(13 \%)$ \\
\hline & Paediatrics & $\mathrm{I}(4 \%)$ \\
\hline & Other & $2(8 \%)$ \\
\hline \multirow[t]{9}{*}{ Targeted behaviour } & Prescribing & $9(38 \%)$ \\
\hline & General management & 7 (29\%) \\
\hline & Clinical preventive services & $5(2 \mid \%)$ \\
\hline & Patient education/advice & $2(8 \%)$ \\
\hline & Diagnosis & $2(8 \%)$ \\
\hline & Procedures & I (4\%) \\
\hline & Test ordering & I (4\%) \\
\hline & Referals & I (4\%) \\
\hline & Professional-patient education & I (4\%) \\
\hline
\end{tabular}

Details of all studies included in the review $(\mathrm{N}=24)$ are available from the corresponding author.

All but seven studies provided information on the evidence base of guideline recommendations. Mainly, sources of evidence included references to previously conducted trials or to expert opinion groups and the levels of evidence varied considerably. The effectiveness of guidelines was established in $75 \%$ of the studies [22-24,26$33,36,39,41,43,45,46,50]$. Prior knowledge of the economic consequences of the guideline recommendations was reported incidentally $(17 \%)$ [26,31,39,45].

The majority of studies $(77 \%)$ evaluated multifaceted guideline implementation strategies, combining two or more strategies. The strategies that were most commonly combined included educational materials, educational meetings, outreach visits, and 
audit and feedback. Single strategies that were evaluated involved professional, financial, and organisational strategies.

Table 2.2 Survey of details of guidelines and strategies to implement them

\begin{tabular}{|c|c|c|}
\hline Characteristic & Type & $\mathrm{n}(\%)$ \\
\hline \multicolumn{3}{|l|}{ Clinical guidelines } \\
\hline \multirow[t]{3}{*}{ Purpose of recommendations } & Appropriate patient management & $15(63 \%)$ \\
\hline & Cost containment & $2(8 \%)$ \\
\hline & Both appropriate management and cost containment & $7(29 \%)$ \\
\hline \multirow[t]{4}{*}{ Nature of desired change } & Initiation of new management & $3(13 \%)$ \\
\hline & Increase of established management & $12(50 \%)$ \\
\hline & Modification of established management & $4(17 \%)$ \\
\hline & Reduction of established management & $5(21 \%)$ \\
\hline \multirow[t]{2}{*}{ Evidence of recommendations } & Establishment of effectiveness & $18(75 \%)$ \\
\hline & Establishment of cost effectiveness & $4(17 \%)$ \\
\hline \multicolumn{3}{|l|}{ Implementation strategies } \\
\hline \multirow[t]{9}{*}{ Professional strategies } & Educational materials & $14(58 \%)$ \\
\hline & Educational meetings & $13(54 \%)$ \\
\hline & Consensus processes & $4(4 \%)$ \\
\hline & Outreach visits & $8(33 \%)$ \\
\hline & Opinion leaders & I (4\%) \\
\hline & Audit and feedback & $16(67 \%)$ \\
\hline & Reminders & $2(8 \%)$ \\
\hline & Mass media & $2(8 \%)$ \\
\hline & Other & $9(38 \%)$ \\
\hline \multirow[t]{2}{*}{ Financial strategies } & Fee-for-services & I (4\%) \\
\hline & Financial incentives & $6(25 \%)$ \\
\hline \multirow[t]{4}{*}{ Organisational strategies } & Quality monitoring mechanisms & I (4\%) \\
\hline & Changes to setting/site of service delivery & I (4\%) \\
\hline & Changes in physical structure, facilities and equipment & I (4\%) \\
\hline & Changes in medical records systems & I (4\%) \\
\hline
\end{tabular}

Details of all studies included in the review $(\mathrm{N}=24)$ are available from the corresponding author.

\subsubsection{Quality of study design}

The studies included 13 (54\%) cluster RCTs [23,26-30,32,33,36,38,41,43,47], one (4\%) patient RCT [24], seven (29\%) cluster CBAs [31,35,39,45,46,48,50] and three $(13 \%)$ ITSs [22,40,49]. Nevertheless, six $(30 \%)$ [26,30,32,38,48,50] out of 20 clustered designs did not report (clearly) to have accounted for clustering effects during data analysis and therefore may have unit of analysis errors. Furthermore, sample size calculations were reported (clearly) in only $29 \%$ of all controlled trials [28,29,33, $36,38,47]$.

Table 2.3 summarises the quality of the studies by design. Overall, the quality of study designs was difficult to determine owing to poor reporting. For example, the ma- 
jority of RCTs did not report the methods of concealment of allocation $(50 \%)$ $[23,24,26,27,30,33,38]$ or protection against contamination $(86 \%)[23,24,26,27$, $30,32,33,36,38,41,43,47]$ in sufficient detail, and in $71 \%$ of the CBAs $[31,39,45$, $46,50]$, it was not clear whether an appropriate control site/activity was chosen.

Table 2.3 Summary of quality of study design

\begin{tabular}{|c|c|c|c|}
\hline & $\begin{array}{c}\text { RCTs or CCTs } \\
(N=14)\end{array}$ & $\begin{array}{l}\text { CBAs } \\
(\mathrm{N}=7)\end{array}$ & $\begin{array}{c}\text { ITSs } \\
(\mathrm{N}=3)\end{array}$ \\
\hline & $\%$ done $(n)$ & $\%$ done $(n)$ & $\%$ done $(n)$ \\
\hline Concealment of allocation & $50 \%(7 / 14)$ & - & - \\
\hline Follow-up of professionals & $31 \%(4 / 13)$ & $14 \%(1 / 7)$ & - \\
\hline Follow-up of patients or episodes of care & $8 \%(1 / 13)$ & $0 \%(0 / 6)$ & - \\
\hline Blinded assessment of primary outcomes & $57 \%(8 / 14)$ & $86 \%(6 / 7)$ & $100 \%(3 / 3)$ \\
\hline Baseline measurement & $86 \%(12 / 14)$ & $57 \%(4 / 7)$ & - \\
\hline Reliable primary outcome measures & $14 \%(2 / 14)$ & $86 \%(6 / 7)$ & $100 \%(3 / 3)$ \\
\hline Protection against contamination & $14 \%(2 / \mid 4)$ & $0 \%(0 / 7)$ & - \\
\hline Appropriate choice of control site/activity & - & $29 \%(2 / 7)$ & - \\
\hline Characteristics of study and control & - & $14 \%(1 / 7)$ & - \\
\hline Contemporaneous data collection & - & $86 \%(6 / 7)$ & - \\
\hline Clearly defined point in time of intervention & - & - & $100 \%(3 / 3)$ \\
\hline Independency of intervention from other interventions & - & - & $33 \%(1 / 3)$ \\
\hline Sufficiency of data points & - & - & $100 \%(3 / 3)$ \\
\hline Formal test for trends & - & - & $33 \%(1 / 3)$ \\
\hline Avoidance of data collection affection & - & - & $33 \%(1 / 3)$ \\
\hline Completeness of data set & - & - & $0 \%(0 / 3)$ \\
\hline
\end{tabular}

The quality of study design was assessed using the listed criteria (Done / Not done / Not clear / Not relevant $(-))$. In the table, the numbers (and percentages) of studies that met each criterium are presented. Details of all studies included in the review $(\mathrm{N}=24)$ are available from the corresponding author.

\subsubsection{Methodological quality of economic evaluations}

\section{Economic evaluation design}

The form of economic evaluation was defined in 11 studies, but clearly justified in only $27 \%$ of these studies $[36,41,45]$. In six out of the 11 studies $[26,40,41,43,47,48]$, it was observed that they had undertaken a different form than stated. Most studies appeared to be cost-minimisation analyses, [22,26,35,38-40,43,48-50], cost-effectiveness analyses [23,24,30,32,36,46] or cost-consequences analyses [29,31,33,47] (see Table 2.4). None of the studies attempted to express patient outcomes in monetary terms as in a cost-benefit analysis [15,16,21].

A viewpoint of analysis was stated in nine studies and in none of these studies clearly justified. Seven out of nine studies applied the viewpoint chosen $[23,26,29,30,32,41,43]$. Table 2.4 shows that the economic evaluation was undertaken from a societal perspective in two studies $[41,48]$, from a third-party payer perspective 
in four studies $[26,33,38,43]$, from a health care provider or providing institution perspective in nine studies [22,29-31,35,39,40,49,50] and from a health programme or system perspective in three studies $[24,28,32]$. Two studies took a combination of perspectives $[23,46]$, and in four studies, it was not clear what viewpoint of analysis had been applied [24,27,36,47].

Table 2.4 Details of design of economic evaluation: form of evaluation and viewpoint of analysis

\begin{tabular}{llc}
\hline & Type & n (\%) applied \\
\hline Form of evaluation & Cost-minimisation analysis & $10(42 \%)$ \\
& Cost-effectiveness analysis & $6(25 \%)$ \\
& Cost-consequences analysis & $4(17 \%)$ \\
& Cost-utility analysis & $1(4 \%)$ \\
& Other & $3(13 \%)$ \\
Viewpoint of analysis & Hot clear & $0(0 \%)$ \\
& Health care provider or providing institution perspective & $9(38 \%)$ \\
& Third-party payer perspective & $4(17 \%)$ \\
& Health programme or system perspective & $3(13 \%)$ \\
& Societal perspective & $2(8 \%)$ \\
& Other & $2(8 \%)$ \\
& Not clear & $4(I 7 \%)$ \\
\hline
\end{tabular}

Details of all studies included in the review $(\mathrm{N}=24)$ are available from the corresponding author.

\section{Data collection}

Table 2.5 provides a summary of the data collection for evaluating the effectiveness of guideline implementation. Fifteen $(63 \%)$ studies reported health care professional outcomes $[22,24,26-28,30,31,33,35,36,39,43,46,47,49]$, five $(21 \%)$ studies reported patient outcomes $[23,29,41,48,50]$, and four $(17 \%)$ studies [32,38,40,45] reported both professional and patient outcomes. None of the five studies solely reporting patient outcomes provided a clear justification for not reporting health care professional outcomes. In total, $79 \%$ of the studies identified measures for the behaviour of health care professionals. In $14(74 \%)$ of these studies, professional behaviour was measured in terms of adherence to guideline recommendations [26-28,30,32,33,35,36,39,40,4547,49 ], whereas five $(26 \%)$ studies measured surrogates of guideline adherence, such as changes in medication use and patient advice rates [22,24,31,38,43].

The methods for measuring the effects of guideline implementation were reported in only seven studies. Of these, it was assessed that the effects had been measured accurately in only four studies. Relevant information that was omitted from measurement descriptions included the completeness or reliability of data sets. Forty-six percent of the studies reported details of the methods used to value implementation effects, and in five studies the effects were credibly valued. In general, the valuation of implementa- 
tion effects is not relevant in studies that report only measures for professional behaviour.

Table 2.6 presents a summary of the collection of data for estimating the costs of the guideline implementation. Fifteen $(63 \%)$ studies reported the costs of developing the implementation strategies [22-24,26,28-31,38-40,43,45,47,49], and all studies reported costs of executing these strategies. In 21 studies $(88 \%)$, it was not clear whether all relevant implementation costs were identified. The majority of these studies omitted opportunity costs for health care professionals, e.g. practitioner time while in training. Guideline development costs were reported in only one study [40] and appeared not to be relevant in the remaining studies. Health care provision costs were reported in 16 $(67 \%)$ studies [22,24,26,29,31,32,35,38-41,43,45,48-50], including mainly direct health care costs, e.g. costs of general practitioner visits or medication use. Only one out of nine studies provided a clear justification for not including costs of health care provision.

In 12 studies, the quantities of resources used for implementation purposes were not reported separately from their unit costs. Although all studies identified implementation strategy execution costs, only one-third of these studies reported the method for measuring resource use. Of the 15 studies that identified strategy development costs, four $(27 \%)$ reported the method for measuring resource use. Overall, it was difficult to determine whether implementation resources were measured accurately in all but two studies owing to poor reporting. Currency or price data of implementation resources were not reported in 16 studies. In $83 \%$ of the studies, the methods for valuing implementation costs were not (sufficiently) described. Sources of all unit costs were identified clearly in only four studies. Overall, it was not clear whether implementation resources were credibly valued in the majority of studies $(71 \%)$. The methods for estimating changes in resource use for providing health care were not (sufficiently) described in ten studies. These health care provision resources were credibly valued in 11 studies.

In our review, only one study [40] evaluated the economic consequences of the guideline recommendations. This study involved an ITS design and compared for three consecutive 10-month periods the economics of the guideline and its implementation separately. Overall, the costs and effects of the guideline of interest were identified, measured and valued accurately. 
Table 2.5 Summary of data collection for evaluating the effectiveness of guideline implementation: the identification, measurement and valuation of health care professional outcomes $\left(\Delta \mathrm{E}_{\mathrm{hpo}}\right)$ and/or patient outcomes $\left(\Delta \mathrm{E}_{\mathrm{pto}}\right)$

\begin{tabular}{lcc}
\hline & $\begin{array}{c}\Delta \mathrm{E}_{\mathrm{hpo}} \\
\% \text { done (n) }\end{array}$ & $\begin{array}{c}\Delta \mathrm{E}_{\mathrm{pto}} \\
\% \text { done (n) }\end{array}$ \\
\hline Identification of effects & $79 \%(19 / 24)$ & $38 \%(9 / 24)$ \\
Reporting of effects & $100 \%(19 / 19)$ & $100 \%(9 / 9)$ \\
Sufficiently detailed reporting of effects & $100 \%(19 / 19)$ & - \\
Inclusion of professional behaviour change & - & $0 \%(0 / 9)$ \\
Inclusion of productivity changes & $79 \%(15 / 19)$ & $67 \%(6 / 9)$ \\
Identification of all relevant effects & $11 \%(2 / 19)$ & $22 \%(2 / 9)$ \\
Omission of items/information from identification of effects & $0 \%(0 / 4)$ & $25 \%(1 / 4)$ \\
Clear justification for omitting items/information & $0 \%(0 / 5)$ & $33 \%(3 / 9)$ \\
Clear justification for not reporting all relevant effects & & \\
Measurement of effects & $100 \%(19 / 19)$ & $100 \%(9 / 9)$ \\
Description of methods for measuring effects & $26 \%(5 / 19)$ & $33 \%(3 / 9)$ \\
Sufficiently detailed description of methods for measuring effects & $100 \%(19 / 19)$ & $100 \%(9 / 9)$ \\
Measurement of effects in appropriate units & $74 \%(14 / 19)$ & - \\
Measurement of health care professional adherence to guidelines & $26 \%(5 / 19)$ & - \\
Measurement of surrogates of health care professional adherence & $0 \%(0 / 1)$ & $11 \%(1 / 9)$ \\
Measurement of patient adherence to guidelines & $16 \%(3 / 19)$ & $22 \%(2 / 9)$ \\
Accurate measurement of effects & $47 \%(9 / 19)$ & $33 \%(3 / 9)$ \\
Omission of items/information from effect measurement & $0 \%(0 / 15)$ & $0 \%(0 / 7)$ \\
Clear justification for omitting of items/information & - & - \\
Clear justification for not reporting methods for measuring effects & & \\
Valuation of effects & $100 \%(8 / 8)$ & $100 \%(5 / 5)$ \\
Description of methods for valuing effects & $50 \%(4 / 8)$ & $80 \%(4 / 5)$ \\
Sufficiently detailed description of methods for valuing effects & $50 \%(4 / 8)$ & $40 \%(2 / 5)$ \\
Credible / appropriate methods for valuing effects & - & $80 \%(4 / 5)$ \\
Details of subjects for valuing effects & - & $60 \%(3 / 5)$ \\
Credible / appropriate subjects for valuing effects & $43 \%(3 / 7)$ & $20 \%(1 / 5)$ \\
Omission of items/information from valuation of effects & $0 \%(0 / 4)$ & $0 \%(0 / 3)$ \\
Clear justification for omitting items/information & - & - \\
Clear justification for not reporting methods for valuing effects & - & \\
\hline & & \\
\hline
\end{tabular}

The data collection was assessed using the listed criteria (done / not done / not clear / not relevant (-)). In the table, the numbers (and percentages) of studies that met each criterium are presented. Details of all studies included in the review $(\mathrm{N}=24)$ are available in from the corresponding author. 
Table 2.6 Summary of data collection for evaluating the costs of guideline implementation: identification, measurement and valuation of guideline development costs $\left(\Delta \mathrm{C}_{\mathrm{cgd}}\right)$, implementation strategy development costs $\left(\Delta \mathrm{C}_{\text {isd }}\right)$, implementation strategy execution costs $\left(\Delta \mathrm{C}_{\text {ise }}\right)$, and/or health care provision costs $\left(\Delta \mathrm{C}_{\text {cge }}\right)$

\begin{tabular}{|c|c|c|c|c|}
\hline & $\begin{array}{c}\Delta \mathrm{C}_{\mathrm{cgd}} \\
\% \text { done }(\mathrm{n})\end{array}$ & $\begin{array}{c}\Delta \mathrm{C}_{\text {isd }} \\
\% \text { done }(\mathrm{n})\end{array}$ & $\begin{array}{c}\Delta \mathrm{C}_{\text {ise }} \\
\% \text { done }(n)\end{array}$ & $\begin{array}{c}\Delta \mathrm{C}_{\mathrm{cge}} \\
\% \text { done }(\mathrm{n})\end{array}$ \\
\hline \multicolumn{5}{|l|}{ Identification of costs } \\
\hline Reporting of costs & $4 \%(1 / 24)$ & $63 \%(15 / 24)$ & $100 \%(24 / 24)$ & $67 \%(16 / 24)$ \\
\hline Sufficiently detailed reporting of identified costs & $0 \%(0 / 1)$ & $33 \%(5 / 15)$ & $42 \%(10 / 24)$ & $81 \%(13 / 16)$ \\
\hline Inclusion of operating (variable) costs & $0 \%(0 / 1)$ & $29 \%(4 / 14)$ & $79 \%(19 / 24)$ & $88 \%(14 / 16)$ \\
\hline Inclusion of capital (fixed) costs & $0 \%(0 / 1)$ & $36 \%(5 / 14)$ & $8 \%(2 / 24)$ & $6 \%(1 / 16)$ \\
\hline Inclusion of opportunity costs & $0 \%(0 / 1)$ & $7 \%(1 / 14)$ & $17 \%(4 / 24)$ & - \\
\hline Identification of all relevant costs & $0 \%(0 / 1)$ & $40 \%(6 / 15)$ & $21 \%(5 / 24)$ & $69 \%(11 / 16)$ \\
\hline Omission of items/information from identification of costs & $0 \%(0 / 1)$ & $7 \%(1 / 15)$ & $42 \%(10 / 24)$ & $0 \%(0 / 16)$ \\
\hline Clear justification of omitting costs/information & $0 \%(0 / 1)$ & $0 \%(0 / 9)$ & $0 \%(0 / 19)$ & $0 \%(0 / 6)$ \\
\hline Clear justification of not reporting of costs & $10 \%(1 / 10)$ & $22 \%(2 / 9)$ & - & $17 \%(1 / 6)$ \\
\hline \multicolumn{5}{|l|}{ Measurement of costs } \\
\hline Separate reporting of resource quantities from unit costs & $100 \%(1 / 1)$ & $40 \%(6 / 15)$ & $48 \%(11 / 23)$ & $75 \%(12 / 16)$ \\
\hline $\begin{array}{l}\text { Clear justification for not reporting resource quantities and } \\
\text { unit costs separately }\end{array}$ & - & $0 \%(0 / 9)$ & $0 \%(0 / 12)$ & $0 \%(0 / 3)$ \\
\hline Description of methods for estimating resource quantities & $0 \%(0 / 1)$ & $27 \%(4 / 15)$ & $33 \%(8 / 24)$ & $81 \%(13 / 16)$ \\
\hline Sufficiently detailed description of methods for estimation & - & $0 \%(0 / 4)$ & $13 \%(1 / 8)$ & $46 \%(6 / 13)$ \\
\hline Measurement of effects in appropriate units & $100 \%(1 / I)$ & $46 \%(6 / 13)$ & $62 \%(13 / 21)$ & $88 \%(14 / 16)$ \\
\hline Accurate measurement of resource quantities & $0 \%(0 / 1)$ & $0 \%(0 / 13)$ & $5 \%(1 / 21)$ & $31 \%(5 / 16)$ \\
\hline Omission of relevant items/information from measurement & $100 \%(1 / I)$ & $77 \%(10 / 13)$ & $65 \%(13 / 20)$ & $33 \%(5 / 15)$ \\
\hline $\begin{array}{l}\text { Clear justification for omitting items/information from meas- } \\
\text { urement }\end{array}$ & $0 \%(0 / 1)$ & $0 \%(0 / 12)$ & $0 \%(0 / 19)$ & $0 \%(0 / 9)$ \\
\hline Clear justification for not reporting measurement of costs & $0 \%(0 / I)$ & $0 \%(0 / 8)$ & $0 \%(0 / 12)$ & $0 \%(0 / 2)$ \\
\hline \multicolumn{5}{|l|}{ Valuation of costs } \\
\hline Recording of currency data & $100 \%(1 / I)$ & $100 \%(15 / 15)$ & $100 \%(24 / 24)$ & $100 \%(16 / 16)$ \\
\hline Recording of price data & $0 \%(0 / 1)$ & $27 \%(4 / 15)$ & $33 \%(8 / 24)$ & $81 \%(13 / 16)$ \\
\hline Description of methods for valuing unit costs & $0 \%(0 / 1)$ & $40 \%(6 / 15)$ & $46 \%(11 / 24)$ & $94 \%(15 / 16)$ \\
\hline Sufficiently detailed reporting of methods for valuation & - & $50 \%(3 / 6)$ & $33 \%(4 / / 2)$ & $60 \%(9 / 15)$ \\
\hline Clear identification of sources of all values & $0 \%(0 / 1)$ & $20 \%(3 / 15)$ & $17 \%(4 / 24)$ & $56 \%(9 / 16)$ \\
\hline $\begin{array}{l}\text { Details of any adjustment for inflation, or currency conver- } \\
\text { sion }\end{array}$ & $0 \%(0 / 1)$ & $7 \%(1 / 15)$ & $8 \%(2 / 24)$ & $25 \%(4 / 16)$ \\
\hline Omission of relevant information regarding valuation & $100 \%(1 / 1)$ & $73 \%(11 / 15)$ & $74 \%(17 / 23)$ & $27 \%(4 / 15)$ \\
\hline $\begin{array}{l}\text { Clear justification for omitting items/information from valua- } \\
\text { tion }\end{array}$ & $0 \%(0 / 1)$ & $0 \%(0 / 12)$ & $0 \%(0 / 20)$ & $0 \%(0 / 8)$ \\
\hline $\begin{array}{l}\text { Credible/appropriate method for valuation given research } \\
\text { objectives }\end{array}$ & $0 \%(0 / 1)$ & $33 \% 5 / 15$ & $29 \%(7 / 24)$ & $63 \%(10 / 16)$ \\
\hline Clear justification for not reporting methods for valuation & $0 \%(0 / I)$ & $0 \%(0 / 8)$ & $0 \%(0 / I I)$ & $50 \%(1 / 2)$ \\
\hline
\end{tabular}

The data collection was assessed using the listed criteria (done / not done / not clear / not relevant (-)). In the table, the numbers (and percentages) of studies that met each criterium are presented. Details of all studies included in our review $(\mathrm{N}=24)$ are available from the corresponding author. 


\section{Data modelling and analysis}

Data modelling for the extrapolation of guideline implementation costs was reported in four studies $[26,29,38,45]$, and for the extrapolation of both costs and effects of implementing guidelines in three studies [32,43,48]. One study [45] applied a modelling approach for both data synthesis and data extrapolation. This study provides a perfect illustration of one of the potential uses of models in the full economic evaluation of implementing a clinical guideline, as an attempt is made to derive the cost-utility of practice change by combining the empiric cost-effectiveness data of implementation strategies with an estimated cost-utility of the guidelines promoted in terms of US dollars per quality-adjusted life-year. Nonetheless, none of the studies explicitly reported the quality assessment of the models used.

Adjustments for differential timing of guideline implementation costs were required in nine studies $[22,23,29,31,35,39,40,48,49]$ and made in one-third of these studies $[22,29,35]$. Costing discount rates were reported in only one study [29]. Sensitivity analyses were performed in five studies $[26,30,41,43,45]$ to explore the influence of ranges of cost values. The most commonly used approach was a one-way sensitivity analysis.

Incremental analyses of costs or cost-effectiveness of guideline implementation were not performed in $58 \%$ of the studies [22,23,29,31,35,39,40,48,49]. One study [28] did not report an incremental analysis as there was no difference detected in implementation effects. Additionally, in eight studies $[23,24,26,39,40,43,45,50]$ an (explicit) association was made between the efficiency of implementation strategies and the costeffectiveness of the guidelines promoted. The majority of these studies involved costminimisation analyses weighing up the implementation costs and the resulting savings in health care provision $[23,24,26,39,40,43,50]$.

\subsection{Discussion}

In order to gain insight into advances in the economic evaluation of guideline implementation into clinical practice, we conducted a systematic review of English literature from January 1998 to July 2004. We identified 24 empiric studies that evaluated guideline implementation strategies to change the behaviour of health care professionals and that reported implementation costs. Overall, it was difficult to determine the quality of study designs owing to poor reporting in the economic evaluations included. In addition, the studies generally lacked economic methodological rigour: most economic evaluations in our review did not follow methodological guidelines on economic evaluation design, data collection, data analysis, and interpretation of results. Hence, we conclude that the evidence from economic evaluations of guideline implementation is still of limited use in decision making. 
Following our review, we have some comments. In comparison to the 25 economic evaluations identified in the review by Grimshaw et al. before 1998 [14], we observed a relative increase in the number of studies evaluating the efficiency of implementing guidelines to change clinical practice. Nonetheless, the number of economic evaluations remains comparatively small given the quantity of studies evaluating solely the effectiveness of guideline implementation [14,51-53]. Also, given constrained health budgets, it is surprising that many of the guidelines which the strategies sought to implement where still not based firmly on evidence of cost-effectiveness. Nevertheless, this may well be due to fact that there is no widely accepted way to incorporate considerations of costs into the development and implementation of guidelines so far [9].

Our review identified an increase in the number of cluster randomised trials, potentially indicating that methodological guidelines for the optimal design of guideline implementation evaluation [54-56] are often followed. Nonetheless, potential unit of analysis errors are still present. Also, standards of reporting need to be improved considerably to allow one to determine whether studies meet qualitative standards for other important design aspects, such as statistical significance, protection against contamination and reliability of outcome measures.

Regarding the data collection for the economic evaluation of guideline implementation, it is encouraging to have observed that a considerable number of the studies in our review used guideline adherence by health care professionals as the primary outcome measure for estimating the effectiveness of an implementation strategy. We consider this the most appropriate measure for clinical behavioural change. In terms of estimating the costs of guideline implementation, we observed a limited number of studies considering the costs of developing guidelines or developing strategies to implement them. Notwithstanding the fact that these development costs (so called 'sunk costs') often do not differentiate between the guideline implementation strategies, health policy makers must always pay attention to the balance between the development costs, implementation costs and the costs of changes in health care provision. Also, economic evaluations of guideline implementation often wrongly omit to take into account implementation costs incurred by health care professional time spent on implementation activities like attending educational meetings or receiving outreach visitors. Noteworthy, many studies do report health care provision costs to differentiate between implementation strategies - but these costs are merely the result of changes in patient management following guideline recommendations [9].

Although the data collection in most studies in our review may be insufficient for a full economic evaluation of guideline implementation [15,21], it is possible to adjust or supplement relevant costs and/or effects by modelling [10,15,17,57,58]. Remarkably, in the studies included in our review, models for data synthesis or extrapolation have been applied only incidentally. Moreover, we observed that generally accepted methods for data analysis such as cost discounting, incremental cost-effectiveness or cost-utility analysis, and sensitivity analysis were rarely applied. 
Our review had several limitations. First, our aim was not to extract information on the efficiency of different guideline implementation strategies. Indeed, the studies included in our review appeared too heterogeneous or methodologically flawed to be combined using a formal meta-analysis. Second, as our search was restricted to the EPOC register and the MEDLINE database, it is inevitable that some relevant economic evaluations will have been missed. Nevertheless, the resemblance between the review results by Grimshaw et al. [14] and our findings seems to suggest that we have minimised selection bias. Third, contrary to the review by Grimshaw et al. [14], studies that reported only health care provision costs were not included in our review. Although this would have undoubtedly increased the number of studies included, these studies are not considered full economic evaluations of guideline implementation $[15,21]$. Lastly, the primary aims of several studies included were to assess only the effectiveness of implementation strategies [22,23,27,29,33,35,39,48,49], and in two studies, information on implementation costs was provided solely in the description of alternative strategies [27,33]. Despite the fact that many of these studies seem to address the purpose for which they were designed, we consider economic evaluation an integral component of research [12], and hence assessed the methodological quality of all studies included on the basis of whether these involved full economic evaluations of guideline implementation.

Notwithstanding the limitations of our review, our findings seem to provide an unbiased, representative and reliable overview of advances in the economic evaluation of guideline implementation in literature. Moreover, our findings seem to be in accord with other publications on economic evaluations in health care [5,59-61].

Thus, despite the growing literature on economic methodology in health care $[9,16$ 18,54-56], economic evaluations of guideline implementation continue to lack methodological rigour. Besides underuse or misuse of methodological guidance, this may well be due to biases in the methods and guidelines for guideline implementation evaluation. Although implementation research design and statistical issues are addressed frequently $[17,18,54-56]$, guidelines for data collection and data synthesis still need to be developed further. Answers should hereby be provided on methodological issues such as: what are the relevant costs and effects that should be considered in economic evaluations of guideline development and implementation? How are the costs and effects of clinical guidelines and the costs and effects of strategies to implement them to be combined? What is the use of models in the economic evaluation of guideline implementation and what is good modelling practice in this sense? Only when answers to all current methodological issues are provided can the quality of evaluations of the value for money of guideline implementation be improved, and the resulting evidence be used to inform health policy makers in setting priorities and allocating resources efficiently. Our review has contributed in revealing the gaps in economic methodology of guideline implementation evaluation and speeding up the process of methodological improvement. 


\section{References}

1. Institute of Medicine Committee on Clinical Practice Guidelines. Guidelines for clinical practice: from development to use. Washington, DC: National Academy Press 1992.

2. Cabana MD, Rand CS, et al. Why don't physicians follow clinical practice guidelines? A framework for improvement. JAMA 1999;282(15):1458-65.

3. Shekelle PG, Woolf SH, et al. Clinical guidelines: developing guidelines. BMJ 1999;318(7183):5936.

4. Woolf $\mathrm{SH}$, Grol R, et al. Clinical guidelines: potential benefits, limitations, and harms of clinical guidelines. BMJ 1999;318(7182):527-30.

5. Cleemput I, Kesteloot K, DeGeest S. A review of the literature on the economics of noncompliance. Room for methodological improvement. Health Policy 2002;59(1):65-94.

6. Grimshaw J, Eccles M, Tetroe J. Implementing clinical guidelines: current evidence and future implications. J Contin Educ Health Prof 2004;24 Suppl 1:S31-7.

7. Freemantle N. Implementation strategies. Fam Pract 2000;17 Suppl 1:S7-10.

8. Gandjour A, Lauterbach KW. When is it worth introducing a quality improvement program? A mathematical model. Med Decis Making 2003;23(6):518-25.

9. McIntosh E. Economic evaluations of guideline implementation strategies. In: Thorsen T, Makela M, editors. Changing professional practice: Theory and practice of clinical guidelines implementation. Copenhagen: Danish Institute for Health Services Research and Development; 1999.

10. Mason J, Freemantle N, et al. When is it cost-effective to change the behavior of health professionals? JAMA 2001;286(23):2988-92.

11. Severens JL. Value for money of changing health care services? Economic evaluation of quality improvement. Qual Saf Health Care 2003;12(5):366-71.

12. Bero LA, Grilli, et al. Closing the gap between research and practice: an overview of systematic reviews of interventions to promote the implementation of research findings. BMJ 1998;317(7156): 465-8.

13. Dowie R. A review of research in the United Kingdom to evaluate the implementation of clinical guidelines in general practice. Fam Pract 1998;15(5):462-70.

14. Grimshaw JM, Thomas RE, et al. Effectiveness and efficiency of guideline dissemination and implementation strategies. Health Technol Assess 2004;8(6):iii-iv, 1-72.

15. Drummond MF, Sculpher MJ, et al. Methods for the economic evaluation of health care programmes. 3rd edition ed. Oxford: Oxford University Press; 2005.

16. McIntosh E, Donaldson C, Ryan M. Recent advances in the methods of cost-benefit analysis in health care. Matching the art to the science. Pharmacoeconomics 1999;15(4):357-67.

17. Mason J, Wood J, Freemantle N. Designing evaluations of interventions to change professional practice. J Health Serv Res Policy 1999;4(2):106-11.

18. Sculpher M. Evaluating the cost-effectiveness of interventions designed to increase the utilization of evidence-based guidelines. Fam Pract 2000;17 Suppl 1:S26-31.

19. Effective Practice and Organization of Care Group (EPOC). EPOC register. Available at: http://www.epoc.uottawa.ca/register.htm. Accessibility verified September 16, 2006.

20. Effective Practice and Organization of Care Group (EPOC). Data collection checklist. Available at: http://www.epoc.uottawa.ca/checklist2002.doc. Accessibility verified September 16, 2006.

21. Drummond MF, Jefferson TO. Guidelines for authors and peer reviewers of economic submissions to the BMJ. The BMJ Economic Evaluation Working Party. BMJ 1996;313(7052):275-83.

22. Ansari F, Gray K, et al. Outcomes of an intervention to improve hospital antibiotic prescribing: interrupted time series with segmented regression analysis. J Antimicrob Chemother 2003;52(5): 842 . 
23. Costanza ME, Stoddard AM, et al. Promoting mammography: results of a randomized trial of telephone counseling and a medical practice intervention. Am J Prev Med 2000;19(1):39-46.

24. Cowper PA, Weinberger $\mathrm{M}$, et al. The cost-effectiveness of a clinical pharmacist intervention among elderly outpatients. Pharmacotherapy 1998;18(2):327-32.

25. Hanlon JT, Weinberger M, et al. A randomized, controlled trial of a clinical pharmacist intervention to improve inappropriate prescribing in elderly outpatients with polypharmacy. Am J Med 1996;100(4):428-37.

26. Delate T, Fairman KA, et al. Randomized controlled trial of a dose consolidation program. J Manag Care Pharm 2004;10(5):396-403.

27. Fairbrother G, Hanson KL, et al. The impact of physician bonuses, enhanced fees, and feedback on childhood immunization coverage rates. American Journal of Public Health 1999;89(2):171.

28. Foy R, Penney GC, et al. A randomised controlled trial of a tailored multifaceted strategy to promote implementation of a clinical guideline on induced abortion care. $\mathrm{Br} \mathrm{J}$ Obstet Gynaecol 2004;111(7):726.

29. Frenkel H, Harvey I, Newcombe RG. Improving oral health in institutionalised elderly people by educating caregivers: a randomised controlled trial. Community Dent Oral Epidemiol 2001;29(4): 289-97.

30. Gomel MK, Wutzke SE, et al. Cost-effectiveness of strategies to market and train primary health care physicians in brief intervention techniques for hazardous alcohol use. Soc Sci Med 1998;47(2): 203-11.

31. Graff L, Prete M, et al. Implementing emergency department observation units within a multihospital network. Jt Comm J Qual Improv 2000;26(7):421-7.

32. Harrison A, Karim SA, et al. Syndrome packets and health worker training improve sexually transmitted disease case management in rural South Africa: randomized controlled trial. AIDS 2000;14(17):2769-79.

33. Hillman AL, Ripley K, et al. The use of physician financial incentives and feedback to improve pediatric preventive care in Medicaid managed care. Pediatrics 1999;104(4 Pt 1):931.

34. Holloway KA, Gautam BR, Reeves BC. The effects of different kinds of user fees on prescribing quality in rural Nepal. J Clin Epidemiol 2001;54(10):1065.

35. Holloway KA, Gautam BR, Reeves BC. The effects of different kinds of user fee on prescribing costs in rural Nepal. Health Policy Plan 2001;16(4):421-7.

36. Kaner EF, Lock CA, et al. A RCT of three training and support strategies to encourage implementation of screening and brief alcohol intervention by general practitioners. Br J Gen Pract 1999;49(446):699-703.

37. Lock CA, Kaner EF, et al. A randomized trial of three marketing strategies to disseminate a screening and brief alcohol intervention programme to general practitioners. Br J Gen Pract 1999;49(446):695-8.

38. Kenkre JE, Allan TF, et al. Breaking bones, breaking budgets: a clinical and economic evaluation of a prospective, randomized, practice controlled, intervention study in the prevention of accidents in primary care. Fam Pract 2002;19(6):675-81.

39. Kumana CR, Ching TY, et al. Antiulcer drug prescribing in hospital successfully influenced by "immediate concurrent feedback". Clin Pharmacol Ther 1998;64(5):569.

40. Merlani P, Garnerin P, et al. Quality improvement report: Linking guideline to regular feedback to increase appropriate requests for clinical tests: blood gas analysis in intensive care. BMJ 2001;323(7313):620.

41. Pyne JM, Rost KM, et al. Cost-effectiveness of a primary care depression intervention. J Gen Intern Med 2003;18(6):432-41.

42. Pyne JM, Smith J, et al. Cost-effectiveness of a primary care intervention for depressed females. J Affect Disord 2003;74(1):23-32. 
43. Raisch DW, Hammond RW, et al. Effect of a pharmacist-education initiative on ketorolac use and costs in a Medicaid program. Am J Health Syst Pharm 1998;55(12):1274-80.

44. Robinson MB, Thompson E, Black NA. A model for estimating the cost-utility of clinical audit. The example of thrombolysis for suspected acute myocardial infarction. Int J Technol Assess Health Care 1998;14(1):161-71.

45. Robinson MB, Thompson E, Black NA. Why is evaluation of the cost effectiveness of audit so difficult? The example of thrombolysis for suspected acute myocardial infarction. Qual Health Care $1998 ; 7(1): 19-26$.

46. Robinson JS, Burkhalter BR, et al. Low-cost on-the-job peer training of nurses improved immunization coverage in Indonesia. Bull World Health Organ 2001;79(2):150-8.

47. Robling MR, Houston HL, et al. General practitioners' use of magnetic resonance imaging: an open randomized trial comparing telephone and written requests and an open randomized controlled trial of different methods of local guideline dissemination. Clin Radiol 2002;57(5):402.

48. Rossiter LF, Whitehurst Cook MY, et al. The impact of disease management on outcomes and cost of care: a study of low-income asthma patients. Inquiry 2000;37(2):188-202.

49. Teich JM, Merchia PR, et al. Effects of computerized physician order entry on prescribing practices see comments. Archives of Internal Medicine 2000;160(18):2741.

50. Zack JE, Garrison T, et al. Effect of an education program aimed at reducing the occurrence of ventilator-associated pneumonia. Crit Care Med 2002;30(11):2407-12.

51. Gilbody S, Whitty P, et al. Educational and organizational interventions to improve the management of depression in primary care: a systematic review. JAMA 2003;289(23):3145-51.

52. Grol R, Grimshaw J. Evidence-based implementation of evidence-based medicine. Jt Comm J Qual Improv 1999;25(10):503-13.

53. Grol R, Grimshaw J. From best evidence to best practice: effective implementation of change in patients' care. Lancet 2003;362(9391):1225-30.

54. Grimshaw J, Campbell M, et al. Experimental and quasi-experimental designs for evaluating guideline implementation strategies. Fam Pract 2000;17 Suppl 1:S11-6.

55. Campbell MK, Steen N, et al. Design and statistical issues in implementation research. In: Thorsen T, Makela M, editors. Changing professional practice: Theory and practice of clinical guidelines implementation. Copenhagen: Danish Institute for Health Services Research and Development; 1999.

56. Campbell MK, Mollison J, Grimshaw JM. Cluster trials in implementation research: estimation of intracluster correlation coefficients and sample size. Stat Med 2001;20(3):391-9.

57. Barton P, Bryan S, Robinson S. Modelling in the economic evaluation of health care: selecting the appropriate approach. J Health Serv Res Policy 2004;9(2):110-8.

58. Buxton MJ, Drummond MF, et al. Modelling in economic evaluation: an unavoidable fact of life. Health Econ 1997;6(3):217-27.

59. Cleemput I, Kesteloot K. Economic implications of non-compliance in health care. Lancet 2002;359(9324):2129-30.

60. Drummond M, Sculpher M. Common methodological flaws in economic evaluations. Med Care 2005;43(7 Suppl):5-14.

61. Jefferson T, Demicheli V. Quality of economic evaluations in health care. BMJ 2002;324(7333): 313-4. 


\section{Appendix 2.I Medline search strategy}

121. 118 and 119 and 120

120. English in LA

I 19. or / 1998 -2004 in PY

118.19 and 117

117. or / 20-116

I 16. ((effect? or impact or introduc*) near (legislation or regulations)) in $\mathrm{Tl}$ or $\mathrm{AB}$

II5. ((introduc* or impact or effect? or implement* or computer*) near protocol?) in $\mathrm{TI}$ or $\mathrm{AB}$

II4. ((computer* near (dosage or dosing or diagnosis or therapy or decision?)) in $\mathrm{TI}$ or $\mathrm{AB}$

I 13. ((effect? or impact or evaluat* or introduc* or compar*) near prevent* program*) in TI or AB

II2. ((effect? or impact or evaluat* or introduc* or compar*) near screening program*) in $\mathrm{TI}$ or $\mathrm{AB}$

III. ((effect? or impact or evaluat* or introduc* or compar*) near care program*) in $\mathrm{TI}$ or $\mathrm{AB}$

110. ((effect? or impact or evaluat* or introduc* or compar*) nea treatment program*) in $\mathrm{TI}$ or $\mathrm{AB}$

109. (program* adj (health or care or intervention?)) in $\mathrm{TI}$ or $\mathrm{AB}$

108. (program* near (reduc* or increas* or decreas* or chang* or improv* or modify* or monitor* or care)) in TI or AB

107. ((standard or usual or routine or regular or traditional or conventional or pattern) near care) in $\mathrm{TI}$ or $\mathrm{AB}$

106. (hospital? adj merg*) in $\mathrm{TI}$ or $\mathrm{AB}$

105. managed care in $\mathrm{TI}$ or $\mathrm{AB}$

104. "Health-Maintenance-Organizations" / all SUBHEADINGS in MIME,MJME

103. (physician patient adj (interaction? or relationship?)) in $\mathrm{TI}$ or $\mathrm{AB}$

102. "Telephone-" / all SUBHEADINGS in MIME,MJME

I0I. "Medical-History-Taking" / all SUBHEADINGS in MIME,MJME

100. (patient near testing) in $\mathrm{TI}$ or $\mathrm{AB}$

99. triage in $\mathrm{TI}$ or $A B$

98. offset in $\mathrm{TI}$ or $\mathrm{AB}$

97. (early adj discharg*) in $\mathrm{TI}$ or $\mathrm{AB}$

96. "Length-of-Stay" / all SUBHEADINGS in MIME,MJME

95. "Program-Evaluation" / all SUBHEADINGS in MIME,MJME

94. "Process-Assessment-Health-Care" / all SUBHEADINGS in MIME,MJME

93. quality assurance in $\mathrm{TI}$ or $\mathrm{AB}$

92. "Physician's-Practice-Patterns" / all SUBHEADINGS in MIME,MJME

91. "Utilization-Review" / all SUBHEADINGS in MIME,MJME

90. "Peer-Review" / all SUBHEADINGS in MIME,MJME

89. (information near (management or system?)) in $\mathrm{TI}$ or $A B$

88. "Medical-Records-Systems-Computerized" / all SUBHEADINGS in MIME,MJME

87. "Medical-Records" / all SUBHEADINGS in MIME,MJME

86. day surgery in $\mathrm{TI}$ or $\mathrm{AB}$

85. (home adj treat*) in $\mathrm{TI}$ or $\mathrm{AB}$

84. domiciliary in $\mathrm{TI}$ or $\mathrm{AB}$

83. (chang* adj location?) in $\mathrm{TI}$ or $\mathrm{AB}$

82. "Community-Health-Nursing" / all SUBHEADINGS in MIME,MJME

81. "Aftercare-" / all SUBHEADINGS in MIME,MJME

80. "Day-Care" / all SUBHEADINGS in MIME,MJME

79. "Office-Visits" / all SUBHEADINGS in MIME,MJME

78. "Nursing-Homes" / all SUBHEADINGS in MIME,MJME

77. "Hospices-" / all SUBHEADINGS in MIME,MJME

76. "Home-Care-Services" / all SUBHEADINGS in MIME,MJME

75. "Ambulatory-Care" / all SUBHEADINGS in MIME,MJME

74. explode "Ambulatory-Care-Facilities" / all SUBHEADINGS in MIME,MJME

73. (case adj management) in $\mathrm{TI}$ or $\mathrm{AB}$

72. (care near (coordinat* or program* or continuity)) in $\mathrm{TI}$ or $\mathrm{AB}$

7I. (integrat* near (care or service?)) in $\mathrm{TI}$ or $A B$

70. (team near (care or treatment)) in $\mathrm{TI}$ or $A B$

69. "Patient-Care-Team" / all SUBHEADINGS in MIME,MJME
68. paramedic? in $T I$ or $A B \quad 67$. clinical pharmacist? in $T$ I or $A B$ 66. "Pharmacists-" / all SUBHEADINGS in MIME,MJME

65. (nurse adj (rehabilitator? or clinician? or practitioner? or midwi*)) in $\mathrm{TI}$ or $\mathrm{AB}$

64. "Nurse-Practitioners" / all SUBHEADINGS in MIME,MJME

63. "Nurse-Midwives" / all SUBHEADINGS in MIME,MJME

62. "Nurse-Clinicians" / all SUBHEADINGS in MIME,MJME

61. blue cross in $\mathrm{TI}$ or $\mathrm{AB}$

60. "Medicare-" / all SUBHEADINGS in MIME,MJME

59. "Medicaid-" / all SUBHEADINGS in MIME,MJME

58. fundhold* in $\mathrm{TI}$ or $A B$

57. formular* in $\mathrm{TI}$ or $\mathrm{AB}$

56. "Hospital-Charges" / all SUBHEADINGS in MIME,MJME

55. (prepay* or prepaid or prospective payment?) in $T I$ or $A B$

54. (copayment? or co payment?) in $\mathrm{TI}$ or $\mathrm{AB}$

53. cost shar* in $\mathrm{Tl}$ or $\mathrm{AB}$

52. "Deductibles-and-Coinsurance" / all SUBHEADINGS in MIME,MJME

51. "Capitation-Fee" / all SUBHEADINGS in MIME,MJME

50. fee for service in $\mathrm{TI}$ or $A B$

49. explode "Reimbursement-Mechanisms" / all SUBHEADINGS in

MIME,MJME

48. marketing in $\mathrm{TI}$ or $\mathrm{AB}$

47. compliance in $\mathrm{TI}$ or $\mathrm{AB}$

46. counsel* in $\mathrm{TI}$ or $\mathrm{AB}$

45. "Patient-Education" / all SUBHEADINGS in MIME,MJME

44. ((effect? or impact or records or chart?) near audit) in $\mathrm{TI}$ or $\mathrm{AB}$

43. chart review* in $\mathrm{TI}$ or $\mathrm{AB}$

42. feedback in $\mathrm{TI}$ or $\mathrm{AB}$

41. "Feedback-" / all SUBHEADINGS in MIME,MJME

40. algorithm? in $\mathrm{Tl}$ or $\mathrm{AB}$

39. (prompter? or prompting) in $\mathrm{Tl}$ or $\mathrm{AB}$

38. (recall near system*) in $\mathrm{Tl}$ or $\mathrm{AB}$

37. reminder? in $\mathrm{TI}$ or $\mathrm{AB}$

36. "Reminder-Systems" / all SUBHEADINGS in MIME,MJME

35. (effect? or impact or evaluat* or introduc* or compar*) near training program*) in $\mathrm{Tl}$ or $\mathrm{AB}$

34. (guideline? near (introduc* or issu* or impact* or effect? or disseminat* or distribut*)) in $\mathrm{TI}$ or $\mathrm{AB}$

33. practice guideline? in $\mathrm{TI}$ or $\mathrm{AB}$

32. consensus conference? in $\mathrm{Tl}$ or $\mathrm{AB}$

31. group detailing in $\mathrm{TI}$ or $\mathrm{AB}$

30. (facilitator? in $\mathrm{TI}$ or $\mathrm{AB}$

29. (opinion adj leader?) in $\mathrm{TI}$ or $\mathrm{AB}$

28. outreach in $\mathrm{TI}$ or $\mathrm{AB}$

27. (education* adj (method? or material?)) in $T I$ or $A B$

26. (information* near campaign) in $\mathrm{TI}$ or $\mathrm{AB}$

25. ((written or printed or oral) adj information) in $\mathrm{TI}$ or $\mathrm{AB}$

24. ((leaflet? or booklet? or poster or posters) in $T I$ or $A B$

23. "Pamphlets-" / all SUBHEADINGS in MIME,MJME

22. (behavio? ${ }^{*}$ near intervention?) in $\mathrm{TI}$ or $\mathrm{AB}$

21. (education* near (program* or intervention? or meeting? or session? or strateg* or workshop? or visit?)) in $\mathrm{TI}$ or $\mathrm{AB}$

20. explode "Education-Continuing" / all SUBHEADINGS in MIME,MJME

19. 18 not 17

18. or $/ 1-14$

17. 15 not 16

16. human in MESH

15. animal in MESH

14. comparative studies in MESH

13. effect? in $\mathrm{Tl}$ or $\mathrm{AB}$

12. evaluat* in $\mathrm{TI}$ or $\mathrm{AB}$

11. evaluation studies in MESH

10. chang* in $\mathrm{TI}$ or $\mathrm{AB}$

9. intervention? in $\mathrm{TI}$ or $\mathrm{AB}$

8 impact in $\mathrm{TI}$ or $\mathrm{AB}$

7. random allocation in MESH

6. ((pre test or pretest or (posttest or post test)) in $\mathrm{TI}$ or $\mathrm{AB}$

5. (time adj series) in $\mathrm{TI}$ or $\mathrm{AB}$

4. experiment* in $\mathrm{TI}$ or $\mathrm{AB}$

3. intervention studies in MESH

2. RANDOMIZED-CONTROLLED-TRIAL in PT

I. CONTROLLED-CLINICAL-TRIAL in PT 


\section{Value for Money in Changing Clinical Practice:}

Should Decisions about Guidelines and Implementation Strategies Be Made Sequentially or Simultaneously?

Ties Hoomans $^{1}$, Johan L. Severens ${ }^{1,2}$, Silvia M.A.A. Evers ${ }^{1}$, André J.H.A. Ament ${ }^{1}$

${ }^{1}$ Department of Health Organisation, Policy and Economics, Maastricht University, the Netherlands;

${ }^{2}$ Department of Clinical Epidemiology and MTA, University Hospital Maastricht, the Netherlands

Med Dec Making (in press) 


\section{Abstract}

Decisions about clinical practice change, i.e. which guidelines to adopt and how to implement them, can be made sequentially or simultaneously. Decision makers adopting a sequential approach first compare the costs and effects of alternative guidelines to select the best set of guideline recommendations for patient care, and subsequently examine the implementation costs and effects to choose the best strategy to implement the selected guideline. In an integral approach, decision makers simultaneously decide about the guideline and the implementation strategy on the basis of the overall value for money in changing clinical practice.

This chapter demonstrates that the decision to use a sequential versus an integral approach affects the need for detailed information and the complexity of the decision analytic process. More importantly, it may lead to different choices of guidelines and implementation strategies for clinical practice change. The differences in decision making and decision analysis between the alternative approaches are comprehensively illustrated using two hypothetical examples. We argue that, in most cases, an integral approach to deciding about change in clinical practice is preferred, as this provides more efficient use of scarce health care resources. 


\section{I Introduction}

Clinical practice guidelines aim to improve patient care by providing patients and health care professionals with information that helps them in making clinical decisions [1]. Guidelines (usually consisting of a set of recommendations) are not automatically diffused into clinical practice [2-4]. Resources need to be committed to strategies to implement them [5-8]. Implementation strategies aim to enhance the adherence by health care professionals and patients to guideline recommendations, and may involve educational, financial, organisational and regulatory interventions. Frequently used strategies include educational materials and meetings, outreach visits, audit and feedback, and reminders [2,8-10]. Given constrained health budgets, it is important for decision makers to carefully consider whether developing and implementing a guideline is worthwhile [7,11-13], and economic evaluations are increasingly being used to inform decisions about the efficient allocation of resources for changing clinical practice $[8,10]$.

The literature on the economics of implementing clinical guidelines to change practice advocates that the assessment of the value for money of implementation strategies should be done in terms of guideline outcomes [7,11,12,14-17]. This suggests that a sequential approach is 'best practice' for resource allocation. Specifically, it implies that decision makers first compare the costs and effects of alternative guidelines to select a guideline for implementation; then compare the implementation costs and effects of different strategies to implement the selected guideline. These two sequential decisions can be informed by separate economic evaluations of (1) the alternative clinical guidelines, and of (2) the alternative implementation strategies. Nevertheless, considering that clinical guidelines differ in both their efficiency and in the feasibility of their implementation (also referred to as implementability) [18-22], it is not evident that this approach leads to optimal patient care and resource use. Therefore, it might be worthwhile to question whether decisions about guidelines and implementation strategies would be better made simultaneously, based on an overall estimate of the value for money of change in clinical practice. Would this integral approach to decision making have implications for the common approach to decision analysis and the utilisation of available health care resources?

The aim of this chapter is to demonstrate that the decision to use a sequential versus an integral approach affects the choice of guidelines and the implementation strategies adopted for changing clinical practice. We argue that, in most cases, an integral approach yields more efficient resource utilisation. The chapter is structured as follows. The next section provides some methodological background to the economic evaluation of clinical practice change. In the third section, we use two hypothetical examples to illustrate the differences in decision making and decision analysis between the alternative approaches. The last section offers a general discussion and some conclusions. 


\subsection{Methodological background}

Figures $3.1 \mathrm{a}$ and $3.1 \mathrm{~b}$ detail the differences in the sequence of analyses (including data collection and the comparison of alternatives) and in the decisions between a sequential approach and an integral approach to decision making about implementing clinical guidance, depicting separate economic evaluations of guidelines and also implementation strategies versus economic evaluations of clinical practice change. Some considerations regarding the methods for economic evaluation are outlined below.

Figure 3.Ia Process flow of a sequential approach to decision making about clinical practice change

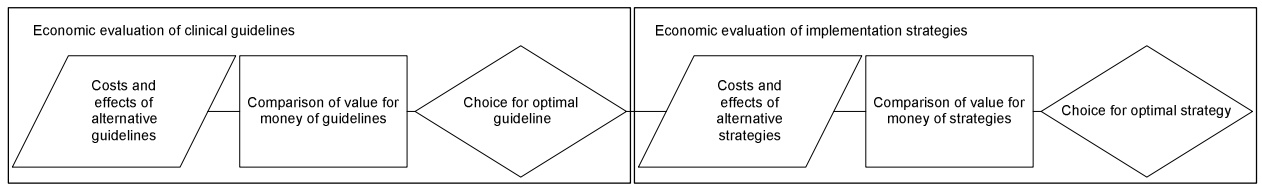

Figure 3.Ib Process flow of an integral approach to decision making about clinical practice change

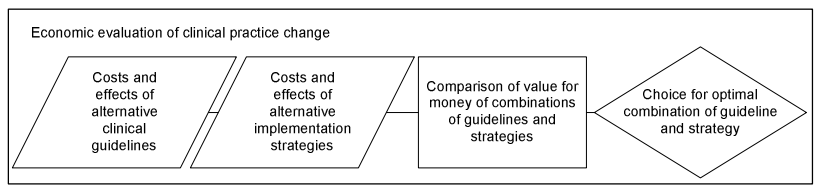

Economic evaluation of clinical guidelines. In order to examine the value for money of clinical guidelines, the costs and effects of the guideline recommendations need to be assessed (see Figure 3.1a). Guideline costs include the costs of developing the clinical guidelines and the costs of health care provision. Guideline development costs are usually one-off, fixed expenses and may include time costs of staff attending development meetings and research costs. Health care provision costs, such as the costs for medication or treatment, are the result of patient management following guideline recommendations. Ideally, the effectiveness of clinical guidelines is measured in terms of final health outcomes at patient level, such as patient mortality and morbidity. In general, alternative guidelines are compared in terms of incremental costs and effects [23-25]. The ultimate choice for the best guideline for patient management depends on the maximum decision makers are willing to pay for an additional gain in health $[24,26$ 28].

Economic evaluation of implementation strategies. For estimating the value for money of implementation strategies, information is needed on the costs of developing and executing the strategy and its effect upon the adherence to guideline recommendations (see Figure 3.1a). Examples of strategy development costs are staff time costs, expenses for training outreach visitors and software development costs. The execution costs of im- 
plementation strategies may involve media costs and opportunity costs of physicians attending educational meetings or receiving outreach visitors; these costs will vary with the format, intensity and degree of implementation activities. For a meaningful comparison of alternative strategies, it would be necessary to examine the additional costs that one implementation strategy imposes over another, compared with the change in guideline adherence it delivers.

Although the analysis of incremental costs per unit of changed guideline adherence yields an indication of the best strategy to implement the selected guideline (e.g. by ranking and comparing the cost-effectiveness ratios of alternative implementation strategies), it does not inform decision makers about whether implementation is at all worthwhile. As implementation strategies themselves require a share of health care service's finite resources, it is therefore important to assess their value for money in terms of their effect on health care and hence on health outcomes [7]. In effect, the likelihood that an implementation strategy will represent a cost-effective use of resources depends on a number of factors including its cost, its effectiveness in terms of change in guideline adherence and the costs and effects of a particular clinical guideline being promoted. Given that information on these factors is acquired at different levels (patient, professional, practice, institution, system), scale factors of the clinical setting, such as the number of practices or professionals targeted and the prevalence and incidence of the targeted disease or condition, need to be taken into account when determining the value for money of implementation [5]. Several authors portrayed a relationship between the implementation costs and effects and the cost-effectiveness of clinical guidelines for exploring the economics of implementation strategies in terms of costs per health effect at patient level (i.e. including scale factors to the specific local context) $[11,12,29]$, and for determining whether implementation makes economic sense, in particular in view of alternative uses (i.e. other programs or interventions) of health care resources.

Economic evaluation of clinical practice change. In the integral approach to decision making, the conceptually separate but related decisions about which clinical guideline and what implementation strategy to adopt are made simultaneously. An integral decision is based on overall estimates of the value for money of changing clinical practice, for all relevant combinations of clinical guidelines and their implementation strategies (see Figure 3.1b). For this reason, evidence is required on both the costs and effects of all guidelines and the costs and effects of all implementation strategies under consideration. Additionally, in order to examine the combined worth of clinical practice change, information is needed on guideline adherence at baseline. Moreover, to appropriately explore the value for money of practice change also requires the inclusion of scale factors specific to the clinical context [5]. On the basis of an incremental comparison of the overall costs and effects, an informed decision could be made about the best combination of a guideline and an implementation strategy for changing clinical practice. 


\subsection{Illustration}

\subsection{Methods}

Decision problem. To improve care for a group of patients, decision makers consider developing and implementing a clinical practice guideline. Adopting either a sequential or an integral approach to decision making may hereby lead to different decisions about which guideline to adopt and how to implement it. This is comprehensively illustrated using two related hypothetical examples. In example 1, the decisions concern (1) whether to adopt a set of national guideline recommendations (clinical guideline A) and (2) whether to adopt one of the two alternative implementation strategies (a1 or a2) to implement this guideline. In example 2, decision makers face the additional option for guideline A to be translated locally into a more specific and detailed set of recommendations (clinical guideline B), which differs in its cost, effectiveness and baseline adherence. To ensure the use of guideline B in clinical practice, implementation strategies (b1 and b2) that consume considerably fewer resources are available. Table 3.1 presents a summary of all the economic evidence relevant for decision making, including the mean net effectiveness $\left(\Delta \mathrm{E}_{\mathrm{cg}}\right)$, the mean net costs $\left(\Delta \mathrm{C}_{\mathrm{cg}}\right)$ and the mean baseline adherence (adr) for clinical guidelines A and $\mathrm{B}$, the effects $\left(\mathrm{E}_{\text {is }}\right.$ or $\left.\Delta \mathrm{adr}\right)$ and costs $\left(\mathrm{C}_{\mathrm{is}}\right)$ of implementation strategies $\mathrm{a} 1, \mathrm{a} 2, \mathrm{~b} 1$ and $\mathrm{b} 2$, and the scale factors specific to the clinical setting. In the legend, equations are formulated for calculating the incremental cost-effectiveness ratios for (1) clinical guidelines $\left(\mathrm{ICER}_{\mathrm{cg}}\right)$, (2) implementation strategies $\left(\mathrm{ICER}_{\mathrm{is}}\right.$ ) and (3) clinical practice change $\left(\mathrm{ICER}_{\mathrm{cpc}}\right)$. 
Table 3.I Economic evidence and incremental analyses of clinical practice change

\begin{tabular}{|c|c|c|c|c|}
\hline & \multicolumn{2}{|c|}{ Example I } & \multicolumn{2}{|c|}{ Example 2} \\
\hline Guidance on prescribing & \multicolumn{2}{|c|}{ Guideline A } & \multicolumn{2}{|c|}{ Guideline B } \\
\hline Net cost of clinical guideline $\left(\Delta \mathrm{C}_{\mathrm{cg}}\right)^{*}$ & \multicolumn{2}{|c|}{$€ 4980$} & \multicolumn{2}{|c|}{$€ 4065$} \\
\hline Net effect of clinical guideline $\left(\Delta \mathrm{E}_{\mathrm{cg}}\right)^{*}$ & \multicolumn{2}{|c|}{0.25 QALYs } & \multicolumn{2}{|c|}{0.36 QALYs } \\
\hline Baseline adherence to guidance (adr)* & \multicolumn{2}{|c|}{$50 \%$} & \multicolumn{2}{|c|}{$70 \%$} \\
\hline Implementation of guidance & Strategy al & Strategy a2 & Strategy bl & Strategy b2 \\
\hline Costs of implementation strategy $\left(\mathrm{C}_{\mathrm{is}}\right)^{\dagger}$ & $€ I I 0,500$ & $€ 4 I, 250$ & $€ 2,500$ & $€ 42,336$ \\
\hline Effectiveness of implementation $\left(\mathrm{E}_{\mathrm{is}}, \Delta \mathrm{adr}\right)^{*}$ & 34 \%-points & $21 \%$-points & $21 \%$-points & $23 \%$-points \\
\hline \multicolumn{5}{|l|}{ Incremental analysis ${ }^{\S}$} \\
\hline $\begin{array}{l}\text { Incremental cost-effectiveness ratio of } \\
\text { clinical guideline }\left(I C E R_{\mathrm{cg}}\right)^{*}\end{array}$ & \multicolumn{2}{|c|}{$€ I 3,727$ per QALY } & \multicolumn{2}{|c|}{$\begin{array}{c}\text { - } \\
\text { (extended } \\
\text { dominated) }\end{array}$} \\
\hline $\begin{array}{l}\text { Incremental cost-effectiveness ratio of } \\
\text { implementation strategy }\left(I C E R_{i s}\right)^{*}\end{array}$ & $\begin{array}{c}€ 62,669 \text { per } \\
\text { QALY } \\
\text { (not cost- } \\
\text { effective) }\end{array}$ & $\begin{array}{l}€ 3 I, 774 \text { per } \\
\text { QALY }\end{array}$ & Not applicable & Not applicable \\
\hline $\begin{array}{l}\text { Incremental cost-effectiveness ratio of } \\
\text { clinical practice change }\left(I^{-C E R_{c p c}}\right)^{*}\end{array}$ & $\begin{array}{c}€ 62,669 \text { per } \\
\text { QALY } \\
\text { (not cost- } \\
\text { effective) }\end{array}$ & $\begin{array}{c}€ 43,408 \text { per } \\
\text { QALY } \\
\text { (not cost- } \\
\text { effective) }\end{array}$ & $\begin{array}{l}€ I 6,332 \text { per } \\
\text { QALY }\end{array}$ & $\begin{array}{c}\text { - } \\
\text { (extended } \\
\text { dominated) }\end{array}$ \\
\hline
\end{tabular}

Scale factors

Number of health care professionals targeted

$\left(\mathrm{n}_{\mathrm{hp}}\right)$

Number of patients per professionals $\left(n_{p t}\right)$

100

Prevalence of disease $\left(p_{d}\right)$

Cost-effectiveness threshold $(\lambda)$

$3 \%$

$€ 35,000$ per

QALY

* Per patient; † Per professional; QALY: quality-adjusted life-year

$\S$ The following equations are used to calculate the incremental cost-effectiveness ratios:

Equation 3.I: $\operatorname{ICER}_{\mathrm{cg}}=\frac{\Delta \mathrm{C}_{\mathrm{cg}}}{\Delta \mathrm{E}_{\mathrm{cg}}}$

Equation 3.2: $\operatorname{ICER}_{\text {is }}=\frac{\mathrm{C}_{\text {is }} / \mathrm{n}_{\mathrm{pt}} \times \mathrm{p}_{\mathrm{d}}+\Delta \mathrm{adr} \times \Delta \mathrm{C}_{\mathrm{cg}}}{\Delta \mathrm{adr} \times \Delta \mathrm{E}_{\mathrm{cg}}}$

Equation 3.3: $\operatorname{ICER}_{\mathrm{cpc}}=\frac{\mathrm{C}_{\mathrm{is}} / \mathrm{n}_{\mathrm{pt}} \times \mathrm{p}_{\mathrm{d}}+(\mathrm{adr}+\Delta \mathrm{adr}) \times \Delta \mathrm{C}_{\mathrm{cg}}}{(\mathrm{adr}+\Delta \mathrm{adr}) \times \Delta \mathrm{E}_{\mathrm{cg}}}$ 


\subsubsection{Results}

\section{Example I}

Decision making adopting a sequential approach. In Figure 3.2a, both the incremental costs and effects of guideline A (assuming 100\% [perfect] adherence) and A' (given a baseline adherence of $50 \%$ ), and the incremental costs and effects of implementing this guideline with strategies a 1 and $\mathrm{a} 2$ are plotted on a cost-effectiveness plane. Additionally, the cost-effectiveness threshold $\lambda$ and the net benefit isoquant $\lambda$ ' [26] are shown.

Adopting a sequential approach to decision making, decision makers first decide about (1) guideline adoption by determining whether the incremental cost-effectiveness ratio of a clinical guideline $\left(\mathrm{ICER}_{\mathrm{cg}}\right.$ ) compared to standard practice (i.e. the origin [0] in the plane) is higher or lower than $\lambda$, representing the maximum a decision maker is willing to pay for a unit of health gain. The $\mathrm{ICER}_{\mathrm{cg}}$ is calculated as in Equation 3.1 (see Table 3.1), where $\Delta \mathrm{C}_{\mathrm{cgA}}$ and $\Delta \mathrm{E}_{\mathrm{cgA}}$ are the mean incremental costs and the mean incremental effects of guideline A, respectively. Given that the $\operatorname{ICER}_{\mathrm{cgA}}(€ 13,727$ per qualityadjusted life-year [QALY]) is lower than $\lambda$ (set at $€ 35,000$ per QALY), the guideline is deemed cost-effective and should be adopted. Evidently, this decision is not affected by information about the baseline adherence to the guideline. That is, any adherence level (ranging from $0 \%-100 \%$ ) has the same $\mathrm{ICER}_{\mathrm{cg}}$ and is proportionately represented on the line 0 -A (see A' for a mean baseline adherence to guideline A of 50\%).

Subsequently, decision makers decide (2) whether it is worthwhile adopting an implementation strategy to change adherence to the adopted, cost-effective guideline. The incremental cost-effectiveness ratio of an implementation strategy $\left(\mathrm{ICER}_{\mathrm{is}}\right)$ is hereby compared to $\lambda$ or the parallel drawn $\lambda$ '. The $\mathrm{ICER}_{\text {is }}$ is a function of the incremental costs and effectiveness of the guideline $\left(\Delta \mathrm{C}_{\mathrm{cg}}\right.$ and $\left.\Delta \mathrm{E}_{\mathrm{cg}}\right)$, the effected change in guideline adherence $\left(\mathrm{E}_{\mathrm{is}}, \Delta \mathrm{adr}\right)$ and the cost of implementation $\left(\mathrm{C}_{\mathrm{is}}\right)$, where the $\mathrm{ICER}_{\text {is }}$ is calculated per patient and expressed in terms of cost per QALY (see Equation 3.2 in Table 3.1). With implementation costs imposing a loading or addition on the costeffectiveness of guideline $A[11]$, the $\mathrm{ICER}_{\mathrm{is}} \mathrm{s}$ are graphically represented in the area above the line A'-A (see a1 and a2 in Figure 3.2a). The sequential decision about whether to adopt a strategy to implement a cost-effective guideline is based on the slope of the $\operatorname{ICER}_{\text {is }}$ (i.e. lines A'-a2 and a2-a1); information about the baseline adherence to the clinical guideline is of no relevance. Given a $\lambda$ of $€ 35,000$ per QALY, implementation strategy a2 (where ICER $_{\text {is }}=€ 31,774$ per QALY) is deemed cost-effective, as opposed to implementation strategy a1 (where $\mathrm{ICER}_{\text {is }}=€ 62,669$ per QALY). 
Figure 3.2a Cost-effectiveness plane, illustrating the incremental costs and effects of guideline $A$ (and $A^{\prime}$ for a baseline adherence of 50\%), implementation strategies al and a2, and cost-effectiveness threshold $\lambda$ (and net benefit isoquant $\lambda^{\prime}$ ) of $€ 35,000$ per QALY (i.e. data relevant for a sequential approach to decision making) (QALY: quality-adjusted life-year)

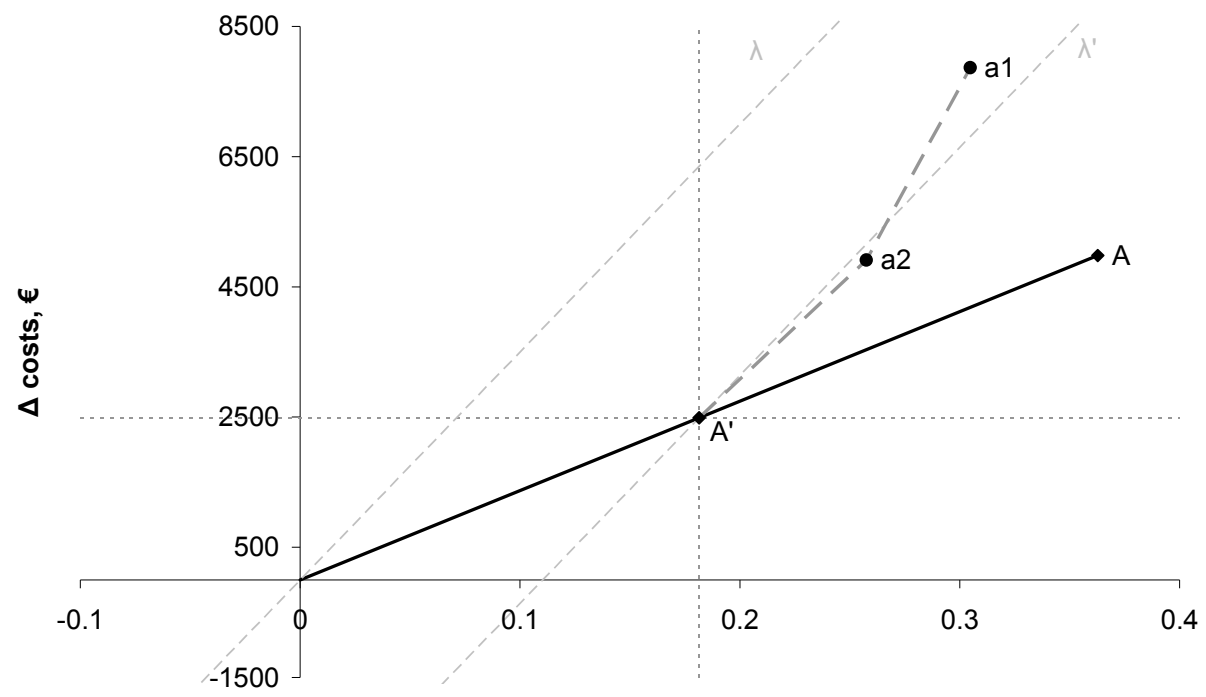

$\Delta$ effects, QALYs

Figure 3.2b Cost-effectiveness plane, illustrating the incremental costs and effects of guideline $A$ (and $A^{\prime}$ for a baseline adherence of 50\%), and implementation strategies al and a2, and cost-effectiveness threshold $\lambda$ (and net benefit isoquant $\lambda^{\prime}$ ) of $€ 35,000$ per QALY (i.e. data relevant for an integral approach to decision making) (QALY: quality-adjusted life-year)

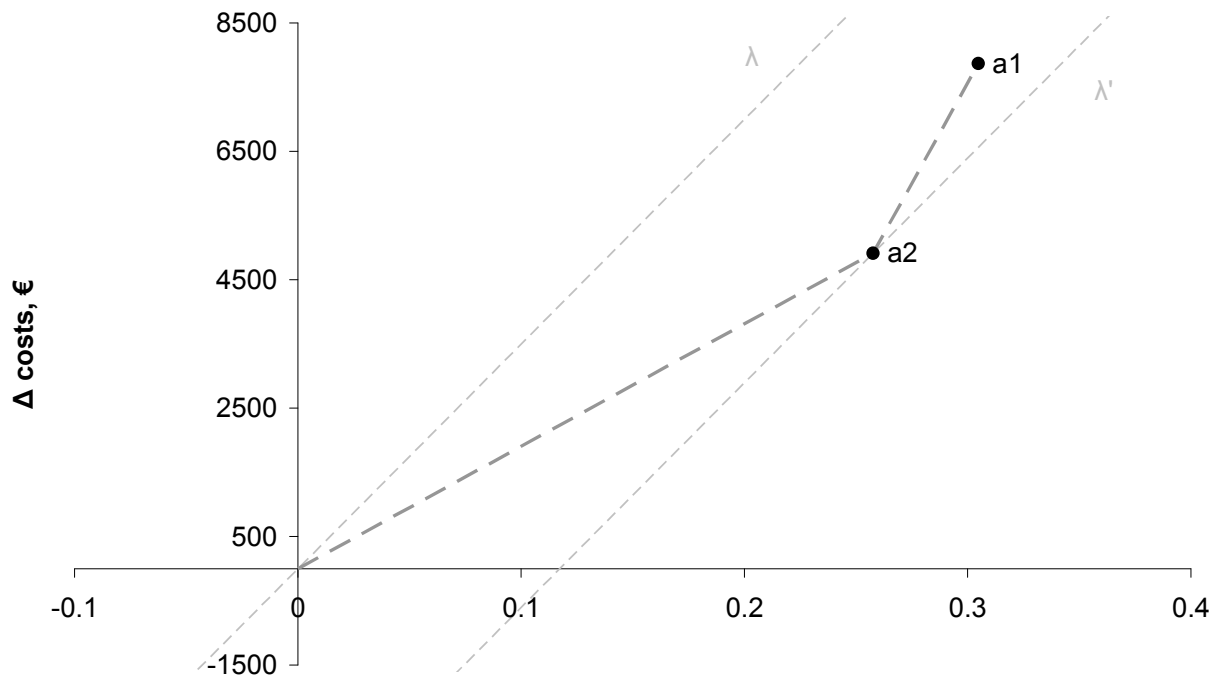

$\Delta$ effects, QALYs 
Decision making adopting an integral approach. In an integral approach to decision making, decisions about (1) which clinical guideline, and (2) what implementation strategy to adopt are based on the overall incremental cost-effectiveness ratios of clinical practice change $\left(\mathrm{ICER}_{\mathrm{cpc}}\right.$ ). The overall $\mathrm{ICER}_{\mathrm{cpc}}$ is derived in Equation 3.3 (see Table 3.1), where economic evidence on guidelines $\left(\Delta \mathrm{C}_{\mathrm{cg}}, \Delta \mathrm{E}_{\mathrm{cg}}\right.$ and $\left.\mathrm{adr}\right)$ and implementation strategies $\left(\mathrm{C}_{\mathrm{is}}\right.$ and $\left.\mathrm{E}_{\mathrm{is}}, \Delta \mathrm{adr}\right)$ is combined with estimates for the scale factors specific to the clinical setting. The scale factors include the number of health care professionals targeted $\left(\mathrm{n}_{\mathrm{hp}}\right)$, the mean number of patients per professional $\left(\mathrm{n}_{\mathrm{pt}}\right)$ and the prevalence of the targeted disease or condition $\left(\mathrm{p}_{\mathrm{d}}\right)$. The overall ICER $\mathrm{Ipc}_{\mathrm{c} S}$ are then compared to $\lambda$ (or $\left.\lambda^{\prime}\right)$.

Figure $3.2 \mathrm{~b}$ shows a cost-effectiveness plane representing the economic data (i.e. overall values for change in practice $\mathrm{a} 1$ and $\mathrm{a} 2$ and $\lambda$ [or $\left.\left.\lambda^{\prime}\right]\right)$ relevant for decision makers adopting an integral approach to deciding about clinical guidelines and implementation strategies. In this figure, the combined ICER $_{\mathrm{cpc}}$ for implementing guideline $\mathrm{A}$ with strategy a 1 and that for guideline implementation with strategy a 2 are represented by the lines $0-\mathrm{a} 2$ and $\mathrm{a} 2-\mathrm{a} 1$, respectively. Clearly, the slopes of the overall $\mathrm{ICER}_{\mathrm{cpc}} \mathrm{s}$ may differ from those of the separate ICERs of the guideline (line 0-A) and the alternative implementation strategies (lines A'-a2 and a2-a1). Moreover, the level of baseline guideline adherence affects the slope of the overall ICER $\mathrm{Cpc}_{\mathrm{cp}}$ and thus the decisions about change in clinical practice. Calculating the incremental costs and effects between a1 and $\mathrm{a} 2$ reveals that option a1 is too costly. The $\mathrm{ICER}_{\mathrm{cpc}}$ of a1 (€62,669 per QALY) exceeds the maximum decision makers are willing to pay $(\lambda=€ 35,000$ per QALY), and only option a2 is deemed cost-effective (with an ICER $_{\mathrm{cpc}}$ of $€ 19,065$ per QALY).

Explanation of the differences in decision making. In example 1, a sequential and an integral approach to decision making yield the same cost-effective option for change in clinical practice, i.e. to adopt guideline A and to implement it with strategy a2. This is easily explained because the decision problem essentially involves a simple, straightforward comparison of two alternative implementation strategies. The second example will show that the decisions may differ when alternative guidelines that vary in their efficiency and implementability, are being considered.

\section{Example 2}

In Figures 3.3a and 3.3b, the incremental costs and effects of guideline A and B (assuming perfect $[100 \%]$ adherence) and their respective implementation strategies (a1 and a 2 versus $b 1$ and $b 2)$, and the cost-effectiveness threshold ( $\lambda$ and $\lambda$ ' [i.e. the net benefit isoquant] [26]) are plotted on a cost-effectiveness plane. Figures 3.3a and 3.3b represent, respectively, economic data relevant for a sequential and an integral approach to decision making about changing clinical practice. 
Figure 3.3a Cost-effectiveness plane, illustrating the incremental costs and effects of guidelines $A$ and $B$ (and $A^{\prime}$ and $B^{\prime}$ for a baseline adherence of $50 \%$ and $70 \%$, respectively), implementation strategies a l, a2, bl and b2, and cost-effectiveness threshold $\lambda$ (and net benefit isoquant $\lambda^{\prime}$ ) of $€ 35,000$ per QALY (i.e. data relevant for a sequential approach to decision making) (QALY: quality-adjusted life-year)

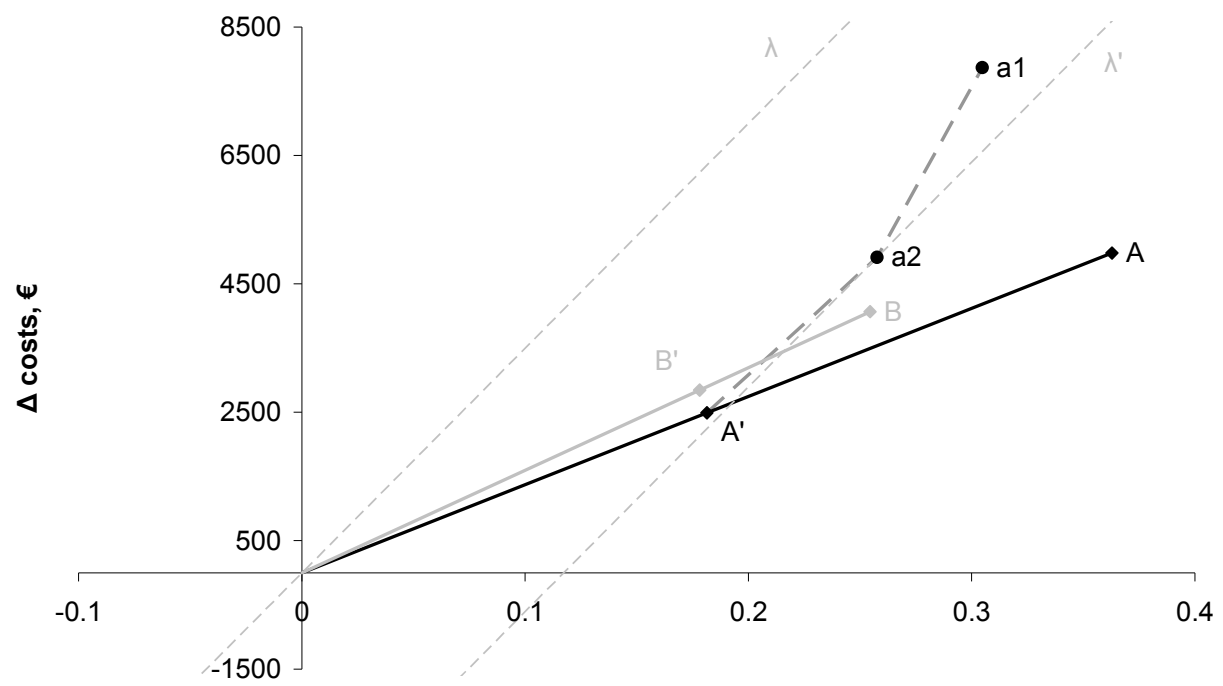

$\Delta$ effects, QALYs

Figure 3.3b Cost-effectiveness plane, illustrating the incremental costs and effects of guidelines $A$ and $B$, implementation strategies al, a2, bl and b2, and cost-effectiveness threshold $\lambda$ (and net benefit isoquants $\lambda^{\prime}$ and $\lambda$ ”) of $€ 35,000$ per QALY (i.e. data relevant for an integral approach to decision making) (QALY: qualityadjusted life-year)

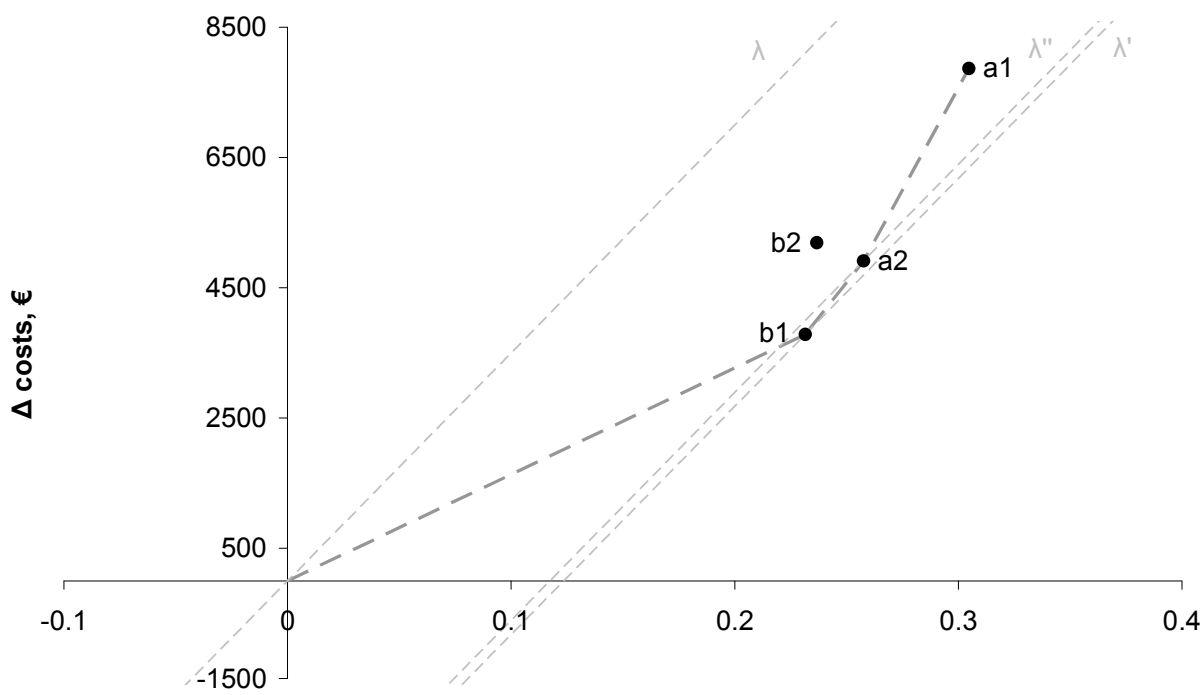

$\Delta$ effects, QALYs 
Decision making adopting a sequential approach. In case of sequential decision making considering multiple guidelines and multiple implementation strategies for changing clinical practice, decision makers (1) first select the best set of guideline recommendations (i.e. guideline $\mathrm{A}$ or $\mathrm{B}$ ) on the basis of the $\mathrm{ICER}_{\mathrm{cg}}$ and $\lambda$. Figure 3.3a shows that guideline $\mathrm{B}$ is extended dominated by guideline $\mathrm{A}$ (i.e. ICER $_{\mathrm{cg}}$ of guideline $\mathrm{A}$ is lower [€13,727 per QALY] than that of guideline B [€15,972 per QALY]).

An incremental comparison of (2) the strategies to implement cost-effective guideline A reveals that implementation strategy a1 is both more costly and more effective than implementation strategy a2; the $\mathrm{ICER}_{\text {is }}$ of options a1 and a2 are, respectively, $€ 62,669$ per QALY and €31,774 per QALY. Thus, if the decisions about change in clinical practice are made sequentially and $\lambda$ is set at $€ 35,000$ per QALY, decision makers should adopt guideline A and choose strategy a2 to implement it, as for example 1.

Decision making adopting an integral approach. Decision makers who simultaneously decide about the clinical guideline and the implementation strategy consider only the overall ICER $\mathrm{cpc}_{\mathrm{c}}$ of clinical practice change and hence mutually compare the values for a1, a2, b1 and b2 (see Figure 3.3b). In doing so, the line O-b1-a2-a1 depicts all (potentially) cost-effective combinations of a guideline and an implementation strategy (also called the efficiency frontier $[23,30]$ ), where the option to implement guideline B with strategy $\mathrm{b} 2$ is extended dominated by option a1 and option b1. The ICER $\mathrm{Cpc}_{\mathrm{cp}}$ for $\mathrm{b} 1$, a2 and $\mathrm{a} 1$ are calculated, respectively, to be $€ 16,332, € 43,408$ and $€ 62,669$ per QALY. Given that $\lambda$ is $€ 35,000$ per QALY, integral decision making would lead decision makers to opt for a combination of guideline B and strategy b1 to change clinical practice; the other options ( $\mathrm{a} 1, \mathrm{a} 2$ and $\mathrm{b} 2)$ are not deemed cost-effective.

Explanation of the differences in decision making. The second example illustrates that a sequential approach and an integral approach to decision making differ in their approach to analysis (i.e. considering the value for money of clinical guidance [ICER ${ }_{\mathrm{cg}}$ ], and then considering the value for money of implementation strategies [ICER $\mathrm{i}_{\mathrm{is}}$ ] versus considering the overall value for money of clinical practice change $\left.\left[\mathrm{ICER}_{\mathrm{cpc}}\right]\right)$ and may yield different cost-effective options for change in clinical practice (i.e. option A plus a2 versus option B plus b1, respectively). Consequently, the different approaches offer different solutions to how best to use health care resources.

\subsection{Discussion}

General discussion. Decisions about change in clinical practice, i.e. which guidelines to adopt and how to implement them, can be made sequentially or simultaneously. As illustrated, the approach to decision making has important implications for the choice 
of clinical guidelines and implementation strategies and therefore on patient care and use of resources. It also affects the need for detailed information and the complexity of the decision analytic process. Nonetheless, the collection of relevant economic data can be done by separate economic evaluations of the alternative clinical guidelines and the alternative implementation strategies, and the evidence collected from different sources can be combined using decision models. Following published guidance on economic methodology [24,31], it is emphasised that the reporting of the results of the economic evaluations of clinical practice change should not be limited to overall values. The different cost items (i.e. guideline costs and implementation costs, preferably detailed in terms of volumes and prices) and effect measures (i.e. guideline effects and implementation effects) should be reported separately and in sufficient detail, allowing readers to make a judgement on the usefulness of the evidence for decision making.

Advantages and disadvantages of the sequential approach. A sequential approach to decision making about clinical practice change, i.e. first deciding on the guideline and then deciding on which strategy to implement it, is more or less common sense in the context of health care. This approach is in line with the continuous, incremental process of quality improvement in health care, where in circumstances of suboptimal care alternatives for improvement are compared, selected and executed [13,21]. In addition, a sequential approach corresponds to the incremental approach to analysis addressed in the literature on economic evaluation in health care [23-25], emphasising that the primary outcome of interest for decision making is the difference in costs and/or effects between two or more health care programs or interventions being compared. Nevertheless, if decision making about clinical practice change is based on a sequential approach, the decisions are primarily driven by the evidence on the value for money of particular clinical guidelines. In selecting a guideline to change practice, decision makers ignore information about its implementability [3,18-22,32] and the resources that need be committed to achieve a profitable or desirable level of guideline adherence $[8,11,12,29]$. Consequently, decision makers implicitly may omit considering potentially more valuable combinations of clinical guidelines and implementation strategies, e.g. less valuable guidelines that might be implemented more efficiently and offer more value for money. As such, a sequential approach to decision making may not lead to an efficient use of scarce health care resources.

Advantages and disadvantages of the integral approach. In an integral approach to decision making, decision makers consider the overall value for money of change in clinical practice to simultaneously select guidelines and implementation strategies, in order to provide optimal patient care and efficient resource utilisation. Nonetheless, this approach to decision making may not be feasible or may be impractical owing to informational and/or analytical issues. That is, to inform integral decision making, information needs to be gathered on the alternative guidelines as well as on their estimated 
baseline adherence, and the costs and effects of strategies to implement all of the guidelines being considered. In addition, the processing (i.e. the analysis and interpretation) of a larger amount of detailed information is more complex. As a consequence, research efficiency may be reduced, particularly when a multiplicity of combinations of guidelines and strategies are being considered. Moreover, it is preferable to have the information available before the decisions are made.

Considering the informational and/or analytical issues related to adopting an integral approach to decision making, the appropriate decision analytic framework for exploring the economics of clinical practice change seems to be the use of explicit evidence synthesis and a decision modelling component $[5,33]$, e.g. by combining the findings from guideline trials with the findings from implementation trials. In guideline trials, health gain estimates and the resource implications of patient management following clinical guidance are measured, whereas in implementation trials, the effected change in guideline adherence by implementation activities and their costs is assessed [5]. In combining evidence from multiple sources, considerations need to be made for the rigour and transferability of data; relevant evidence may have to be assumed to be transferable not just to different localities but also to different treatments and diseases $[11,12]$.

Given that decision analytic modelling provides a valuable framework within which evidence can be brought to bear on specific decision problems for defined populations and contexts [33,34], it is anticipated that decision makers will increasingly opt for an integral approach to set priorities when confronted with multiple instances of suboptimal care, and to analyse the economics of a multiplicity of combinations of guidelines and implementation strategies that may be adopted to change clinical practice. An integral approach within an appropriate analytic framework may also be of particular use in: (i) the planning and organisation of the delivery health care services (e.g. in setting up disease management or screening programmes), and in (ii) the planning, undertaking, and review of economic evaluations of clinical practice change.

Comments on illustration. There are several comments to be made regarding our illustration of the differences between the alternative approaches to deciding about change in clinical practice. First of all, the citing of an actual, real world example would illustrate our argument (i.e. preferring an integral approach over a sequential approach considering the utilisation of resources) in a more compelling and tangible manner, and underline its importance for decision makers. Nevertheless, two systematic reviews of economic evaluations of guideline implementation $[8,10]$ revealed that no single empirical study reported all relevant or sufficiently rigorous economic evidence for comparison and illustration. Information from these reviews was used to obtain realistic estimates of the efficiency of guidelines, the baseline guideline adherence and the implementation costs and effects. Second, decision making about resource allocation for changing clinical practice is inevitably undertaken in a context of uncertainty surround- 
ing the cost-effectiveness of both guidelines and implementation strategies. The economic analyses in the hypothetical examples did not consider the uncertainty associated with the decisions about the adoption of clinical guidance nor of implementation strategies. Irrespective of the argument that these decisions are to be based on expected means [35], it seems important that decision makers also consider decision uncertainty simultaneously. Third, the differences between the alternative approaches to decision making could be more evident when comparing more than two guidelines and more than two implementation strategies, and including coverage or scale effects in the case of clinical practice change. Methodological guidance on economic evaluation in health care recommends that decision makers compare a (complete) range of plausible options to change clinical practice [23-25]. Moreover, to set priorities between multiple instances of suboptimal practice across different localities, treatments and diseases, it is important that decision makers consider the scale factors specific to the clinical context, e.g. the incidence and prevalence of the disease or condition targeted $[5,7,13]$. Finally, it is emphasised that, in reality, decision making about clinical practice change is not always based on economic considerations and rigorous analyses. In many circumstances, data regarding the cost and/or effectiveness of particular implementation strategies for specific clinical problems or particular contexts are not available $[8,36]$ or the economic evaluations fail to meet other methodological standards to appropriately inform decision making [8,10,31]. Moreover, decisions about the adoption of clinical guidance and implementation strategies are to a considerable extent driven by other than strictly economic factors, such as political, legal and ethical issues.

In conclusion. Various arguments can be made for the use of either a sequential or an integral approach to decision making about change in clinical practice, and each approach has both advantages and disadvantages. Clearly, the sequential (or incremental) approach is firmly embedded in economic evaluation in health care. With this approach, decision makers are advocated to repeatedly make trade-offs between the additional or marginal costs and additional or marginal effects of each of the separate interventions (i.e. guidelines or even individual guideline recommendations, and implementation strategies or even individual implementation efforts) being considered for changing clinical practice. Nonetheless, whenever relevant evidence is available and information processing is not too complex, we argue that decision makers should consider an integral approach to form better judgement about how best to use scarce health care resources. In effect, given our demonstration of the preference of an integral approach over a sequential approach to decision making in the case of clinical practice change, it is likely that integral decision making is also preferable in other areas of health care. 


\section{References}

1. Institute of Medicine Committee on Clinical Practice Guidelines. Guidelines for clinical practice: from development to use. National Academy Press 1992.

2. Grol R, Grimshaw J. From best evidence to best practice: effective implementation of change in patients' care. Lancet 2003;362(9391):1225-30.

3. Grol R, Buchan H. Clinical guidelines: what can we do to increase their use? Med J Aust 2006; 185(6):301-2.

4. Cabana MD, Rand CS, et al. Why don't physicians follow clinical practice guidelines? A framework for improvement. JAMA 1999;282(15):1458-65.

5. Mason J, Wood J, Freemantle N. Designing evaluations of interventions to change professional practice. J Health Serv Res Policy 1999;4(2):106-11.

6. McIntosh E. Economic evaluations of guideline implementation strategies. In: Thorsen T, Makela $\mathrm{M}$, editors. Changing professional practice: Theory and practice of clinical guidelines implementation. Copenhagen: Danish Institute for Health Services Research and Development; 1999.

7. Sculpher M. Evaluating the cost-effectiveness of interventions designed to increase the utilization of evidence-based guidelines. Fam Pract 2000;17 Suppl 1:S26-31.

8. Grimshaw JM, Thomas RE, et al. Effectiveness and efficiency of guideline dissemination and implementation strategies. Health Technol Assess 2004;8(6):iii-iv, 1-72.

9. Freemantle N. Implementation strategies. Fam Pract 2000;17 Suppl 1:S7-10.

10. Hoomans T, Evers SMAA, et al. The methodological quality of economic evaluations of guideline implementation into clinical practice: a systematic review of empiric studies. Value Health 2007;10(4):305-16.

11. Mason J, Freemantle N, et al. When is it cost-effective to change the behavior of health professionals? JAMA 2001;286(23):2988-92.

12. Gandjour A, Lauterbach KW. When is it worth introducing a quality improvement program? A mathematical model. Med Decis Making 2003;23(6):518-25.

13. Severens JL. Value for money of changing healthcare services? Economic evaluation of quality improvement. Qual Saf Health Care 2003;12(5):366-71.

14. Mason JM, Freemantle N, et al. Specialist nurse-led clinics to improve control of hypertension and hyperlipidemia in diabetes: economic analysis of the SPLINT trial. Diabetes Care 2005;28(1):40-6.

15. Gandjour A, Lauterbach KW. How much does it cost to change the behavior of health professionals? A mathematical model and an application to academic detailing. Med Decis Making 2005;25(3):341-7.

16. Fenwick E, Claxton K, Sculpher M. The value of implementation and the value of information: combined and uneven development. Med Decis Making 2008;28:21-32.

17. Hoomans T, Fenwick EAL, et al. Value of information and value of implementation: application of an analytic framework to inform resource allocation decisions in metastatic hormone-refractory prostate cancer. Value Health (in press).

18. Shekelle P, Eccles MP, et al. When should clinical guidelines be updated? BMJ 2001;323(7305): 155-7.

19. Woolf SH, Grol R, et al. Clinical guidelines: potential benefits, limitations, and harms of clinical guidelines. BMJ 1999;318(7182):527-30.

20. Foy R, MacLennan G, et al. Attributes of clinical recommendations that influence change in practice following audit and feedback. J Clin Epidemiol 2002;55(7):717-22.

21. Grol R, Wensing M, Eccles M. Improving patient care: the implementation of change in clinical practice. London: Elsevier Limited; 2005. 
22. Shiffman RN, Dixon J, et al. The GuideLine Implementability Appraisal (GLIA): development of an instrument to identify obstacles to guideline implementation. BMC Med Inform Decis Mak 2005;5:23.

23. Gold MR, Siegel JE, et al. Cost-effectiveness in health and medicine. Oxford: Oxford University Press; 1996.

24. Drummond MF, Sculpher MJ, et al. Methods for the economic evaluation of health care programmes. 3rd edition ed. Oxford: Oxford University Press; 2005.

25. Drummond M, McGuire A. Economic evaluation in health care: merging theory with practice. Oxford: Oxford University Press; 2001.

26. Ament A, Baltussen R. The interpretation of results of economic evaluation: explicating the value of health. Health Econ 1997;6(6):625-35

27. Eichler HG, Kong SX, et al. Use of cost-effectiveness analysis in health-care resource allocation decision-making: how are cost-effectiveness thresholds expected to emerge? Value Health 2004; 7(5):518-28.

28. Stinnett AA, Mullahy J. Net health benefits: a new framework for the analysis of uncertainty in cost-effectiveness analysis. Med Decis Making 1998;18(2 Suppl):S68-80.

29. Gandjour A, Lauterbach KW. How much does it cost to change the behavior of health professionals? A mathematical model and an application to academic detailing. Med Decis Making 2005;25(3):341-7.

30. Hunink MGM, Glasziou PP, et al. Decision making in health and medicine : integrating evidence and values. Cambridge etc.: Cambridge University Press; 2001.

31. Drummond M, Sculpher M. Common methodological flaws in economic evaluations. Med Care 2005;43(7 Suppl.):S5-14.

32. Eccles M, Grimshaw J, et al. Changing the behavior of healthcare professionals: the use of theory in promoting the uptake of research findings. J Clin Epidemiol 2005;58(2):107-12.

33. Sculpher M, Claxton $\mathrm{K}$, et al. Whither trial-based economic evaluation for health care decision making? Health Econ 2006;15(7):677-87.

34. Briggs A, Sculpher M, Claxton K. Decision modelling for health economic evaluation. Oxford: Oxford University Press; 2006.

35. Claxton K, Fenwick E, Sculpher M. Decision-making with uncertainty: the value of information. In: Jones AM, editor. Elgar Companion to Health Economics. Cheltenham: Elgar Publishing; 2006. p. 514-25.

36. Grimshaw J, Eccles M, Tetroe J. Implementing clinical guidelines: current evidence and future implications. J Contin Educ Health Prof 2004;24 Suppl 1:S31-7. 



\section{Implementing Guidelines to Change Clinical Practice: How Much to Invest and What Is the Value?}

Ties Hoomans ${ }^{1}$, Silvia M.A.A. Evers ${ }^{1}$, André J.H.A. Ament ${ }^{1}$, Johan L. Severens ${ }^{1,2}$

${ }^{1}$ Department of Health Organisation, Policy and Economics, Maastricht University, the Netherlands;

${ }^{2}$ Department of Clinical Epidemiology and MTA, University Hospital Maastricht, the Netherlands 


\section{Abstract}

Given health budget constraints, it becomes increasingly important to determine whether implementing guidelines to change clinical practice is worthwhile. We provide a model (1) to assess the economic impact of non-adherence to guideline recommendations by patients and health care professionals, and to determine the total investment potential for guideline implementation. Additionally, the model allows (2) to examine the value for money of implementation strategies to change guideline adherence and to mutually compare the investments in guideline implementation with alternative uses of health care resources.

The core value of our model lies in the explicit monetary valuation of health outcomes and the combining of evidence on guidelines and implementation strategies with information on clinical practice. By adopting a total net benefit approach, the model overcomes problems with the use of combined implementation cost-effectiveness ratios at patient level, e.g. when comparing multiple guidelines and multiple strategies across different clinical settings, or when analysing the uncertainty associated with decision making about clinical practice change. We illustrate the use of our model with a hypothetical example, and demonstrate the influence of the cost-effectiveness threshold $\lambda$, the baseline guideline adherence and the patient population size on the efficiency of resource allocation. 


\section{I Introduction}

In recent years, evidence-based clinical guidelines have become a major feature of health care. Their general aim is to improve patient care by providing patients and health care professionals with information that helps them in making clinical decisions [1]. Nonetheless, the implementation of guidelines into clinical practice does not necessarily follow: patients and health care professionals may not adhere to guideline recommendations [2-5]. Implementation strategies aim to change adherence to costeffective guidelines but cost money to enact [6-8]. Given health budget constraints, decision makers need to carefully consider whether investing in guideline implementation makes economic sense, in particular in view of alternative uses (i.e. other programmes or interventions) of health care resources [9-14].

Before deciding on whether and how to change clinical practice, it is important to assess the impact of non-adherence to evidence-based guidelines in terms of health gain and resources forgone, and to determine the investment potential for guideline implementation. Weighing up the expected costs and effects of alternative implementation strategies, decision makers subsequently decide about whether to adopt a strategy to implement the selected guideline. Clearly, whether an implementation strategy represents an efficient use of resources depends on its cost-effectiveness in terms of resources needed to effect change in guideline adherence, and the health gain estimates and resource implications of the guideline recommendations $[7,10]$. Considering the nature and purpose of practice change $[8,15]$, it is likely that the automatic use of guidelines without implementation efforts (i.e. guideline adherence at baseline), the size of the eligible patient population, and the maximum decision makers are willing to pay for health gain (i.e. cost-effectiveness threshold $\lambda$ ) also affect the scope for cost-effective implementation of clinical guidelines.

The aim of this chapter is to provide a model for exploring (1) the maximum total potential to invest in guideline implementation, and (2) the value for money of strategies to change adherence to guideline recommendations. As an alternative to published models for calculating implementation cost-effectiveness ratios at patient level $[12,16-$ 18], we suggest a total net benefit (i.e. assigning monetary values to health effects) modelling approach, combining evidence on the efficiency of guidelines and that of strategies with information on clinical practice. We illustrate the use of our model with a hypothetical example and examine the extent to which alternative modelling assumptions influence the efficiency of resource allocation. 


\subsection{Model}

There is a series of related questions which decision makers need to address in efficiently allocating resources for changing clinical practice: (1) whether it is cost-effective to adopt a guideline recommending on patient management; (2) whether there is investment potential for implementing the clinical guideline, given that adherence to guideline recommendations does not necessarily follow; and (3) whether it is worthwhile adopting implementation strategies to change guideline adherence. The model equations for informing these questions are derived in Box 4.1.

Box 4.I Decision making about resource allocation for guideline implementation

\begin{tabular}{|c|c|c|}
\hline Guideline adoption & $(4.1)$ & $\begin{array}{l}\mathrm{TNB}_{\mathrm{cg}}=\mathrm{TMB}_{\mathrm{cg}}-\mathrm{TC}_{\mathrm{cg}} \\
\text { where } \\
\mathrm{TMB}_{\mathrm{cg}}=\Delta \overline{\mathrm{E}}_{\mathrm{cg}} \times \lambda \times \mathrm{s}_{\mathrm{pp}} \\
\mathrm{TC}_{\mathrm{cg}}=\Delta \overline{\mathrm{C}}_{\mathrm{cg}} \times \mathrm{s}_{\mathrm{pp}} \\
\mathrm{s}_{\mathrm{pp}}=\mathrm{d}_{\mathrm{cg}} \times \mathrm{p}_{\mathrm{d}} \times \mathrm{n}_{\mathrm{pt}} \times \mathrm{n}_{\mathrm{hp}}\end{array}$ \\
\hline \multirow[t]{2}{*}{ Investment potential } & $(4.2 a)$ & $\begin{array}{l}\text { If } \mathrm{TNB}_{\mathrm{cg}} \geq 0, \text { then } \max \mathrm{TIP}_{\mathrm{gi}}(\mathrm{adr})=\mathrm{TNB}_{\mathrm{cg}}-\mathrm{TNB}_{\mathrm{cg}}(\mathrm{adr}) \\
\text { where } \\
\mathrm{TNB}_{\mathrm{cg}}(\mathrm{adr})=\mathrm{TMB}_{\mathrm{cg}}(\mathrm{adr})-\mathrm{TC}_{\mathrm{cg}}(\mathrm{adr}) \\
\mathrm{TMB}_{\mathrm{cg}}(\mathrm{adr})=\mathrm{TMB}_{\mathrm{cg}} \times \mathrm{adr} \\
\mathrm{TC}_{\mathrm{cg}}(\mathrm{adr})=\mathrm{TC}_{\mathrm{cg}} \times \mathrm{adr} \\
\mathrm{adr}=\mathrm{adr} r_{\mathrm{pt}} \times \mathrm{adr}_{\mathrm{hp}}\end{array}$ \\
\hline & $(4.2 b)$ & If $\mathrm{TNB}_{\mathrm{cg}}<0$, then $\max \mathrm{TIP}_{\mathrm{gi}}(\mathrm{adr})=-\mathrm{TNB}_{\mathrm{cg}}(\mathrm{adr})$ \\
\hline \multirow[t]{9}{*}{ Strategy adoption } & $(4.3 \mathrm{a})$ & $\mathrm{TNB}_{\text {is }}(\Delta \mathrm{adr})=\frac{\mathrm{d}_{\text {is }}}{\mathrm{d}_{\mathrm{cg}}} \times \mathrm{TNB}_{\mathrm{cg}}(\Delta \mathrm{adr})-\mathrm{TC}_{\text {isd }}-\mathrm{TC}_{\text {ise }}(\Delta \mathrm{adr})$ \\
\hline & & where \\
\hline & & $\mathrm{TC}_{\text {ise }}(\Delta \mathrm{adr})=\mathrm{n}_{\mathrm{hp}} \times \Delta \mathrm{adr} \times \frac{\partial \mathrm{C}_{\text {ise }}}{\partial \mathrm{adr}}$ \\
\hline & $(43 b)$ & $\left(\frac{d_{\text {is }}}{d_{c g}} \times T_{N M B}{ }_{c g}-n_{h p} \times \frac{\partial C_{\text {ise }}}{\partial a d r}\right)$ \\
\hline & $(4.3 b)$ & $\Delta \mathrm{adr}_{\text {bep }}=\frac{\mathrm{T}_{\text {isd }}}{}$ \\
\hline & $(4.4)$ & $\operatorname{TNB}_{\mathrm{gi}}\left(\operatorname{adr} r^{\prime}\right)=\mathrm{TNB}_{\mathrm{cg}}(\mathrm{adr})+\mathrm{TNB}_{\mathrm{is}}(\Delta \mathrm{adr})$ \\
\hline & & where \\
\hline & & $a d r^{\prime}=a d r+\Delta a d r$ \\
\hline & $(4.5)$ & $\operatorname{maxTIP}_{\mathrm{gi}}\left(\mathrm{adr} \mathrm{r}^{\prime}\right)=\left(\mathrm{TNB}_{\mathrm{cg}}-\mathrm{TNB}_{\mathrm{cg}}(\mathrm{adr}+\Delta \mathrm{adr})\right)+\mathrm{TNB}_{\mathrm{is}}(\Delta \mathrm{adr})$ \\
\hline
\end{tabular}




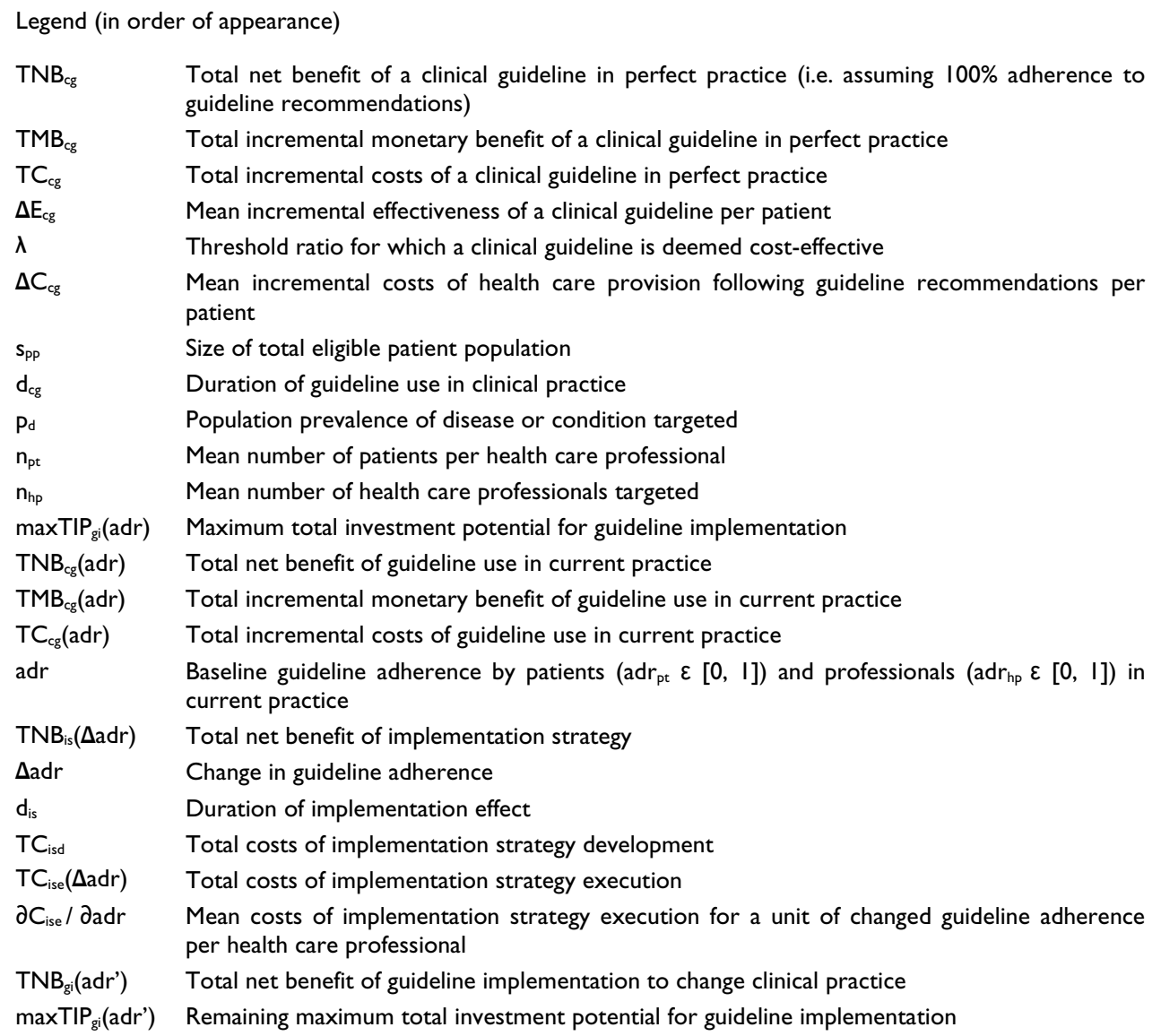

Guideline adoption. Given a decision maker's objective of maximising health gain subject to a budget constraint, the decision about whether to adopt a clinical guideline should be based on its expected net benefit $\left(\mathrm{NB}_{\mathrm{cg}}\right)$ compared to alternative guidelines or standard care $[19,20]$. The net benefit of guideline adoption is derived by subtracting the mean incremental health care provision costs $\left(\Delta \mathrm{C}_{\mathrm{cg}}\right)$ from the mean incremental monetary benefit of the guideline $\left(\Delta \mathrm{MB}_{\mathrm{cg}}\right)$. The latter is the product of the mean incremental guideline effectiveness $\left(\Delta \overline{\mathrm{E}}_{\mathrm{cg}}\right)$ and the threshold for which a clinical guideline is deemed cost-effective $(\lambda)$. For $\mathrm{NB}_{\mathrm{cg}}>0$, the guideline should be adopted for implementation into clinical practice. Generally, this decision is made under the assumption that the clinical use of guideline recommendations automatically or immediately follows, i.e. guideline adherence by patients $\left(\mathrm{adr}_{\mathrm{pt}}\right)$ and health care professionals $\left(\mathrm{adr}_{\mathrm{hp}}\right)$ is perfect $(100 \%)$.

In order to determine the scope of clinical practice change, the population value for money of guideline adoption should be calculated. Assuming 100\% baseline adherence 
to guideline recommendations, the total net benefit of a guideline in perfect clinical practice $\left(\mathrm{TNB}_{\mathrm{cg}}\right)$ is a function of the cost-effectiveness of the clinical guideline, $\lambda$ and the population of eligible patients (see Equation 4.1). The size of the patient population $\left(s_{\mathrm{pp}}\right)$ is determined by the duration of guideline use in clinical practice $\left(\mathrm{d}_{\mathrm{cg}}\right)$, the population prevalence of the disease or condition targeted $\left(\mathrm{p}_{\mathrm{d}}\right)$, the average number of patients per health care professional $\left(\mathrm{n}_{\mathrm{pt}}\right)$ and the average number of health care professionals targeted $\left(\mathrm{n}_{\mathrm{hp}}\right)[7]$.

Implementation investment potential. Caused by multiple factors such as patient knowledge, attitude of health care professionals or even chance, evidence-based guidelines may not get implemented into clinical practice perfectly $[2,3,21,22]$. Nonadherence to guideline recommendations by patients and health care professionals compromises the expected net benefit of adopting a guideline into clinical practice. With the incremental effectiveness and costs of a clinical guideline being proportionally related to guideline adherence ( $\mathrm{adr}$ ), the total net benefit of guideline use in current practice $\left(\mathrm{TNB}_{\mathrm{cg}}(\mathrm{adr})\right)$ is determined by the proportionate expected total incremental monetary guideline benefit $\left(\mathrm{TMB}_{\mathrm{cg}}(\mathrm{adr})\right)$ less the proportionate expected total incremental health care provision costs $\left(\mathrm{TC}_{\mathrm{cg}}(\mathrm{adr})\right)$.

The difference between the estimates of the total net benefit of guideline use in perfect practice $\left(\mathrm{TNB}_{\mathrm{cg}}\right)$ and that in current practice $\left(\mathrm{TNB}_{\mathrm{cg}}(\mathrm{adr})\right)$ implies opportunity losses (in terms of health gain and resources forgone) that could be invested in implementation strategies to achieve perfect $(100 \%)$ adherence to guideline recommendations (see Equation 4.2a). The maximum total investment potential for guideline implementation $\left(\right.$ maxTIP $\left._{g_{i}}(\mathrm{adr})\right)$ is evidently not only dependent on the cost-effectiveness of the clinical guideline but also on the baseline guideline adherence, $\lambda$ and the size of the eligible patient population.

Essentially, if a clinical guideline is not deemed cost-effective (with $\mathrm{TNB}_{\mathrm{cg}}<0$ ) but currently implemented into clinical practice $(\mathrm{adr}>0)$, there is a potential to invest in strategies to promote non-adherence to the guideline. In that case, the total investment potential to achieve $0 \%$ guideline adherence is equal to the total net benefit (i.e. losses) of undesirable guideline use in current practice (see Equation 4.2b).

Strategy adoption. Indicating the expected value of perfect implementation [23], the guideline implementation investment potential provides a maximum return to investing in the implementation of cost-effective guidelines. In effect, implementation strategies are only worthwhile if the additional resources invested for implementation are less or at most equal to the additional net benefit gained from effected guideline adherence change $\left(\mathrm{TC}_{\mathrm{is}}(\Delta \mathrm{adr}) \leq \mathrm{TNB}_{\mathrm{cg}}(\Delta \mathrm{adr})\right)$. In this context, it is important to take into consideration the duration of the implementation effect $\left(\mathrm{d}_{\mathrm{is}}\right)$ relative to the time period that guidelines are in clinical use $\left(\mathrm{d}_{\mathrm{cg}}\right)[10]$. 
The expected total net benefit of an implementation strategy $\left(\mathrm{TNB}_{\text {is }}(\Delta \mathrm{adr})\right)$ is simply the difference between the total net benefit gained from expected change in guideline adherence and the total resources committed to developing and executing the strategy (see Equation 4.3a). The total execution costs of an implementation strategy $\left(\mathrm{TC}_{\mathrm{ise}}(\Delta \mathrm{adr})\right)$ may involve media costs or opportunity costs of physicians attending educational meetings or receiving outreach visitors; and vary with the format, intensity and degree of implementation activities as well as the number of health care professionals targeted $\left(\mathrm{n}_{\mathrm{hp}}\right)$. Examples of strategy development costs $\left(\mathrm{TC}_{\text {isd }}\right)$ are time costs of staff attending development meetings, expenses on training outreach visitors, and software development costs.

Given that costs are enacted for strategy development, a minimum change in guideline adherence exists for which an implementation strategy is deemed beneficial. The implementation break-even point $\left(\Delta \mathrm{adr}_{\text {bep }}\right)$ is derived by equating the total net benefit of an implementation strategy with zero (see Equation 4.3b). Evidently, if there are no costs involved in implementation strategy development $\left(\mathrm{TC}_{\text {isd }}=0\right)$ or these implementation development costs per patient are small, the minimum guideline adherence change equals zero.

The sum of the total net benefit of current (i.e. automatic or baseline) clinical use of an evidence-based guideline $\left(\mathrm{TNB}_{\mathrm{cg}}(\mathrm{adr})\right)$ and that of changed guideline use due to implementation efforts $\left(\mathrm{TNB}_{\mathrm{is}}(\Delta \mathrm{adr})\right)$ yields the expected total net benefit of guideline implementation into clinical practice $\left(\mathrm{TNB}_{\mathrm{gi}}\left(\mathrm{adr}^{\prime}\right)\right)$ (see Equation 4.4$)$. Essentially, if $\mathrm{TNB}_{\mathrm{gi}}\left(\mathrm{adr}^{\prime}\right)$ is lower than the expected total net benefit of guideline use in perfect practice $\left(\mathrm{TNB}_{\mathrm{cg}}\right)$ and the adherence to the guideline is less than perfect $\left(\mathrm{adr} \mathbf{r}^{\prime}<1\right)$, there remains potential to invest in achieving perfect guideline implementation $\left(\operatorname{maxTIP}_{\mathrm{g}_{i}}\left(\operatorname{adr}^{\prime}\right)\right)$ (see Equation 4.5). In that case, decision makers could opt to extend the adopted strategy or even decide to adopt a new, additional implementation strategy.

\subsection{Example}

\subsection{Methods}

To illustrate the use of our model, we evaluated the hypothetical implementation of a guideline into clinical practice by adopting strategy A and strategy B. Table 4.1 summarises all relevant evidence on the clinical guideline, current practice, and both implementation strategies. 
Table 4.I Hypothetical evidence on the clinical guideline (cg), current practice, implementation strategies $A$ (is $\mathrm{A})$ and $\mathrm{B}$ (is $\mathrm{B}$ ), local configuration factors and other model parameters

\begin{tabular}{|c|c|c|c|}
\hline Evidence on clinical guideline and current practice & & \multicolumn{2}{|c|}{ cg } \\
\hline Mean incremental effectiveness of clinical guideline (QALYs) & $\Delta \overline{\mathrm{E}}_{\mathrm{cg}}$ & \multicolumn{2}{|c|}{0.37} \\
\hline Mean incremental costs of health care provision $(€)$ & $\Delta \mathrm{C}_{\mathrm{cg}}$ & \multicolumn{2}{|c|}{7,500} \\
\hline Baseline guideline adherence by patients (\%) & $\mathrm{adr}_{\mathrm{pt}}$ & \multicolumn{2}{|c|}{1.00} \\
\hline Baseline guideline adherence by health care professionals (\%) & $a_{d r}$ & \multicolumn{2}{|c|}{0.60} \\
\hline Evidence on implementation strategies & & is $\mathrm{A}$ & isB \\
\hline Change in guideline adherence by patients $(\Delta \%)$ & $\Delta \mathrm{adr}_{\mathrm{pt}}$ & 0.00 & 0.00 \\
\hline Change in guideline adherence by health care professionals $(\Delta \%)$ & $\Delta \mathrm{adr}_{\mathrm{hp}}$ & 0.08 & 0.12 \\
\hline Total costs of implementation strategy development $(€)$ & $\mathrm{TC}_{\text {isd }}$ & 0 & 400,000 \\
\hline $\begin{array}{l}\text { Mean costs of implementation strategy execution ( } € \text { per } \Delta \% a d r_{\text {hp }} \\
\text { per health care professional) }\end{array}$ & $\mathrm{C}_{\text {ise }}$ & 3,500 & 300 \\
\hline \multicolumn{4}{|l|}{ Local configuration factors and other model parameters } \\
\hline Cost-effectiveness threshold ( $€$ per QALY) & $\lambda$ & \multicolumn{2}{|c|}{25,000} \\
\hline Duration of guideline use in clinical practice (years) & $d_{c g}$ & \multicolumn{2}{|c|}{1} \\
\hline Prevalence of condition or disease targeted by guideline (\%) & $\mathrm{Pd}$ & \multicolumn{2}{|c|}{0.03} \\
\hline Mean number of patients per health care professional & $\mathrm{n}_{\mathrm{pt}}$ & \multicolumn{2}{|c|}{2,000} \\
\hline Mean number of health care professionals targeted & $\mathrm{n}_{\mathrm{hp}}$ & \multicolumn{2}{|c|}{25} \\
\hline Duration of implementation effect (years) & $d_{\text {is }}$ & \multicolumn{2}{|c|}{1} \\
\hline
\end{tabular}

QALY: quality-adjusted life-year

Given a $\lambda$ of $€ 25,000$ per quality-adjusted life-year (QALY), we first explored the expected total net benefit of guideline use in perfect and current practice $\left(\mathrm{TNB}_{\mathrm{cg}}\right.$ and $\mathrm{TNB}_{\mathrm{cg}}(\mathrm{adr})$ ) and the maximum total investment potential for guideline implementation $\left(\operatorname{maxTIP}_{\mathrm{gi}}(\mathrm{adr})\right)$ for the range of guideline adherence $(\mathrm{adr})$ from 0 to 1 . We interpreted the expectations regarding the expected net benefit and investment potential for a baseline adherence to guideline recommendations of $60 \%$ in regard to their implications for decision making about resource allocation.

Assuming a guideline adherence at baseline of $60 \%$, we subsequently determined the total net benefit of adopting strategy $A\left(\mathrm{TNB}_{\text {isA }}(\Delta \mathrm{adr})\right)$ and strategy $\mathrm{B}$ $\left(\mathrm{TNB}_{\mathrm{isB}}(\Delta \mathrm{adr})\right)$ and the respective total net benefit of guideline implementation $\left(\mathrm{TNB}_{\text {gilisA }}\left(\mathrm{adr} \mathrm{r}^{\prime}\right)\right.$ and $\left.\mathrm{TNB}_{\text {gilisB }}\left(\mathrm{adr} \mathbf{r}^{\prime}\right)\right)$ to change clinical practice. In addition, we extrapolated evidence on both implementation strategies over a range from no practice change $(\Delta \mathrm{adr}=0)$ to perfect implementation $(\Delta \mathrm{adr}=1$-adr $)$, assuming that any change in guideline adherence is proportionately related to the intensity and degree of implementation activities and hence to the total implementation strategy execution costs $\left(\mathrm{TC}_{\text {ise }}(\Delta \mathrm{adr})\right)$.

Finally, we performed sensitivity analyses to examine the influence of alternative assumptions regarding $\lambda$, baseline guideline adherence $(\mathrm{adr})$, and size of the total eligible patient population $\left(s_{\mathrm{pp}}\right)$ on the values for maxTIP ${ }_{\mathrm{gi}}, \mathrm{TNB}_{\mathrm{is}}$ and $\mathrm{TNB}_{\mathrm{gi}}$, and the efficiency of resource allocation. 
The results of our deterministic calculations and sensitivity analyses are graphically represented for a better understanding of such potentially complex decisions problems. All model calculations and analyses were done in MS Excel.

\subsubsection{Results}

\section{Deterministic calculations}

Total net benefit of guideline use and investment potential for implementation. Figure 4.1 shows the relationship between the baseline guideline adherence (adr) and the expected total incremental monetary guideline benefit $\left(\mathrm{TMB}_{\mathrm{cg}}(\mathrm{adr})\right)$, total incremental guideline costs $\left(\mathrm{TC}_{\mathrm{cg}}(\mathrm{adr})\right)$, total net benefit of guideline use $\left(\mathrm{TNB}_{\mathrm{cg}}(\mathrm{adr})\right)$ and maximum total investment potential for guideline implementation $\left(\operatorname{maxTIP}_{\mathrm{gi}}(\operatorname{adr})\right)$, given a $\lambda$ of $€ 25,000$ per QALY.

Since the mean incremental monetary value of guideline health effects is larger than the mean incremental guideline costs, the expected total net benefit function of guideline use $\left(\mathrm{TNB}_{\mathrm{cg}}(\mathrm{adr})\right)$ is continuously linearly increasing. This implies that for any imperfect baseline adherence $(\mathrm{adr}<1)$, there are additional net monetary benefit to be gained from promoting guideline adherence and hence a potential exists to invest in guideline implementation. The maximum total guideline implementation investment potential function $\left(\operatorname{maxTIP} \mathrm{gi}_{\mathrm{g}}(\mathrm{adr})\right)$ is hereby inversely proportional to $\mathrm{TNB}_{\mathrm{cg}}(\mathrm{adr})$, with $\max \operatorname{TIP}_{\text {is }}(0)$ equal to $\mathrm{TNB}_{\mathrm{cg}}$. That is, the lower the (baseline) adherence to the guideline, the more budget available for its implementation. If baseline adherence is $100 \%$, then the total net benefit of guideline use in current practice equals the total net monetary benefit of clinical guidelines in perfect practice $\left(\mathrm{TNB}_{\mathrm{cg}}(1)=\mathrm{TNB}_{\mathrm{cg}}\right)$, and any resources invested in guideline implementation is wasted $\left(\operatorname{maxTIP}_{\text {is }}(1)=0\right)$.

Evidence on current practice, with a baseline guideline adherence of $60 \%$ (see Table 4.1), is indicated with the dotted line ' $a$ dr $_{\mathrm{cp}}$ ', where the expected total net benefit of current guideline use $\left(\mathrm{TNB}_{\mathrm{cg}}(0.60)\right)$ is $€ 1,575,000$ and the implementation budget ( $\left.\max \operatorname{TIP}_{\mathrm{gi}}(0.60)\right)$ is estimated to be $€ 1,050,000$. Thus, given that the adopted clinical guideline is deemed cost-effective, current practice yields monetary benefit. Nevertheless, non-adherence $(40 \%)$ to guideline recommendations implies a monetary opportunity loss of about one million euros, which could be invested to improve patient care. 
Figure 4.I Total incremental monetary guideline benefit $\left(\mathrm{TMB}_{\mathrm{cg}}\right)$, total incremental guideline costs $\left(\mathrm{TC}_{\mathrm{cg}}\right)$, total net benefit of guideline use $\left(\mathrm{TNB}_{\mathrm{cg}}\right)$ and maximum total investment potential for guideline implementation (maxTIP ${ }_{\mathrm{g}}$ ) as a function of baseline guideline adherence (adr), given a cost-effectiveness threshold $\lambda$ of $€ 25,000$ per QALY and evidence on current practice $\left(\operatorname{adr}_{\mathrm{cp}}=60 \%\right)$ (QALY: quality-adjusted life-year)

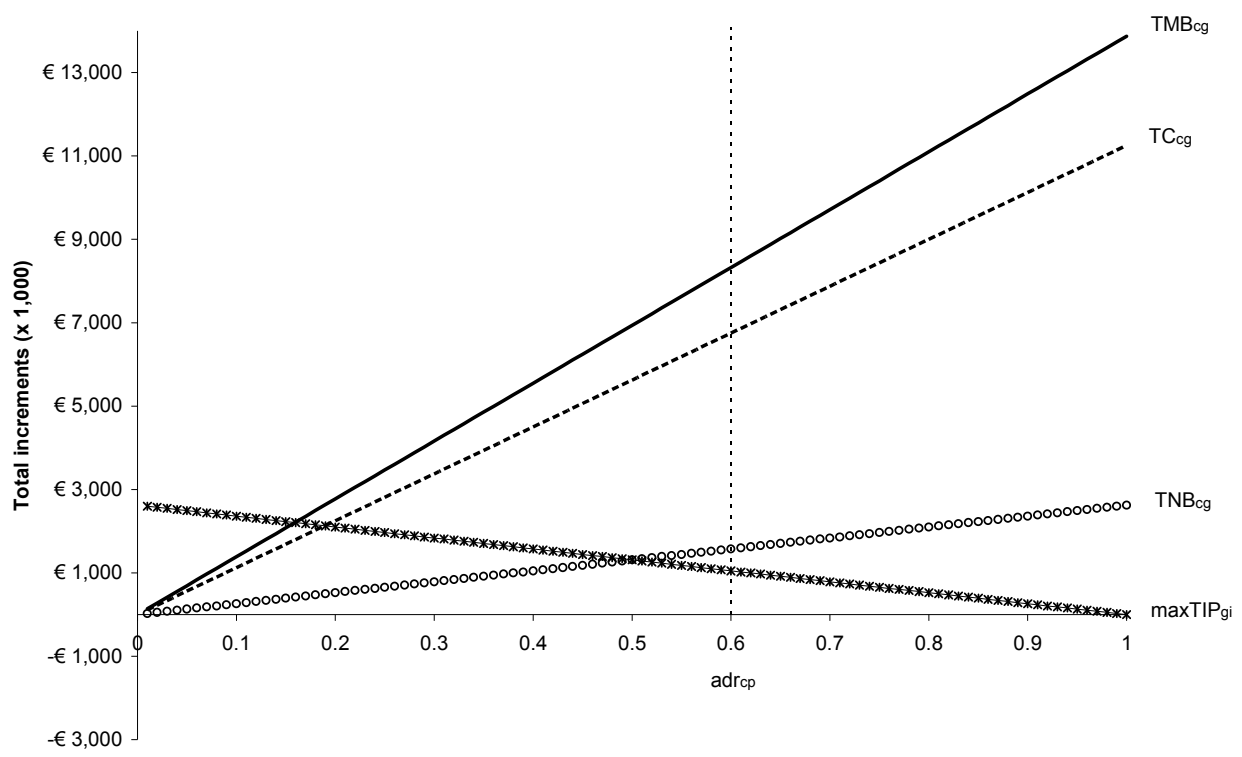

Guideline adherence adr

Value for money of implementation strategy and guideline implementation. Figures $4.2 \mathrm{a}$ and $4.2 \mathrm{~b}$ show the relationship between the expected total net guideline benefit $\left(\mathrm{TNB}_{\mathrm{cg}}(\mathrm{adr})\right)$, total implementation costs (where $\left.\mathrm{TC}_{\mathrm{is}}(\Delta \mathrm{adr})=\mathrm{TC}_{\text {isd }}+\mathrm{TC}_{\text {ise }}(\Delta \mathrm{adr})\right)$, total net implementation strategy benefit $\left(\mathrm{TNB}_{\mathrm{is}}(\Delta \mathrm{adr})\right)$, total net guideline implementation benefit $\left(\mathrm{TNB}_{\mathrm{gi}}\left(\mathrm{adr} \mathbf{r}^{\prime}\right)\right)$ and the maximum total investment potential for further guideline implementation $\left(\operatorname{maxTIP}_{\mathrm{gi}}\left(\mathrm{adr}^{\prime}\right)\right)$ and the changes in guideline adherence $(\Delta \mathrm{adr})$ as a result of, respectively, implementation strategy $\mathrm{A}$ and implementation strategy $\mathrm{B}$, given a $\lambda$ of $€ 25,000$ per QALY and a baseline guideline adherence of $60 \%$ (see dotted lines ' $\operatorname{adr}_{\mathrm{cp}}$ ' in both figures for evidence on current practice).

Since there are no costs associated with strategy development $\left(\mathrm{TC}_{\mathrm{isAd}}=0\right)$, the total costs of implementation strategy $\mathrm{A}\left(\mathrm{TC}_{\mathrm{isAe}}(\Delta \mathrm{adr})\right)$ increase linearly with guideline adherence change (see Figure 4.2a). Consequently, this implementation strategy imposes an increasingly depreciating effect upon the total net benefit of guideline use in changed practice $\left(\mathrm{TNB}_{\text {gilisA }}(\mathrm{adr})\right)$. Nevertheless, as the total implementation costs are less than the total gain in net benefit of changed guideline use $\left(\mathrm{TC}_{\mathrm{isA}}(\Delta \mathrm{adr})<\mathrm{TNB}_{\mathrm{cg}}(\Delta \mathrm{adr})\right)$, it is beneficial to adopt implementation strategy A to achieve $100 \%$ guideline adherence. 
Indeed, implementation strategies are worthwhile as long as the slope of the $\mathrm{TNB}_{\mathrm{gi}}(\mathrm{adr}$ ') curve is greater than or at least equal to zero. Moreover, since for adr' $\varepsilon$ $[0.60,1]$ holds that $\mathrm{TNB}_{\mathrm{gi}}\left(\mathrm{adr}{ }^{\prime}\right) \geq 0$, we could potentially invest additional resources for further guideline implementation. For perfect guideline adherence $\left(\mathrm{adr}^{\prime}=1\right)$, the additional total maximum investment potential equals the total net benefit of adopting implementation strategy $\mathrm{A}\left(\max \operatorname{TIP}_{\mathrm{gi}}(1)=\mathrm{TNB}_{\mathrm{isA}}(1)\right)$.

Given a baseline guideline adherence of $60 \%$ and evidence on implementation strategy A (see Table 4.1), the expected total net benefit of the $8 \%$ change in guideline adherence $\left(\mathrm{TNB}_{\mathrm{isA}}(0.68)\right)$ is $€ 122,500$. The total net benefit of guideline implementation $\left(\mathrm{TNB}_{\text {gilisA }}(0.68)\right)$ and the remaining guideline implementation investment potential $\left(\operatorname{maxTIP}_{\text {gilisA }}(0.68)\right)$ are estimated to be $€ 1,697,500$ and $€ 962,500$, respectively. Although there are costs associated with implementation (€700,000), these costs are less than the monetary revenues from the effected change $(+8 \%)$ in guideline adherence. Moreover, there remains an investment potential of nearly 1 million euros to achieve perfect implementation ( $\Delta \mathrm{adr} \mathbf{r}^{\prime}=+32 \%$ ) of the cost-effective guideline.

For implementation strategy $\mathrm{B}$, there are strategy development costs $\left(\mathrm{TC}_{\text {isBd }}\right)$ enacted and hence implementation efforts are only worthwhile unless guideline adherence is changed to a minimum of approximately $16 \%$ (see Figure $4.2 \mathrm{~b}$ ). Implementation beyond this break-even point $\left(\Delta \mathrm{adr}_{\mathrm{bep}}\right)$ results in additional net benefit of guideline use, up to a potential maximum of $€ 2,200,000$ (for $\operatorname{TNB}_{\text {gilisB }}(1)$ ).

The dotted line ' $\mathrm{adr}_{\mathrm{ep}}$ ' indicates current evidence on implementation strategy $\mathrm{B}$, where the expected total net benefit of the strategy $\left(\mathrm{TNB}_{\text {isB }}(0.72)\right)$ and guideline implementation $\left(\mathrm{TNB}_{\text {gilisB }}(0.72)\right)$ are, respectively, $-€ 92,500$ and $€ 1,482,500$, and the maximum total investment potential for further guideline implementation (max$\left.\operatorname{TIP}_{\text {gilisB }}(0.72)\right)$ is estimated to be $€ 642,500$. Clearly, it is non-beneficial to adopt implementation strategy $\mathrm{B}$ to realise a change in guideline adherence less than the implementation break-even point (i.e. $12 \%<\Delta \mathrm{adr}_{\text {bep }}$ ). Nevertheless, implementation with strategy $\mathrm{B}$ beyond this break-even point would yield net benefit.

\section{Sensitivity analysis}

Varying cost-effectiveness threshold $\lambda$. Figure 4.3 illustrates the relationship between $\lambda$ and the expected total net benefit of guideline use in perfect and current practice $\left(\mathrm{TNB}_{\mathrm{cg}}\right.$ and $\left.\mathrm{TNB}_{\mathrm{cg}}(0.6)\right)$, the total investment potential for guideline implementation $\left(\operatorname{maxTIP}{ }_{g i}(0.6)\right)$, and the expected total net benefit of adopting implementation strategy $\mathrm{A}\left(\mathrm{TNB}_{\mathrm{isA}}(0.68)\right)$ and implementation strategy $\mathrm{B}\left(\mathrm{TNB}_{\mathrm{isB}}(0.72)\right)$ regarding the decision about whether and how to change clinical practice, given a baseline adherence (adr) to the adopted guideline of $60 \%$. 
Figure 4.2a Total net benefit of clinical guideline in perfect practice $\left(T_{N B_{c g}}\right)$, total net benefit of implementation strategy $\left(\mathrm{TNB}_{\mathrm{isA}}\right)$, total net benefit of guideline implementation $\left(\mathrm{TNB}_{\mathrm{gi} \mid \mathrm{isA}}\right)$ and maximum total investment potential for (further) guideline implementation $\left(\max T \mathrm{TP}_{\mathrm{g} i}\right)$ as a function of guideline adherence (adr') for implementation strategy A, given a cost-effectiveness threshold $\lambda$ of $€ 25,000$ per QALY, baseline guideline adherence of $60 \%\left(a d r_{c p}\right)$ and evidence on current implementation ( $\left.\Delta \mathrm{adr}_{\mathrm{ep}}=8 \%\right)(\mathrm{QALY}$ : quality-adjusted life-year)

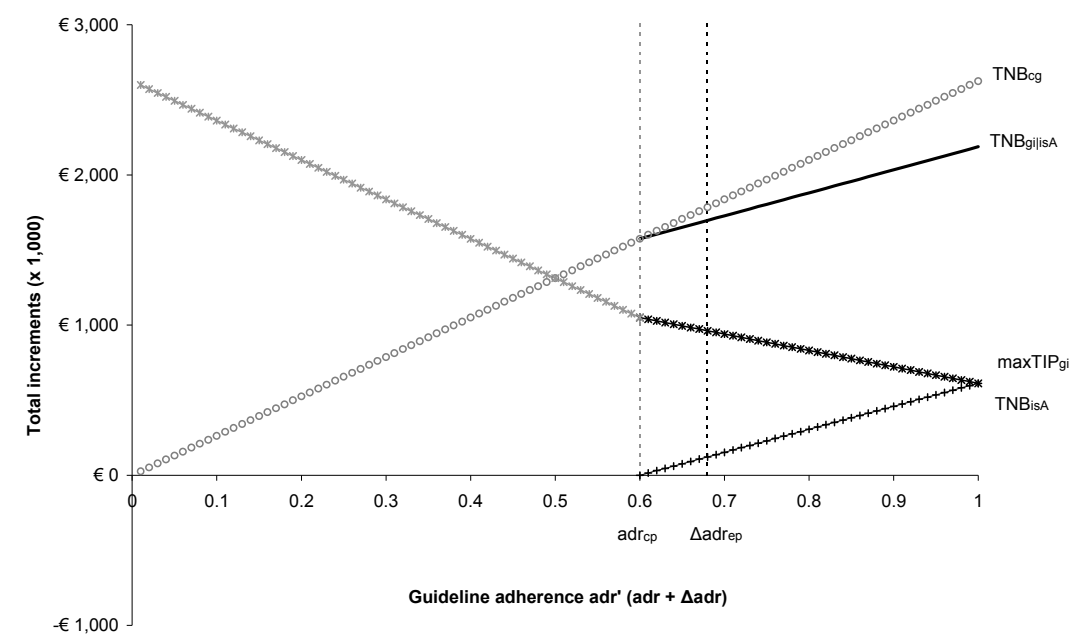

Figure 4.2b Total net benefit of clinical guideline in perfect practice $\left(\mathrm{TNB}_{\mathrm{cg}}\right)$, total net benefit of implementation strategy $\left(\mathrm{TNB}_{\mathrm{isB}}\right)$, total net benefit of guideline implementation $\left(\mathrm{TNB}_{\mathrm{g} \mid i \mathrm{sB}}\right)$ and maximum total investment potential for (further) guideline implementation $\left(\max \operatorname{TIP}_{g_{i}}\right)$ as a function of guideline adherence (adr') for implementation strategy $B$, given a cost-effectiveness threshold $\lambda$ of $€ 25,000$ per QALY, baseline guideline adherence of $60 \%\left(a d r_{\mathrm{cp}}\right)$ and evidence on current implementation ( $\left.\triangle \mathrm{adr}_{\mathrm{ep}}=12 \%\right)$ (QALY: quality-adjusted life-year)

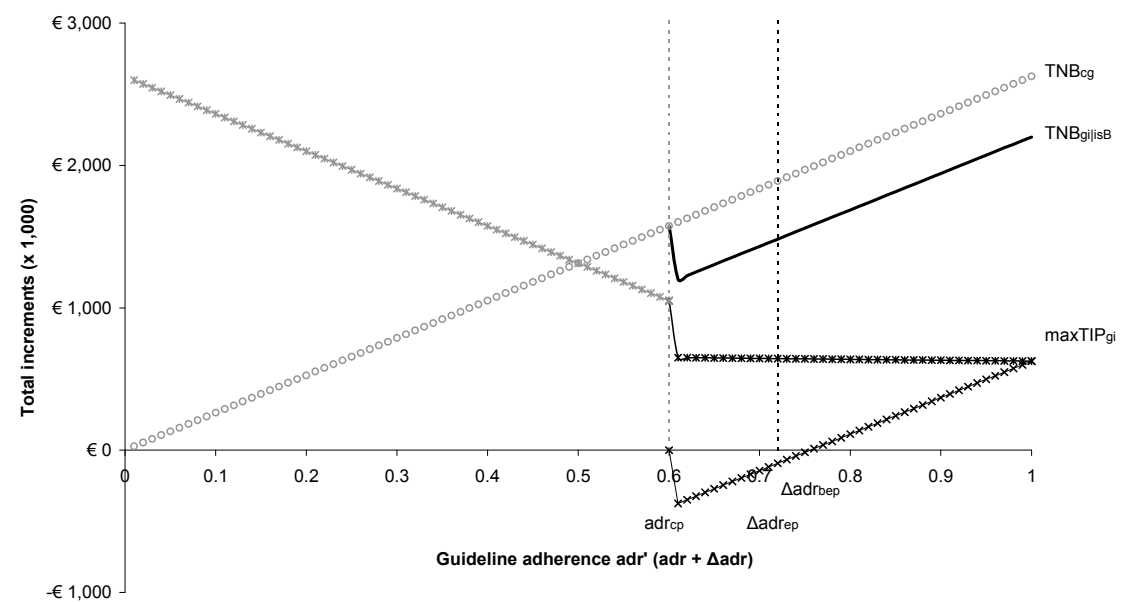


Figure 4.3 Total net benefit of clinical guideline in perfect practice $\left(\mathrm{TNB}_{\mathrm{cg}}\right)$, total net benefit of guideline use in current practice $\left(\mathrm{TNB}_{\mathrm{cg}}(0.60)\right)$, maximum total investment potential for guideline implementation (max$\left.\mathrm{TIP}_{g^{\prime}}(0.60)\right)$, total net benefit of implementation strategy $A\left(\mathrm{TNB}_{\text {isA }}(0.68)\right)$ and implementation strategy $B$ $\left(\mathrm{TNB}_{\text {iss }}(0.72)\right)$ for different values of cost-effectiveness threshold $\lambda$, given a baseline guideline adherence of $60 \%$ and evidence on current implementation (with $\Delta \mathrm{adr}_{\text {eplisA }}=8 \%$ and $\Delta \mathrm{adr}_{\text {eplisB }}=12 \%$ ) (i.e. results from a one-way sensitivity analysis; QALY: quality-adjusted life-year)

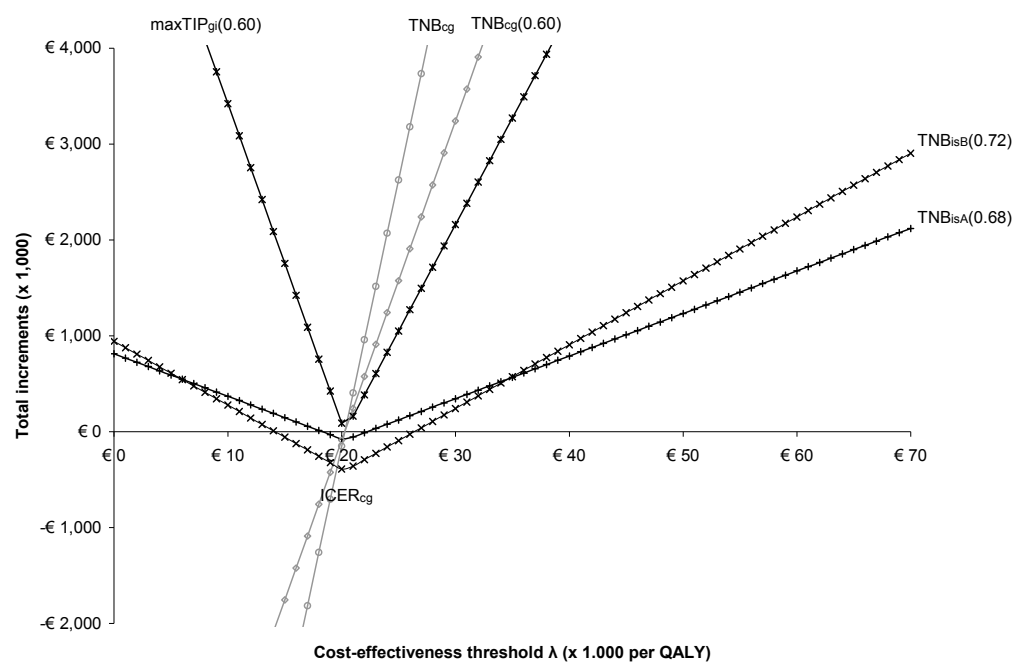

If decision makes are not willing to pay for health gain resulting from modified patient management following guideline recommendations $(\lambda=0)$, the total net benefit of the clinical use of the guideline (i.e. $\mathrm{TNB}_{\mathrm{cg}}$ and $\left.\mathrm{TNB}_{\mathrm{cg}}(0.6)\right)$ has negative value, corresponding to the total (proportionate) guideline costs. Consequently, for low values of $\lambda$, standard care is preferred to 'guided' care. The valuations for $\operatorname{TNB}_{\mathrm{cg}}$ and $\operatorname{TNB}_{\mathrm{cg}}(0.6)$ increase linearly with $\lambda$, and intersect the $\mathrm{x}$-axis at the value of $\lambda$ that corresponds to the incremental cost-effectiveness ratio $\left(\mathrm{ICER}_{\mathrm{cg}} \approx € 21,000\right.$ per QALY) for which the guideline without implementation efforts is deemed beneficial. In effect, the more monetary value is associated with health gain, the more net benefit (with health care provision costs being equal) is gained from clinical use of guideline recommendations.

Although the guideline is deemed non-beneficial for values of $\lambda$ less than ICERcg, $60 \%$ of patients currently receive care following guideline recommendations. Hence, there is a potential to invest in strategies to promote non-adherence to the guideline. This maximum total investment potential for guideline de-implementation (max$\left.\operatorname{TIP}_{\mathrm{gi}}(0.6)\right)$ falls as $\lambda$ increases, and turns zero for the $\mathrm{ICER}_{\mathrm{cg}}$. At this value for $\lambda$, decision makers ought to be indifferent about whether the guideline is implemented. For values of $\lambda$ larger than the $\operatorname{ICER}_{\mathrm{cg}}$, the investment potential rises as a result of the total net benefit to be gained from enhancing adherence to the cost-effective guideline (with $\left.\mathrm{TNB}_{\mathrm{cg}}>\mathrm{TNB}_{\mathrm{cg}}(0.6)\right)$. 
In common with the 'V-shaped' $\operatorname{maxTIP} \mathrm{P}_{\mathrm{gi}}(0.6)$ curve, the total net benefit of implementation strategy $\mathrm{A}\left(\mathrm{TNB}_{\mathrm{isA}}(0.68)\right)$ and implementation strategy $\mathrm{B}\left(\mathrm{TNB}_{\text {isB }}(0.72)\right)$ also vary with $\lambda$. To ensure the most efficient use of investment potential, decision makers should adopt, for a given $\lambda$, the most beneficial option for guideline implementation. For example, if decision makers are willing to pay a maximum of $€ 50,000$ per gained QALY, they should opt for strategy B. The choice for the implementation strategy alters where the curves for $\mathrm{TNB}_{\mathrm{isA}}(0.68)$ and $\mathrm{TNB}_{\mathrm{isB}}(0.72)$ intersect. Whilst implementation strategies cost money to enact, total net benefit of implementation (for both $\operatorname{TNB}_{\text {isA }}(0.68)$ and $\left.\mathrm{TNB}_{\mathrm{isB}}(0.72)\right)$ turns negative for values of $\lambda$ near the $\mathrm{ICER}_{\mathrm{cg}}$. In that case, it is more beneficial not to change current practice at all.

Varying baseline guideline adherence (adr) and size of patient population (spp). Given guideline evidence and a $\lambda$ of $€ 25,000$ per QALY, Figure 4.4 shows three isoquant lines for the maximum total investment potential in guideline implementation (with maxTIP $_{\text {gi }}$ estimated to be $€ 2,100,000, € 1,050,000$ and $€ 525,000$, respectively) over a range of values for baseline guideline adherence (adr) and the size of the total target patient population $\left(\mathrm{s}_{\mathrm{pp}}\right)$. All points on these isoquant lines, which form combinations of adr and $s_{p p}$, have the same value for maxTIP gi. The three isoquant lines show that implementation decisions should not only be based on the rate of non-adherence to a guideline but also on the size of the patient population targeted. Indeed, this figure indicates that it might be more beneficial to invest in guideline implementation for large populations with high baseline adherence than to invest in case of small populations with low baseline guideline adherence.

Figure 4.4 Three isoquant lines of the maximum total investment potential for guideline implementation ( $m a x T I P_{g i}=€ 2,100,000, € I, 050,000$ and $€ 525,000$ ) for a range of combinations of baseline guideline adherence $(\mathrm{adr})$ and size of patient population $\left(\mathrm{s}_{\mathrm{pP}}\right)$, given a cost-effectiveness threshold $\lambda$ of $€ 25,000$ per QALY (i.e. results from a two-way sensitivity analysis; QALY: quality-adjusted life-year)

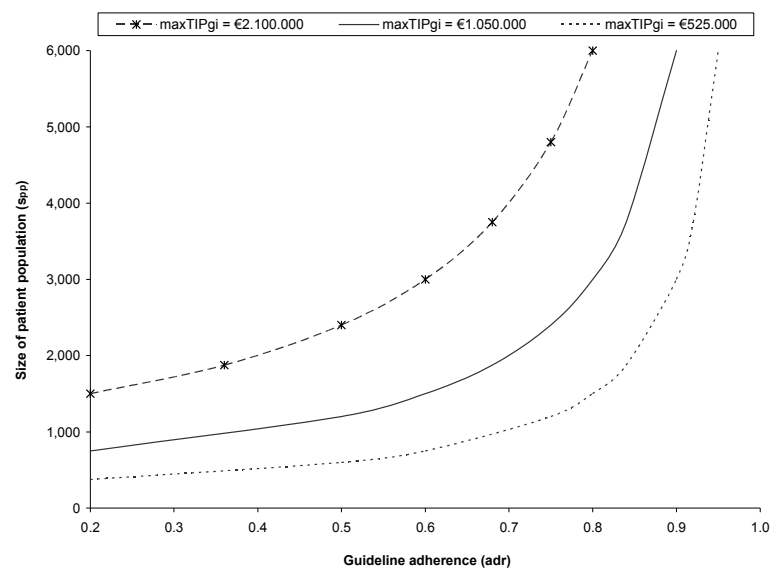




\subsection{Discussion}

In a budget constrained health care system, it becomes increasingly important to determine whether implementing guidelines into clinical practice is worthwhile. We presented a model (1) to assess the economic impact of non-adherence to guideline recommendations, and to determine the total investment potential to implement clinical guidelines. In addition, the model allows (2) to examine the value for money of implementation strategies to change guideline adherence as well as to mutually compare the investments in guideline implementation with alternative uses of health care resources. The core value of our model lies in the explicit monetary valuation of health outcomes $[19,24]$ and the combining of evidence on guidelines and implementation strategies with information on clinical practice. We illustrated the use of our model with a hypothetical example, and demonstrated the influence of the cost-effectiveness threshold $\lambda$, the baseline guideline adherence and the patient population size on the efficiency of resource allocation.

Several models for analysing the economics of implementing research findings into clinical practice were recently published $[12,16-18]$. Although these models provide a valuable framework for health economic evaluation, they concentrate on deriving costeffectiveness estimates of implementation strategies at patient level, and therefore are of limited use in informing resource allocation decisions. First, the interpretation of an overall cost-effectiveness ratio that combines guideline efficiency and implementation efficiency is ambiguous without information on all the costs and effects being considered [19]. Second, the priority setting process regarding multiple combinations of guidelines and implementation strategies across different settings requires sophisticated and complex decision analytic techniques and may easily result in erroneous decisions $[24,25]$. Third, it can be problematic to quantify and explore the uncertainty associated with decision making about adopting guidelines and implementation strategies to change clinical practice on the basis of (combined) cost-effectiveness ratios [19,25,26]. Finally, patient-level cost-effectiveness ratios give no idea of the size or scale of changes being considered nor inform questions of allocative efficiency [20,27].

By adopting a total net benefit approach, our model overcomes the restrictions with the use of implementation cost-effectiveness ratios at patient level. The model provides a simple and useful tool for decision makers to explore the size or scale of suboptimal practice, the implementation investment potential, and the economics of changing clinical practice. In principle, any viewpoint of analysis (e.g. society, third-party payer or health care provider) can be adopted, and the model is easily applicable to different localities, e.g. by adjusting evidence on guidelines, implementation strategies and clinical settings. The process of analysing the value for money of combinations of clinical guidelines and strategies to implement them is also far more straightforward. In effect, the determination of the guideline implementation investment potential $\left(\operatorname{maxTIP}_{\mathrm{gi}}(\mathrm{adr})\right)$ and the expected total net benefit of implementing guidelines $\left(\mathrm{TNB}_{g_{i}}\left(\operatorname{adr} \mathbf{r}^{\prime}\right)\right)$ allows deci- 
sion makers to set priorities when confronted with multiple instances of suboptimal practice. Considering the decision uncertainty regarding clinical practice change, the use of net benefit statistic finally avoids problems associated with (combined) ratio statistics $[19,25,26,28]$.

As with any model, decision makers need to be aware of the modelling assumptions necessary. First, the costs associated with guideline development are assumed to be sunk and therefore considered irrelevant for informing decisions about guideline implementation. When a priori considering the 'true' value for money of guideline implementation, however, several authors advocate the importance of incorporating estimates of the costs of actually developing the guideline as well $[9,11,13]$. Second, the total incremental monetary guideline benefit $\left(\mathrm{TMB}_{\mathrm{cg}}(\mathrm{adr})\right)$ and total incremental health care provision costs $\left(\mathrm{TC}_{\mathrm{cg}}(\mathrm{adr})\right)$ are assumed to be linearly proportionate to the adherence to the clinical guideline. Resource utilisation and costs are usually considered to be non-linear $[27,28]$. Third, the total costs of executing an implementation strategy are extrapolated linearly with the change in guideline adherence $\left(\mathrm{TC}_{\mathrm{ise}}(\Delta \mathrm{adr})\right)$. In reality, it is assumed that as guideline adherence nears $0 \%$ or $100 \%$, it will bring increasing incremental costs to change adherence. Finally, it is assumed to be possible to reach perfect $100 \%$ adherence to guidelines in clinical practice. As there will always be a proportion of non-adherence by healthcare professionals and patients, it would be more realistic to incorporate a maximum guideline adherence rate (e.g. $95 \%$ ) into our model. Non-adherence to guideline may thereby be caused by multiple factors such as knowledge, attitude or even chance $[2,3,21,22]$.

Some other comments have to be made when using the model and interpreting its results. First, the use of cost-effectiveness thresholds in health care resource allocation decision making is criticised [29-31]. In effect, it is not without debate to assume that the maximum decision makers are willing to pay for health gain comprises resources that need to be committed for ensuring the implementation of 'worthwhile' health care technologies. Second, the use of evidence on guidelines and implementation strategies from other settings in model calculations for local decision making should be done with caution $[12,16]$. Relevant evidence may have to be assumed transferable not just to different localities but also to different treatments and diseases [17]; it has been suggested adjusting for differences between study and target populations [12]. Third, in our model, no considerations are made for the rigour of evidence or uncertainty surrounding the costs and effects of guidelines, and that of implementation strategies. As it is beyond the scope of this chapter to discuss the stochastic approach to modelling the economics of changing clinical practice, we restricted ourselves to making deterministic model calculations and using sensitivity analysis as a tool for exploring the robustness of the model. Fourth, there are several suggestions to be made to extend our model. These include: the incorporation of guideline development costs, and the explicit distinction between guideline adherence and change therein by patients and that by health care professionals. Additionally, if the duration of guideline use and/or implementation 
efforts are more than one year, it is important to model the net present values of relevant costs and effects of guideline implementation $[12,20]$. Such extensions could be incorporated into our model rather easily, but would overcomplicate model explanation. Finally, we did not formally verify and validate our model nor demonstrate the practical significance and merits of our model for decision makers.

Clinical guidelines and strategies to implement them are more and more tailored to local situations. Partly due to this, there is growing prominence in the use of economic decision models to support local decision making about investing in guideline implementation. Notwithstanding the potential advantages of such modelling exercises, however, it remains important to collect useful and reliable evidence on clinical practice change. We therefore underline the approach advocated by others $[7,10,13,14]$ that trial-based studies should concentrate on evaluating change in adherence to guideline recommendations and costs of developing and implementing of a guideline, while in modelling studies evidence from a wide range of sources (e.g. guideline trials and implementation trials) are synthesised using decision models. Even so, for decision modelling and evidence synthesis for guideline implementation evaluation to be more informative, several important methodological challenges need to be tackled. These include: how to model the costs and effects of combinations of multiple guideline recommendations and multiple strategies aimed at changing health care professional as well as patient behaviour? How to appropriately synthesise and extrapolate relevant evidence in this respect? How to appropriately make allowance for differences in the rigour of evidence and uncertainty of data? Our model, based on net benefit calculated across the population of patients, seems to offer the appropriate tool to tackle these challenges. 


\section{References}

1. Institute of Medicine Committee on Clinical Practice Guidelines. Guidelines for clinical practice: from development to use. National Academy Press 1992.

2. Cabana MD, Rand CS, et al. Why don't physicians follow clinical practice guidelines? A framework for improvement. JAMA 1999;282(15):1458-65.

3. Foy R, MacLennan G, et al. Attributes of clinical recommendations that influence change in practice following audit and feedback. J Clin Epidemiol 2002;55(7):717-22.

4. Grol R, Grimshaw J. From best evidence to best practice: effective implementation of change inpatients' care. Lancet 2003;362(9391):1225-30.

5. Grol R, Buchan H. Clinical guidelines: what can we do to increase their use? Med J Aust 2006;185(6):301-2.

6. Freemantle N. Implementation strategies. Fam Pract 2000;17 Suppl 1:S7-10.

7. Mason J, Wood J, Freemantle N. Designing evaluations of interventions to change professional practice. J Health Serv Res Policy 1999;4(2):106-11.

8. Grol R, Wensing M, Eccles M. Improving patient care: the implementation of change in clinical practice. London: Elsevier Limited; 2005.

9. McIntosh E. Economic evaluations of guideline implementation strategies. In: Thorsen T, Makela M, editors. Changing professional practice: Theory and practice of clinical guidelines implementation. Copenhagen: Danish Institute for Health Services Research and Development; 1999.

10. Sculpher M. Evaluating the cost-effectiveness of interventions designed to increase the utilization of evidence-based guidelines. Fam Pract 2000;17 Suppl 1:S26-31.

11. Severens JL. Value for money of changing healthcare services? Economic evaluation of quality improvement. Qual Saf Health Care 2003;12(5):366-71.

12. Gandjour A, Lauterbach KW. When is it worth introducing a quality improvement program? A mathematical model. Med Decis Making 2003;23(6):518-25.

13. Grimshaw JM, Thomas RE, et al. Effectiveness and efficiency of guideline dissemination and implementation strategies. Health Technol Assess 2004;8(6):iii-iv, 1-72.

14. Hoomans T, Evers SMAA, et al. The methodological quality of economic evaluations of guideline implementation into clinical practice: a systematic review of empiric studies. Value Health $2007 ; 10$ (4):305-16.

15. Thorsen T, Makela M, editors. Changing professional practice: Theory and practice of clinical guidelines implementation. Copenhagen: Danish Institute for Health Services Research and Development; 1999.

16. Mason J, Freemantle N, et al. When is it cost-effective to change the behavior of health professionals? JAMA 2001;286(23):2988-92.

17. Mason JM, Freemantle N, et al. Specialist nurse-led clinics to improve control of hypertension and hyperlipidemia in diabetes: economic analysis of the SPLINT trial. Diabetes Care 2005;28(1):40-6.

18. Gandjour A, Lauterbach KW. How much does it cost to change the behavior of health professionals? A mathematical model and an application to academic detailing. Med Decis Making 2005; 25(3):341-7.

19. Stinnett AA, Mullahy J. Net health benefits: a new framework for the analysis of uncertainty in cost-effectiveness analysis. Med Decis Making 1998;18(2 Suppl):S68-80.

20. Drummond MF, Sculpher MJ, et al. Methods for the economic evaluation of health care programmes. 3rd edition ed. Oxford: Oxford University Press; 2005.

21. Shekelle P, Eccles MP, et al. When should clinical guidelines be updated? BMJ 2001;323(7305): 155-7.

22. Eccles M, Grimshaw J, et al. Changing the behavior of healthcare professionals: the use of theory in promoting the uptake of research findings. J Clin Epidemiol 2005;58(2):107-12. 
23. Fenwick E, Claxton K, Sculpher M. The value of implementation and the value of information: combined and uneven development. Med Decis Making 2008;28(1):21-32.

24. Ament A, Baltussen R. The interpretation of results of economic evaluation: explicating the value of health. Health Econ 1997;6(6):625-35.

25. Willan AR. Analysis, sample size, and power for estimating incremental net health benefit from clinical trial data. Control Clin Trials 2001;22(3):228-37.

26. Briggs A, Fenn P. Confidence intervals or surfaces? Uncertainty on the cost-effectiveness plane. Health Econ 1998;7(8):723-40.

27. Drummond M, McGuire A. Economic evaluation in health care: merging theory with practice. Oxford: Oxford University Press; 2001.

28. Willan A, Briggs A. Statistical analysis of cost-effectiveness data. West Sussex, England: John Wiley \& Sons Ltd; 2006.

29. Sendi PP, Briggs AH. Affordability and cost-effectiveness: decision-making on the cost-effectiveness plane. Health Econ 2001;10:675-80.

30. O'Brien BJ, Gertsen K, et al. Is there a kink in consumers' threshold value for cost-effectiveness in health statistic by varying the value of the ceiling ratio and care? Health Econ 2002; 11: 175-80.

31. Eichler HG, Kong SX, et al. Use of cost-effectiveness analysis in health-care resource allocation decision-making: how are cost-effectiveness thresholds expected to emerge? Value Health 2004; 7(5):518-28. 



\section{Modelling the Value for Money of Changing Clinical Practice: A Stochastic Application in Diabetes Care}

Ties Hoomans ${ }^{1}$, Keith R. Abrams ${ }^{2}$, Andre J.H.A. Ament ${ }^{1}$, Silvia M.A.A. Evers ${ }^{1}$, Johan L. Severens ${ }^{1,3}$

${ }^{1}$ Department of Health Organisation, Policy and Economics, Maastricht University, the Netherlands;

${ }^{2}$ Division of Health Sciences, University of Leicester, United Kingdom; ${ }^{3}$ Department of Clinical Epidemiology and MTA, University Hospital Maastricht, the Netherlands

Submitted for publication 


\section{Abstract}

Decision making about resource allocation for guideline implementation to change clinical practice is inevitably undertaken in a context of uncertainty surrounding the cost-effectiveness of both clinical guidelines and implementation strategies. Adopting a total net benefit approach, a model has recently been developed to overcome problems with the use of combined ratio statistics when analysing decision uncertainty. We demonstrate the stochastic application of the model for informing decision making about the adoption of an audit and feedback strategy for implementing a guideline recommending intensive blood glucose control in type 2 diabetes in primary care in the Netherlands.

An integrated Bayesian approach to decision modelling and evidence synthesis is adopted using MCMC simulation in WinBUGs. Data on model parameters is gathered from various sources, with effectiveness of implementation being estimated using pooled, random-effects meta-analysis. Decision uncertainty is illustrated using costeffectiveness acceptability curves (CEACs) and frontier (CEAF). Decisions about whether to adopt intensified glycemic control and whether to adopt audit and feedback alter for the maximum values that decision makers are willing to pay for health gain. Through simultaneously incorporating uncertain economic evidence on both guidance and implementation strategy, the CEACs and CEAF show an increase in decision uncertainty concerning guideline implementation.

The stochastic application in diabetes care demonstrates that the model provides a simple and useful tool for quantifying and exploring the (combined) uncertainty associated with decision making about adopting guidelines and implementation strategies and, therefore, for informing decisions about efficient resource allocation to change clinical practice. 


\section{I Introduction}

Diabetes is a common chronic condition that accounts for a huge burden of morbidity and mortality through micro and macro vascular complications [1,2]. Evidence suggests that patients with diabetes benefit from strict control of blood glucose, blood pressure and cholesterol [3-6]. Although several guidelines and diabetes management programmes have been established to achieve better metabolic control, clinical use of guidance on diabetic care does not necessarily follow $[7,8]$. Non-adherence to guideline recommendations reduces the efficiency of health care delivery in terms of health and resources forgone. Implementation strategies, such as education, outreach visits and reminders, attempt to change guidance adherence $[9,10]$. Nonetheless, no single strategy or combination of strategies has been found to be consistently cost-effective [1113]. Since implementation efforts compete with other health care programmes for limited resources, decision makers should carefully consider the likely value for money of guideline implementation in diabetes care [14-17].

Economic evaluation based on decision analytic modelling can generate valuable information to aid decision makers to allocate resources efficiently [18]. Recently, a model for analysing the scope of cost-effective guideline implementation was developed [19]. By combining evidence from different sources, the model allows exploring the investment potential for guideline implementation and the value for money of implementation strategies. Adopting a total net benefit approach, the model overcomes problems with using combined implementation cost-effectiveness ratios at patient level $[15,20]$, e.g. when comparing multiple guidelines and multiple strategies across different clinical settings or when analysing uncertainty associated with decision making about clinical practice change.

In this chapter, we demonstrate the stochastic application of the model to inform resource allocation decision making in type 2 diabetes (non-insulin-dependent) in primary care in the Netherlands for exploring the economics of implementing a guideline for intensified blood glucose control by means of audit and feedback.

\subsection{Methods}

\subsection{Clinical setting, diabetes guidance and implementation strategy}

In the Netherlands, the prevalence of diabetes is about $2.5 \%$, and about $85 \%$ are estimated to be type 2 diabetes patients [21]. The majority of these patients are being treated in primary care [22]. To reduce the risk of diabetes-related complications, the Dutch College of General Practitioners (NHG) revised their guidance on glycemic control, formulating recommendations for diagnosis and medication of diabetes mellitus type $2[23,24]$. In short, the revised guidance on intensified glycemic control recom- 
mends to test blood glucose concentrations on a regular basis (i.e. every 3, 6 or 12 months), and the prescribing of, depending on glucose concentrations, metformin, sulphonylureas or thiazolidine and insulin alongside ( $>3$ months) patient education and advice, diet and physical activities (i.e. conventional therapy). The intensive policy aimed for glycated haemoglobin $\left(\mathrm{HbA}_{1 \mathrm{c}}\right)<7 \%$, and, in insulin-treated patients, premeal glucose concentrations of 4-7 mmol/l. Based on empiric data from a Dutch study in hospital outpatient clinics [25], current adherence to guideline recommendations on diabetic care is estimated to be $64.1 \%$ (with $6.4 \%$ standard deviation (SD)).

According to the Cochrane Effective Professional and Organisational Change (EPOC) taxonomy, audit and feedback is 'any summary of clinical performance of health care over a specified period of time. The summary may also have included recommendations for clinical action. Information may have been obtained from medical records, computerised databases, or observations from patients' [12].

\subsubsection{Comprehensive decision model}

For quantifying and exploring the uncertainty associated with decision making about changing diabetes practice in Dutch primary care, we adopted an integrated Bayesian approach to decision modelling and evidence synthesis $[18,26]$.

\section{Model structure}

The structure of the model is derived from the model developed by Hoomans et al. [19]. By assigning monetary values to health outcomes $(\lambda)$, and combining economic evidence on guidelines and implementation strategies with information on the clinical setting (including duration of guideline use $\left(\mathrm{d}_{\mathrm{cg}}\right)$, prevalence of disease $\left(\mathrm{p}_{\mathrm{d}}\right)$, and number of professionals $\left(n_{\mathrm{hp}}\right)$ and patients $\left(\mathrm{n}_{\mathrm{pt}}\right)$ targeted), the model establishes the investment potential for implementing guidance on blood glucose control and the value for money of audit and feedback (see Box 5.1).

The maximum total investment potential for guidance implementation $\left(\operatorname{maxTIP}_{\mathrm{gi}}\right)$ is simply the difference between the total net benefit of guideline use in perfect practice (i.e. assuming $100 \%$ adherence to guidance $[\mathrm{adr}]$ ) and that in current practice, where guideline adherence is less than perfect $(\mathrm{adr}<1)$ (see Equation 5.1a). The investment potential provides a maximum upper bound on resources to be committed to achieve $100 \%$ adherence to cost-effective guidance. Essentially, if a clinical guideline is not deemed cost-effective (with $\mathrm{TNB}_{\mathrm{cg}}<0$ ) but currently implemented into clinical practice $(\mathrm{adr}>0)$, there is a potential to invest in strategies to promote non-adherence to guidance (see Equation 5.1b). 
Box 5.I Decision making about resource allocation for guideline implementation

\begin{tabular}{|c|c|c|}
\hline Investment potential & $\begin{array}{l}(5.1 a) \\
(5.1 b)\end{array}$ & $\begin{array}{l}\text { If } \mathrm{TNB}_{\mathrm{cg}} \geq 0, \text { then } \operatorname{maxTIP} \\
\text { If } \mathrm{TNB}_{\mathrm{cg}}<0 \text {, then } \max \mathrm{TIP}_{\mathrm{gi}}=-\mathrm{adr} \times \mathrm{TNB}_{\mathrm{cg}} \\
\text { where } \\
\mathrm{TNB}_{\mathrm{cg}}=\left(\Delta \overline{\mathrm{E}}_{\mathrm{cg}} \times \lambda-\Delta \overline{\mathrm{C}}_{\mathrm{cg}}\right) \times \mathrm{s}_{\mathrm{pp}} \\
\mathrm{adr}=\operatorname{adr}_{\mathrm{pt}} \times \mathrm{adr}_{\mathrm{hp}} \\
\mathrm{s}_{\mathrm{pp}}=\mathrm{d}_{\mathrm{cg}} \times \mathrm{p}_{\mathrm{d}} \times \mathrm{n}_{\mathrm{pt}} \times \mathrm{n}_{\mathrm{hp}}\end{array}$ \\
\hline Value of implementation & $\begin{array}{l}(5.2) \\
(5.3)\end{array}$ & $\begin{array}{l}\mathrm{TNB}_{\text {is }}=\frac{\mathrm{d}_{\text {is }}}{\mathrm{d}_{\mathrm{cg}}} \times \mathrm{TNB}_{\mathrm{cg}} \times \Delta \mathrm{adr}-\Delta \mathrm{C}_{\text {is }} \times \mathrm{n}_{\mathrm{hp}} \\
\mathrm{TNB}_{\mathrm{gi}}=\mathrm{adr} \times \mathrm{TNB}_{\mathrm{cg}}+\mathrm{TNB}_{\text {is }}\end{array}$ \\
\hline
\end{tabular}

Legend (in order of appearance)

$\mathrm{TNB}_{\mathrm{cg}} \quad$ Total net benefit of a clinical guideline

$\operatorname{maxTIP}_{\mathrm{gi}} \quad$ Maximum total investment potential for guideline implementation

adr Baseline guideline adherence by patients $\left(\operatorname{adr}_{\mathrm{pt}} \in[0, \mathrm{I}]\right)$ and professionals (adr $\left.\mathrm{hp}_{\mathrm{hp}} \in[0, \mathrm{I}]\right)$

$\Delta \mathrm{E}_{\mathrm{cg}} \quad$ Mean incremental effectiveness of a clinical guideline per patient

$\lambda \quad$ Cost-effectiveness threshold ratio

$\Delta \mathrm{C}_{\mathrm{cg}} \quad$ Mean incremental cost of health care provision following guideline recommendations per patient

$\mathrm{s}_{\mathrm{pp}} \quad$ Size of total eligible patient population

$\mathrm{d}_{\mathrm{cg}} \quad$ Duration of guideline use

Pd Population prevalence of condition or disease targeted

$\mathrm{n}_{\mathrm{pt}} \quad$ Mean number of patients per health care professional

$\mathrm{n}_{\mathrm{hp}} \quad$ Mean number of health care professionals targeted

$\mathrm{TNB}_{\text {is }} \quad$ Total net benefit of an implementation strategy

$d_{\text {is }} \quad$ Duration of implementation efforts

$\Delta \mathrm{adr} \quad$ Effected change in guideline adherence

$\Delta \mathrm{C}_{\text {is }} \quad$ Mean incremental cost of implementation strategy per health care professional

$\mathrm{TNB}_{\mathrm{gi}} \quad$ Total net benefit of guideline implementation

The total net benefit of adopting an implementation strategy ( $\mathrm{TNB}_{\mathrm{is}}$ ) (e.g. audit and feedback) is derived by subtracting the cost of implementation $\left(\mathrm{C}_{\mathrm{is}}\right)$ from the total net benefit of expected change in guidance adherence ( $\Delta \mathrm{adr}$ ) (see Equation 5.2). As derived in Equation 5.3, the sum of the total net benefit of current clinical use of guidance and that of changed guideline use due to implementation efforts yields the expected total net benefit of guideline implementation into clinical practice $\left(\mathrm{TNB}_{\mathrm{gi}}\right)$.

The outline of the model has been described in more detail elsewhere [19].

\section{Data sources and evidence synthesis}

For the economic evidence on the policy for more intensive blood glucose control, we made use of the United Kingdom Prospective Diabetes Study Outcomes Model (UKPDS OM) [27] and the model developed by the CDC group [28]. Based on patient-level data from a large-scale randomised clinical controlled trial (UKPDS), both models com- 
pared, with model-derived data extrapolation over lifetime of newly diagnosed patient cohorts, intensified glycemic control with conventional therapy in terms of cost per quality-adjusted life-year (QALY). The perspective of analysis was that of a health care purchaser (considering only direct health service costs) in the UKPDS OM, and that of the health care system in the CDC model. The estimated value for money of the clinical guidance were, respectively, €1274 (€3939 SD) for 0.15 QALYs (0.69 SD) per patient [27] and €7045 (€3939 SD) for 0.1915 QALYs (0.692 SD) per patient [28].

We conducted a meta-analysis for estimating the effectiveness of audit and feedback, searching the reference lists of relevant systematic reviews plus key articles on implementation research in diabetes care [11-13,29,30] for relevant studies. Studies were selected for inclusion whether the strategy was single faceted or accompanied by educational activities or (computerised) reminders. We included studies only if audit and feedback was evaluated in a primary care setting and was targeted at changing professional behaviour related to diabetic care. Our search yielded only two relevant studies evaluating change in adherence to diabetes guidance [31,32], of which we extracted data on study details and outcomes (see Appendix 5.1). The derived estimates of the effected change in adherence by health care professionals after 6 months were, respectively, 34.25\% (13.06 SD) [31] and 5.2\% (2.94 SD) [32].

Based on information from the literature [11-13,29,30], we initially assumed the cost of audit and feedback to be $€ 100$ (€25 SD) per health care professional.

\subsubsection{Model analysis and implementation}

\section{Stochastic analysis}

To inform decision making about the adoption of intensified blood glucose control and/or audit and feedback to change diabetes practice in the Netherlands, we first established the posterior distributions (i.e. means, standard deviations and $95 \%$ confidence intervals) for the relevant model parameters $\left(\Delta \mathrm{E}_{\mathrm{cg}}, \Delta \mathrm{C}_{\mathrm{cg}}, \operatorname{adr}, \Delta \mathrm{adr}\right.$ and $\left.\Delta \mathrm{C}_{\mathrm{is}}\right)$ and the expected values for the total net benefit of the guidance $\left(\mathrm{TNB}_{\mathrm{cg}}\right)$, the investment potential for its implementation $\left(\operatorname{maxTIP}_{\mathrm{gi}}\right)$ and the total net benefit of implementation $\left(\mathrm{TNB}_{\mathrm{is}}\right.$ and $\mathrm{TNB}_{\mathrm{gi}}$ ), given a cost-effectiveness threshold $\lambda$ of $€ 30,000$ per QALY. In addition, we examined these model-derived values over a range of $\lambda$ s (€0-€40,000 per QALY).

To explore the influence of uncertainty surrounding the different costs and effects relevant for decision making about practice change, we plotted cost-effectiveness acceptability curves (CEACs) and frontiers (CEAFs), generated from model simulation. The CEAC is a plot of the probability that an option to change practice (i.e. guidance and/or its implementation) is cost-effective as a function of $\lambda$ [33]. The CEAF is constructed from the individual CEACs, depicting the uncertainty associated with the costeffective options over all values of $\lambda[33]$. 
For simplicity, the model calculations were done under the assumption that the duration of the implementation efforts $\left(\mathrm{d}_{\mathrm{is}}\right)$ was only 6 months.

\section{Sensitivity analysis}

Finally, we performed sensitivity analyses to examine whether the cost of implementation influenced valuations for the total net benefit of implementing guidance on diabetic care, and probabilities that audit and feedback and guidance implementation are cost-effective. To weaken our assumption that mean cost of audit and feedback are only $€ 100$, we set this, subsequently, at $€ 1,000$ and $€ 2,500$ per health care professional.

\section{Model implementation}

To evaluate the comprehensive decision model, we performed Markov Chain Monte Carlo (MCMC) simulation using WinBUGs. We applied multi-parameter evidence synthesis using all relevant data inputs that informed incremental costs and effects of blood glucose control guidance and its implementation. The effectiveness of audit and feedback $\left(\Delta \mathrm{E}_{\mathrm{is}}\right)$, in terms of change in guidance adherence $(\Delta \mathrm{adr})$, was estimated using pooled, random-effects meta-analysis performed on normal scale. We used noninformative priors for all model parameters. Table 5.1 summarises the parameter values, distributions, data sources and priors for all model inputs. All costs are expressed in $2007 €$ (discounted at $3.5 \%$ ). The implementation of the comprehensive decision model in WinBUGs is outlined in Appendix 5.2.

Table 5.I Details of model parameters

\begin{tabular}{|c|c|c|c|c|}
\hline Parameter & Mean (SD) & Distribution & Source & Prior \\
\hline Incremental effectiveness of blood glucose & 0.15 QALYs $(0.69)^{*}$ & Normal & [27] & dl $\sim$ dunif(-I, I) \\
\hline guidance $\left(\Delta \mathrm{E}_{\mathrm{cg}}\right)$ & 0.1915 QALYs $\left(0.69^{\dagger}\right)^{*}$ & Normal & [28] & taul $\sim \operatorname{dunif}(0, \mathrm{I})$ \\
\hline Incremental cost of blood glucose guidance & $€ I, 274(3,939)^{*}$ & Normal & [27] & $\mathrm{d} 2 \sim \operatorname{dnorm}(0.0$, I.0E-9); \\
\hline$\left(\Delta \mathrm{C}_{\mathrm{cg}}\right)$ & $€ 7,045\left(3,939^{\dagger}\right)^{*}$ & Normal & [28] & tau2 dunif $(0,100)$ \\
\hline $\begin{array}{l}\text { Baseline adherence to blood glucose guid- } \\
\text { ance (adr) }\end{array}$ & $64.1 \%(6.4)$ & Lognormal & {$[30]$} & $\mathrm{d} 5 \sim \operatorname{dnorm}(0,1.0 \mathrm{E}-6)$ \\
\hline $\begin{array}{l}\text { Incremental effectiveness of audit and feed- } \\
\text { back }(\Delta \mathrm{adr})\end{array}$ & $34.25 \%(13.06)^{\ddagger \S}$ & Normal & {$[31]$} & $\begin{array}{l}\text { d3 dnorm }(0,1.0 \mathrm{E}-6) \\
\text { tau3 }\end{array}$ \\
\hline & $5.2 \%(2.94)^{\S}$ & Normal & [32] & - \\
\hline Cost of audit and feedback $\left(\Delta \mathrm{C}_{\text {is }}\right)$ & $€ 100(19.6)^{\S}$ & Normal & - & $\begin{array}{l}\text { d4 dnorm }(0.0,1.0 \mathrm{E}-9) \\
\text { tau4 dunif }(0,2000)\end{array}$ \\
\hline Duration of guideline use $\left(\mathrm{d}_{\mathrm{cg}}\right)$ & 1.0 years & - & - & - \\
\hline Prevalence of disease $\left(\mathrm{p}_{d}\right)$ & $2.125 \%$ & - & {$[21]$} & - \\
\hline Mean number of professionals targeted $\left(n_{\mathrm{ph}}\right)$ & 8,107 & - & [22] & - \\
\hline Mean number of patients targeted $\left(n_{p t}\right)$ & 2,356 & - & [22] & - \\
\hline Duration of implementation efforts $\left(d_{i s}\right)$ & 0.5 years & - & - & - \\
\hline
\end{tabular}

* Per patient; ${ }^{\dagger}$ Given that no information was reported, the data on the effectiveness was assumed to be normally distributed, with an SD similar to that of the UKPDS OM [27]; ${ }^{\ddagger}$ The mean and 95\% confidence interval was calculated under the assumption that this parameter was normally distributed for both group I and group 2; ${ }^{\S}$ Per professional; QALY: qualityadjusted life-year; SD: standard deviation 
For all model evaluations to achieve convergence, we used initial 50,000 'burn-in' sample iterations (these values were discarded), with inferences based on further runs of 50,000 iterations. Additionally, model convergence of MCMC samples was confirmed by performing multiple WinBUGs runs for different sets of initial parameter values, track tracing and checking for autocorrelation of relevant parameters.

\subsection{Results}

\subsection{Stochastic analysis}

Based on model simulation, posterior means and distributions for all of the model parameters and decision values were derived for base case.

The mean incremental effectiveness $\left(\Delta \mathrm{E}_{\mathrm{cg}}\right)$ and cost $\left(\Delta \mathrm{C}_{\mathrm{cg}}\right)$ of glycemic control are estimated to be 0.16 QALYs (95\% confidence interval -5.03 to 5.34) and $€ 4,132$ $(€ 1,439$ to $€ 6,812)$, respectively. Consequently, the incremental cost-effectiveness ratio of the clinical guideline $\left(\mathrm{ICER}_{\mathrm{cg}}\right)$ is estimated to be approximately $€ 25,000$ per QALY, with an expected baseline adherence to guidance (adr) of $62.55 \%(16.30 \% \mathrm{SD})$. The estimated change in guidance adherence due to audit and feedback ( $\Delta \mathrm{adr}$ ) is $17.75 \%$ $(31.59 \% \mathrm{SD})$ at an expected expense $\left(\Delta \mathrm{C}_{\mathrm{is}}\right)$ of $€ 99.50$ (€37.11 SD).

If decision makers are willing to pay $(\lambda) € 30,000$ per QALY, the guidance on intensified blood glucose control is deemed cost-effective (with a $\mathrm{TNB}_{\mathrm{cg}}$ of $€ 317.3$ million (95\% confidence interval $-€ 63,000 \mathrm{M}$ to $€ 63,310 \mathrm{M}$ ), and there is expected to be considerable potential to invest in its implementation $\left(\operatorname{maxTIP}_{\mathrm{gi}}\right)(€ 113.1$ million $(-€ 24,080 \mathrm{M}$ to $€ 24,190 \mathrm{M})$ ). The adoption of audit and feedback for implementation would yield an additional net benefit $\left(\mathrm{TNB}_{\mathrm{is}}\right)$ of $€ 20.1$ million (-€96.98M to $€ 121.400 \mathrm{M})$, and the total net benefit of adopting and implementing glycemic control in diabetes practice $\left(\mathrm{TNB}_{\mathrm{gi}}\right)$ in the Netherlands is estimated to be $€ 231.5$ million (-€39,160M to $€ 40,490 \mathrm{M})$.

Figure 5.1 shows that the decisions about whether to adopt intensified glycemic control and audit and feedback for its implementation alter over the range of $\lambda$ s (€0-€40,000 per QALY). Given that the guidance is expected to enact both additional QALYs and additional costs, standard care is preferred to 'guided' care for values of $\lambda$ less than the $\mathrm{ICER}_{\mathrm{cg}}$. As a consequence, there is value associated with promoting non-adherence to guidance $(64.1 \%$ currently) in diabetes practice, which is quantified in the positive values for maxTIP ${ }_{\text {gi }}, \mathrm{TNB}_{\text {is }}$ and $\mathrm{TNB}_{\mathrm{gi}}$ for $\lambda$ s less than approximately $€ 25,000$ per QALY. The investment potential for guideline de-implementation $\left(\operatorname{maxTIP}_{\mathrm{gi}}\right)$ falls as $\lambda$ increases, and turns zero for the $\mathrm{ICER}_{\mathrm{cg}}$. At this value for $\lambda$, decision makers ought to be indifferent about whether guidance is implemented. The total net benefit of audit and feedback $\left(\mathrm{TNB}_{\mathrm{is}}\right)$ and that of guideline de-implementation $\left(\mathrm{TNB}_{\mathrm{gi}}\right)$ also vary with $\lambda$. 
While implementation strategies cost money to enact, $\mathrm{TNB}_{\text {is }}$ turns negative for values of $\lambda$ around the ICER $_{\text {cg }}$. For $\lambda$ s larger than approximately $€ 25,000$ per QALY, the implementation investment potential $\left(\operatorname{maxTIP}_{\mathrm{gi}}\right)$ ), value of adopting audit and feedback $\left(\mathrm{TNB}_{\mathrm{is}}\right)$ and value of guideline implementation $\left(\mathrm{TNB}_{\mathrm{gi}}\right)$ rise as a result of the total net benefit to be gained from enhancing adherence to the cost-effective guidance on blood glucose control in Dutch diabetes practice (where $\left.\mathrm{TNB}_{\mathrm{cg}}>0\right)$ ).

Figure 5.I Total net benefit of guidance on intensified glycemic control $\left(\mathrm{TNB}_{\mathrm{cg}}\right)$, maximum total investment potential for guidance implementation $\left(\max T \mathrm{TP}_{\mathrm{gi}}\right)$, total net benefit of audit and feedback $\left(\mathrm{TNB}_{\mathrm{is}}\right)$ and total net benefit of guidance implementation $\left(\mathrm{TNB}_{\mathrm{g}}\right)$ for different values of cost-effectiveness threshold $\lambda$ (QALY: qualityadjusted life-year)

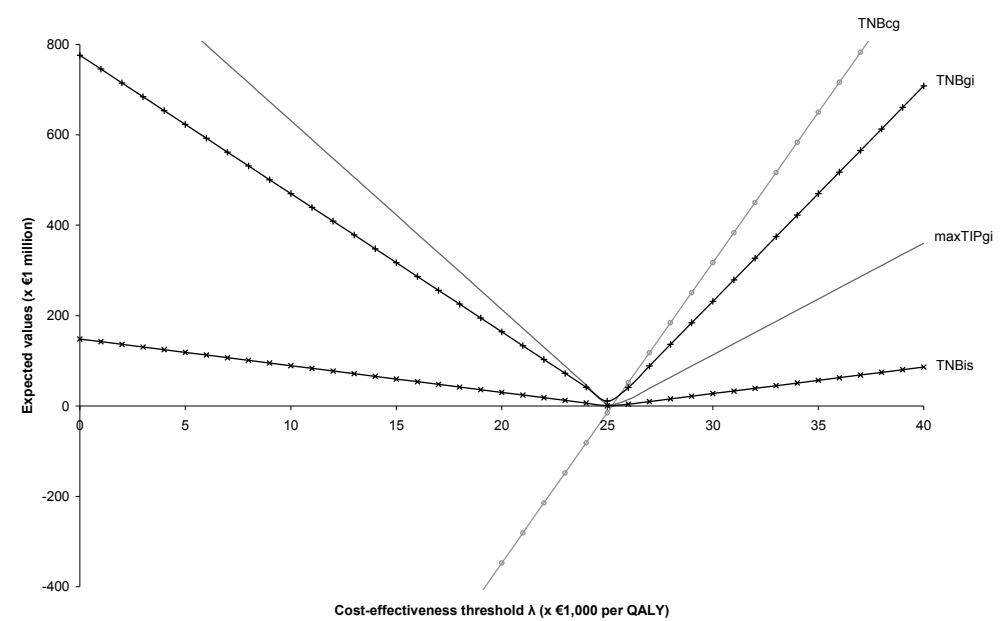

Figures 5.2a, 5.2b and 5.2c illustrate the uncertainty associated with decision making about changing diabetes practice.

In Figure 5.2a, we plotted the probability that blood glycemic control is costeffective $\left(\mathrm{PrCE}_{\mathrm{cg}}\right)$ as a function of $\lambda$. The figure shows that there is considerable uncertainty associated with deciding about whether to adopt the guidance, with the maximum probability that guidance adoption is the correct decision not exceeding $60 \%$.

Figure $5.2 \mathrm{~b}$ illustrates the decision uncertainty surrounding the adoption of audit and feedback to change adherence by health care professionals to diabetes guidance. The estimates for the probabilities that this implementation strategy is cost-effective $\left(\mathrm{PrCE}_{\mathrm{is}}\right)$ are derived by reading in data on rather than iteratively deriving estimates of the mean effectiveness $\left(\Delta \mathrm{E}_{\mathrm{cg}}\right)$ and cost $\left(\Delta \mathrm{C}_{\mathrm{cg}}\right)$ of glycemic control in model simulations. As a result, the ' $V$-shaped' curve solely reflects uncertainty surrounding the economic evidence on audit and feedback. Given the relatively low implementation cost, the 
probabilities that the strategy is cost-effective are fairly high for both low and high values for $\lambda$. As decision makers are more or less indifferent about clinical use of diabetic guidance for values of $\lambda$ around the ICER $\mathrm{C}_{\mathrm{cg}}$, any resources committed to implementation activities are expected to be not cost-effective and therefore the acceptability curve falls.

Figure 5.2a Cost-effectiveness acceptability curve (CEAC) for intensified blood glucose control $\left(\operatorname{PrCE} \mathrm{E}_{\mathrm{cg}}\right)$ in diabetes type 2 patients (QALY: quality-adjusted life-year)

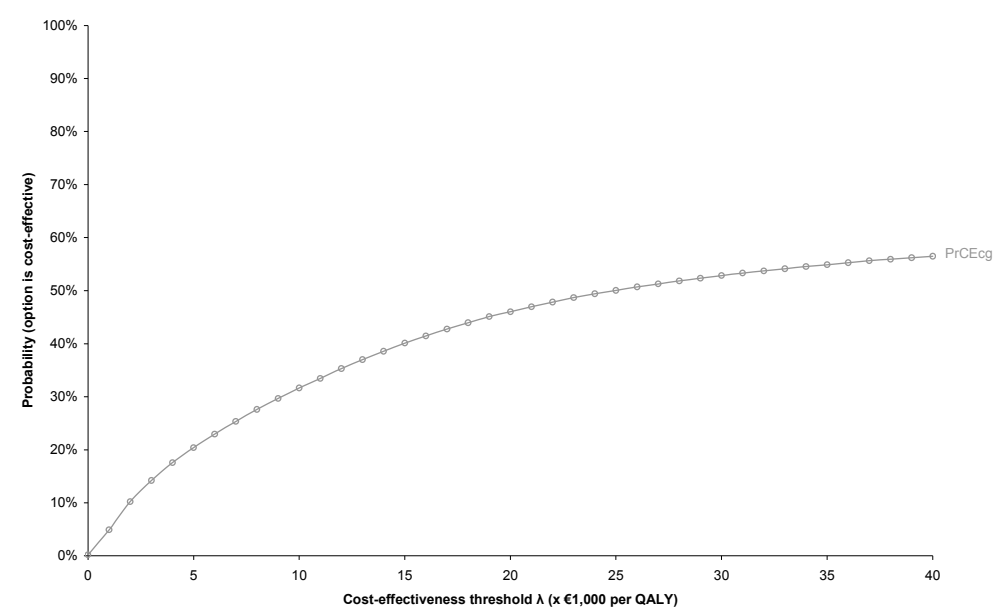

Figure 5.2b Cost-effectiveness acceptability curve (CEAC) for audit and feedback ( $\mathrm{PrCE}_{\mathrm{is}}$ ) for implementing guidance in diabetic care (QALY: quality-adjusted life-year)

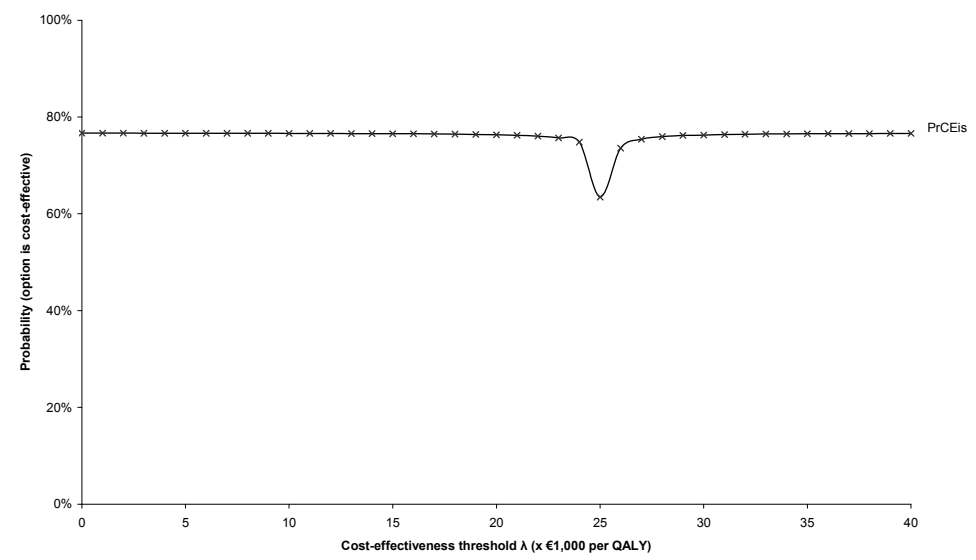


Figure 5.2c Cost-effectiveness acceptability curves (CEACs) and frontier (CEAF) for all options to change diabetes practice: to adopt guidance and implement it $\left(\operatorname{PrCE}_{\mathrm{g}}\right)$ to adopt the guidance without implementation $\left(P r C E_{c g}\right)$, to reject the guidance and promote non-adherence $\left(\operatorname{PrCE} E_{g d i}\right)$ and to reject the guidance and leave diabetes practice as it is ( $\mathrm{PrCE}_{\mathrm{cp}}$ ) (QALY: quality-adjusted life-year)

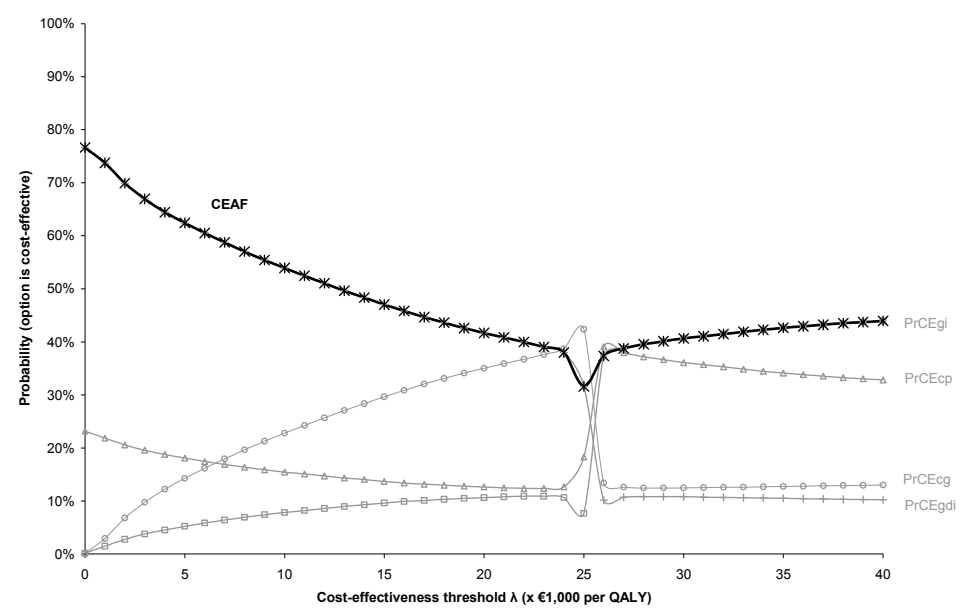

Figure 5.2c shows the CEACs for all relevant combined options to change diabetes practice, i.e. to adopt guidance and implement it $\left(\mathrm{PrCE}_{\mathrm{gi}}\right)$, to adopt guidance without implementation $\left(\mathrm{PrCE}_{\mathrm{cg}}\right)$, to reject guidance and promote non-adherence $\left(\mathrm{PrCE}_{\mathrm{gdi}}\right)$ and to reject guidance but leave practice as it is $\left(\operatorname{PrCE}_{\mathrm{cp}}\right)$, based on evidence on the guidance, adherence and audit and feedback. From the individual CEACs, the CEAF is constructed, depicting the probability that the combination deemed worthwhile on the basis of expected total net benefit (i.e. decision makers should opt to reject the guidance and promote non-adherence for $\lambda s<\mathrm{ICER}_{\mathrm{cg}}$ and to adopt the guidance and ensure its implementation otherwise) is in fact cost-effective.

Compared to the probability plot for the clinical guideline $\left(\mathrm{PrCE}_{\mathrm{cg}}\right)$ and that for the implementation strategy ( $\operatorname{PrCE}_{\text {is }}$ ) (see Figures 5.2a and 5.2b), the different CEACs and the CEAF for possible combinations in Figure 5.2c reflect an increase in decision uncertainty about the adoption and/or implementation of glycemic control. This is a result of simultaneously incorporating uncertainty surrounding the cost-effectiveness of both guidance (including information about baseline guideline adherence) and audit and feedback, and of comparing multiple options to change diabetes practice. The kink in the curves and frontier around the $\mathrm{ICER}_{\mathrm{cg}}$, and their interrupted continuation reflect the fact that different optional combinations (i.e. PrCE $\mathrm{Pi}_{\mathrm{i}}$ versus $\operatorname{PrCE}_{\mathrm{cg}}$ and $\mathrm{PrCE}_{\mathrm{gdi}}$ versus $\operatorname{PrCE}_{\mathrm{cp}}$ ) are complementary. That is, with an increasing maximum decision makers are willing to pay for improving patient care (for $\lambda s>I_{C E R}$ ) it becomes more likely that guideline adoption and its implementation $\left(\mathrm{PrCE}_{\mathrm{gi}}\right)$ is cost-effective, and, as a consequence, its complement (promoting non-adherence to cost-effective clinical guidance $\left.\left[\mathrm{PrCE}_{\mathrm{gdi}}\right]\right)$ realises a lower probability of being worthwhile. In fact, the latter even be- 
comes less likely to be cost-effective than both options rejecting diabetes guidance $\left(\operatorname{PrCE} E_{\mathrm{cg}}\right.$ and $\left.\operatorname{PrCE} E_{\mathrm{cp}}\right)$. An analogous explanation applies to the CEACs for the alternative options to change diabetes practice for $\lambda s$ less than the $\operatorname{ICER}_{\mathrm{cg}}$.

\subsubsection{Sensitivity analysis}

Figures $5.3 \mathrm{a}$ and $5.3 \mathrm{~b}$ illustrate the CEACs for the guidance on intensified glycemic control $\left(\mathrm{PrCE}_{\mathrm{cg}}\right)$ and audit and feedback ( $\left.\mathrm{PrCE}_{\mathrm{is}}\right)$, and the CEAF for guidance (de-)implementation simultaneously, under the assumption that mean implementation cost $\left(\Delta \mathrm{C}_{\mathrm{is}}\right)$ are, respectively, $€ 1000$ or $€ 2500$ per health care professional. These figures provide comprehensive overviews of the construct and extent of decision uncertainty about the (individual and combined) components (i.e. guideline and strategy) of practice change. By way of illustration, the individual CEACs for all relevant combined options to change diabetes practice (i.e. to adopt guidance and implement it $\left(\mathrm{PrCE}_{\mathrm{gi}}\right)$, to adopt guidance without implementation $\left(\mathrm{PrCE}_{\mathrm{cg}}\right)$, to reject guidance and promote nonadherence $\left(\mathrm{PrCE}_{\mathrm{gdi}}\right)$ and to reject guidance but leave practice as it is $\left.\left(\operatorname{PrCE} \mathrm{E}_{\mathrm{cp}}\right)\right)$ are presented in grey-scale.

Figure 5.3a Cost-effectiveness acceptability curves (CEACs) for the guidance on intensified glycemic control $\left(\mathrm{PrCE}_{\mathrm{cg}}\right)$ and audit and feedback ( $\mathrm{PrCE}_{\mathrm{is}}$ ) and cost-effectiveness acceptability frontier (CEAF) for guidance (de-)implementation, under the assumption that the mean implementation cost $\left(\Delta \mathbf{C}_{\text {is }}\right)$ is $€ l, 000$ per health care professional (QALY: quality-adjusted life-year)

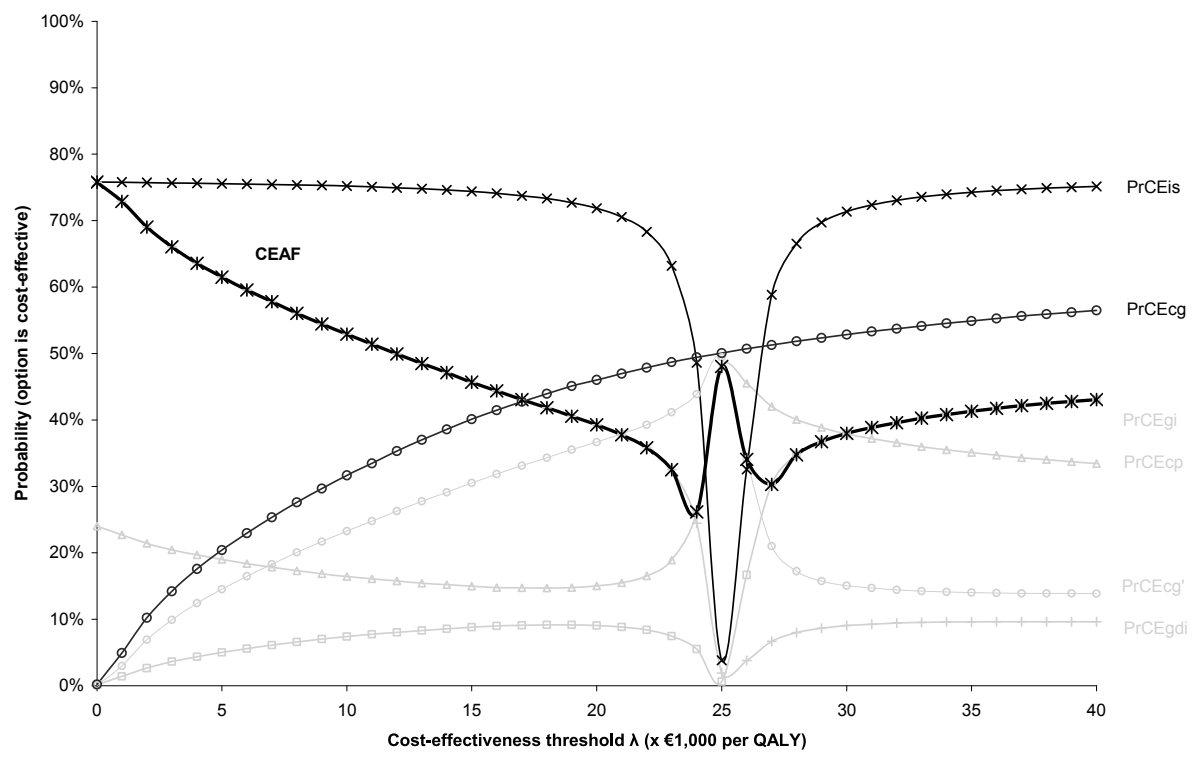


Figure 5.3b Cost-effectiveness acceptability curves (CEACs) for the guidance on intensified glycemic control $\left(\operatorname{PrCE}_{\mathrm{cg}}\right)$ and audit and feedback $\left(\mathrm{PrCE}_{\mathrm{is}}\right)$ and cost-effectiveness acceptability frontier (CEAF) for guidance (de-)implementation, under the assumption that the mean implementation cost $\left(\Delta \mathbf{C}_{\text {is }}\right)$ is $€ 2,500$ per health care professional (QALY: quality-adjusted life-year)

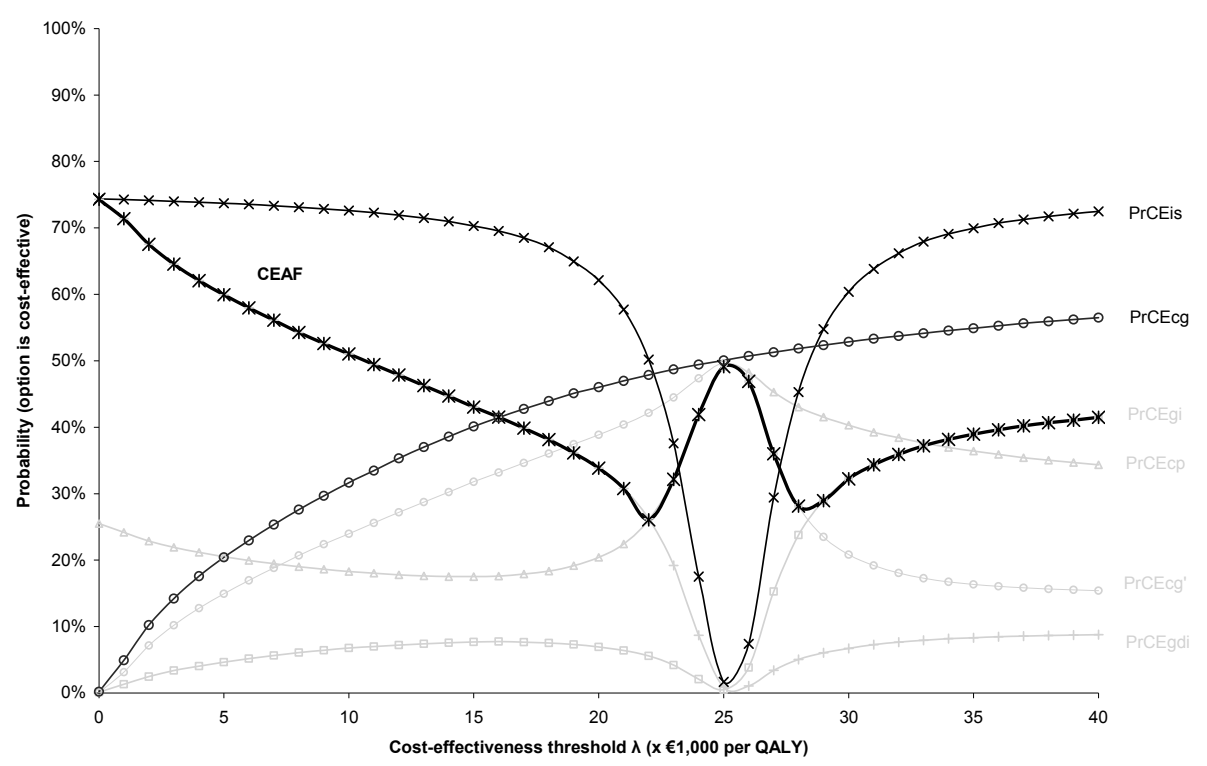

Comparing the curves and frontiers in Figures $5.3 \mathrm{a}$ and $5.3 \mathrm{~b}$, it seems evident that the (possible) higher cost of implementation reduces the range of values for $\lambda$ at which the (de-)implementation of the guidance is worthwhile. For values of $\lambda$ from approximately $€ 21,000-€ 23,500$ per QALY to the ICER $_{\mathrm{cg}}$, it is more valuable to reject the guidance and leave diabetes practice as it. From the ICER $_{\mathrm{cg}}$ to $€ 26,000-€ 28,000$ per QALY, decision makers should adopt the guidance without implementation activities. Outside this range of values for $\lambda$ (from approximately $€ 21,000$ to approximately $€ 28,000$ per QALY), the increasing implementation costs result in lower probabilities that actively changing diabetes practice is indeed cost-effective.

\subsection{Discussion}

In order to provide an efficient allocation of resources for improving primary care of type 2 diabetes in the Netherlands, we applied a comprehensive decision model, which combines evidence from different sources, to determine the scope of cost-effective implementation of guidance on intensified blood glucose control. Depending on the costeffectiveness threshold $(\lambda)$, the policy is deemed cost-effective (with an $\operatorname{ICER}_{\mathrm{cg}}$ of ap- 
approximately $€ 25,000$ per QALY) and there is considerable investment potential $\left(\operatorname{maxTIP}_{\mathrm{gi}}\right)$ to ensure its clinical use in diabetes practice. Under the assumption that its expenses are relatively low ( $€ 100$ per health care professional), audit and feedback is likely to be a cost-effective strategy to change guidance adherence. As illustrated in the CEACs and CEAF, the decisions about guidance adoption and its implementation are associated with a relatively large degree of uncertainty. This is partly caused by combining relatively uncertain economic evidence on both intensified blood glucose control and audit and feedback. Through sensitivity analyses, we found that decisions about the implementation of diabetes guidance and the uncertainty surrounding these decisions will vary with implementation cost.

As with any model, its use for decision making purposes should be done with caution. First of all, the model results are based on limited evidence on model parameters, particularly considering the effectiveness of audit and feedback ( $\Delta \mathrm{adr}$ ) (only 2 studies were included in meta-analysis) and its cost $\left(\Delta \mathrm{C}_{\mathrm{is}}\right)$ (data was extracted from literature). Given missing and/or poorly reported data, assumptions had to be made regarding distributions, means and variances of various model parameters, e.g. regarding derived effects and costs of glycemic control in the CDC model [28]. In addition, we made simplifications regarding the model structure and associated inputs. For example, we based our estimates for incremental costs and QALYs of intensive blood glucose control on reported data, whereas the integration of the UKPDS OM and/or CDC model into the comprehensive decision model would be more ideal. Finally, the findings from different sources (i.e. both guideline and implementation trials) are assumed to be transferable not just to the Dutch primary care setting but also to different recommendations for care and disease aspects.

Notwithstanding the limitations of the model, we found that for reasonable values of $\lambda$ ( > approximately $€ 25,000$ per QALY), the expected total net benefit of intensified glycemic control in patients with type 2 diabetes is such that there is considerable value associated with adopting implementation strategies, like audit and feedback, to ensure guidance use in primary practice. In effect, given that current adherence to diabetes guidance is believed not to exceed $65 \%$, there is substantial potential to invest in implementation activities. Although not formally quantified, it also seems worthwhile to acquire more evidence, concerning both costs and effects of guidance and implementation strategies, to reduce uncertainty associated with resource allocation. Ideally, further research is focused on collecting information relevant for and/or transferable to the Dutch setting for diabetes care.

By adopting an integrated Bayesian modelling approach for establishing the total net benefit of implementing guidance to change clinical practice, decision makers are able to explore the (combined) uncertainty associated with decision making about the adoption of clinical guidelines and implementation strategies. The synthesis of evidence into a single coherent model can be used to analyse the scope of cost-effective guideline implementation, and to set priorities when confronted with multiple instances of 
suboptimal practice. Compared to a conventional 'two stage' approach (i.e. splitting analysis into data synthesis and model evaluation), comprehensive (Bayesian) decision modelling for evaluating clinical practice change allows: (i) incorporation of all available sources of evidence (whether from randomised controlled trials, observational studies or expert opinion) [18] and (ii) (iteratively) adding of additional evidence (or learning) [34]. This unified modelling approach also: (iii) removes the need to make parametric distributional assumptions and facilitates the incorporation of greater parameter uncertainty; and (iv) can make full allowance for any potential interrelationship between model parameters (i.e. both costs and effects of clinical guidance as well as implementation strategies); and relate parameter uncertainty to overall decision uncertainty about all relevant options to change practice. Finally, this flexible analytic framework aids decision makers in (v) addressing (more) complex decision problems, providing a comprehensive understanding of the concept of uncertainty in terms of probabilities and facilitating sensitivity analyses [18]. The increased feasibility of implementing (Bayesian) comprehensive modelling methods has been made possible by advancements in computer power plus software such as WinBUGs [26].

In principle, the model is easily applicable to other health care areas, and any perspective of analysis can be adopted. In addition to cost-effectiveness planes, CEACs and CEAFs are useful in appropriately representing and interpreting (combined) decision uncertainty about guideline implementation [35]. In effect, the complement of the CEAF provides the probability that the decision is incorrect and the option deemed cost-effective on the basis of the expected values is in fact not cost-effective [33]. It is this error probability which is used within the value of information analysis to determine the potential worth of further research [36]. Of course, for model-based evaluations to be valuable for decision makers, decision modelling and evidence synthesis needs to be conducted and reported according to best practicable standards of quality, providing adequate disclosure of data input and modelling assumptions, e.g. concerning transferability of research findings $[14,20]$ or potential selection bias between the target and study population [15].

Some comments have to be made on the model, inducing suggestions for its extension. Given that methodological guidance on health economic evaluation $[37,38]$ advocates decision makers to consider all relevant options for clinical practice change, the model should be extended to compare the value for money of audit and feedback with that of other implementation strategies, e.g. education, outreach visits or reminders. In fact, for decision makers to prioritise between alternative uses of health care resources, it should aid in analysing the economics of implementing various guideline recommendations across different settings, diseases or therapies. Considering common absence of head-to-head trials comparing all relevant options being considered in economic evaluation of changing clinical practice, the model should hereby allow for mixed comparison of guidance and/or implementation [26,39]. Within the model, economic evidence on both guidance and implementation are assumed to be linearly proportion- 
ate to guideline adherence. In reality, it will bring increasing implementation cost with increasing adherence to guidance, and there will always be a proportion of nonadherence by professionals and patients. The model could be adapted to incorporate a more dynamic relationship between guidance adherence and the costs and effects of guideline implementation. To correctly reflect uncertainty in data in case of multiparameter synthesis on practice change, the model hereby also needs to take account of parameter correlations $[39,40]$. Other challenges would be to use more advanced Bayesian methods that permit adjustment for baseline adherence rates, modelling of surrogate outcomes, and incorporation of meta-regression or subgroup analysis. Although the decisions about whether to adopt guidelines and/or implementation strategies are central to most decision makers, many also consider the issue of research priorities [36]. Recently, an analytic framework was presented and applied to establish both the value of implementation (i.e. investment potential for implementing guidance) and value of information simultaneously [41,42]. Following the outline of this framework, our modelling approach could be extended to establish the expected value of conducting further research.

Conclusions. The stochastic application in diabetes care demonstrates that the model provides a simple and useful tool for quantifying and exploring the (combined) uncertainty associated with decision making about adopting guidelines and implementation strategies and, therefore, for informing decisions about the efficient allocation of resources to change clinical practice. 


\section{References}

1. Garcia MJ, McNamara PM, et al. Morbidity and mortality in diabetics in the Framingham population. Sixteen year follow-up study. Diabetes 1974;23(2):105-11.

2. Stamler J, Vaccaro O, et al. Diabetes, other risk factors, and 12-yr cardiovascular mortality for men screened in the Multiple Risk Factor Intervention Trial. Diabetes care 1993;16(2):434-44.

3. Anonymous. The effect of intensive treatment of diabetes on the development and progression of long-term complications in insulin-dependent diabetes mellitus. The Diabetes Control and Complications Trial Research Group. N Engl J Med 1993;329(14):977-86.

4. Anonymous. Tight blood pressure control and risk of macrovascular and microvascular complications in type 2 diabetes: UKPDS 38. UK Prospective Diabetes Study Group. BMJ 1998;317(7160): 703-13.

5. MRC/BHF Heart Protection Study of antioxidant vitamin supplementation in 20,536 high-risk individuals: a randomised placebo-controlled trial. Lancet 2002;360(9326):23-33.

6. Anonymous. Efficacy of atenolol and captopril in reducing risk of macrovascular and microvascular complications in type 2 diabetes: UKPDS 39. UK Prospective Diabetes Study Group. BMJ 1998;317(7160):713-20.

7. Grol R, Grimshaw J. From best evidence to best practice: effective implementation of change in patients' care. Lancet 2003;362(9391):1225-30.

8. Grol R, Buchan H. Clinical guidelines: what can we do to increase their use? Med J Aust 2006; 185(6):301-2.

9. Freemantle N. Implementation strategies. Fam Pract 2000;17 Suppl 1:S7-10.

10. Grol R, Wensing M, et al. Improving patient care: the implementation of change in clinical practice. London: Elsevier Limited; 2005.

11. Hoomans T, Evers SM, et al. The methodological quality of economic evaluations of guideline implementation into clinical practice: a systematic review of empiric studies. Value Health 2007;10(4): 305-16.

12. Grimshaw JM, Thomas RE, et al. Effectiveness and efficiency of guideline dissemination and implementation strategies. Health Technol Assess 2004;8(6):iii-iv, 1-72.

13. Renders CM, Valk GD, et al. Interventions to improve the management of diabetes mellitus in primary care, outpatient and community settings. Cochrane Database Syst Rev 2001(1):Cd001481.

14. Mason J, Wood J, Freemantle, N. Designing evaluations of interventions to change professional practice. J Health Serv Res Policy 1999;4(2):106-11.

15. Gandjour A, Lauterbach KW. When is it worth introducing a quality improvement program? A mathematical model. Med Decis Making 2003;23(6):518-25.

16. Sculpher M. Evaluating the cost-effectiveness of interventions designed to increase the utilization of evidence-based guidelines. Fam Pract 2000;17 Suppl 1:S26-31.

17. Severens JL. Value for money of changing healthcare services? Economic evaluation of quality improvement. Qual Saf Health Care 2003;12(5):366-71.

18. Cooper NJ, Sutton AJ, et al. Comprehensive decision analytical modeling in economic evaluation: a Bayesian approach. Health Econ 2004;13(3):203-26.

19. Hoomans T, Ament AJ, et al. Worthwhile implementation of evidence-based guidelines into clinical practice: how to determine the investment potential for guideline implementation and the value for money of implementation strategies? (submitted for publication).

20. Mason J, Freemantle N, et al. When is it cost-effective to change the behavior of health professionals? JAMA 2001;286(23):2988-92.

21. RIVM. Nationaal Kompas Volksgezondheid. Available from http://www.nationaalkompas.nl [Accessed December 13, 2007] 
22. RIVM. Nationale Atlas Volksgezondheid. Available from http://www.rivm.nl/vtv/home/Atlas [Accessed December 13, 2007]

23. Rutten G, de Grauw WJ, et al. NHG-standaard diabetes mellitus type 2; tweede herziening. Huisarts en wetenschap 2006.

24. Bouma M, Rutten GE, et al. Samenvatting van de standaard 'Diabetes mellitus type 2' (tweede herziening) van het Nederlands Huisartsen Genootschap. Ned Tijdschr Geneeskd 2006;150(41):2251-6.

25. Dijkstra RF, Braspenning JC, et al. Patients and nurses determine variation in adherence to guidelines at Dutch hospitals more than internists or settings. Diabet Med 2004;21(6):586-91.

26. Spiegelhalter DJ, Abrams KR, Myles J. Bayesian approaches to clinical trials and health-care evaluation. New York: Wiley; 2004.

27. Clarke PM, Gray AM, et al. Cost-utility analyses of intensive blood glucose and tight blood pressure control in type 2 diabetes (UKPDS 72). Diabetologia 2005;48(5):868-77.

28. Cost-effectiveness of intensive glycemic control, intensified hypertension control, and serum cholesterol level reduction for type 2 diabetes. JAMA 2002;287(19):2542-51.

29. Jamtvedt G, Young JM, et al. Does telling people what they have been doing change what they do? A systematic review of the effects of audit and feedback. Qual Saf Health Care 2006;15(6):433-6.

30. Dijkstra RF, Niessen LW, et al. Patient-centred and professional-directed implementation strategies for diabetes guidelines: a cluster-randomized trial-based cost-effectiveness analysis. Diabet Med 2006;23(2):164-70.

31. Lobach DF. Electronically distributed, computer-generated, individualized feedback enhances the use of a computerized practice guideline. Proc AMIA Annu Fall Symp 1996:493-7.

32. Palmer RH, Louis TA, et al. What makes quality assurance effective? Results from a randomized, controlled trial in 16 primary care group practices. Med Care 1996;34(9 Suppl):Ss29-39.

33. Fenwick E, Claxton K, Sculpher M. Representing uncertainty: the role of cost-effectiveness acceptability curves. Health Econ 2001;10(8):779-87.

34. Fenwick E, Palmer S, et al. An iterative Bayesian approach to health technology assessment: application to a policy of preoperative optimization for patients undergoing major elective surgery. Med Decis Making 2006;26(5):480-96.

35. Fenwick E, O'Brien BJ, Briggs A. Cost-effectiveness acceptability curves - facts, fallacies and frequently asked questions. Health Econ 2004;13(5):405-15.

36. Claxton K, Fenwick E, Sculpher M. Decision-making with uncertainty: the value of information. In: Jones AM, editor. Elgar Companion to Health Economics. Cheltenham: Elgar Publishing; 2006. p. 514-25.

37. Drummond M, Sculpher M. Common methodological flaws in economic evaluations. Med Care 2005;43(7 Suppl):5-14.

38. Drummond MF, Sculpher M, et al. Methods for the economic evaluation of health care programmes. 3rd edition ed. Oxford: Oxford University Press; 2005.

39. Ades AE, Claxton K, Sculpher M. Evidence synthesis, parameter correlation and probabilistic sensitivity analysis. Health Econ 2006;15(4):373-81.

40. Ades AE, Sculpher M, et al. Bayesian methods for evidence synthesis in cost-effectiveness analysis. Pharmacoeconomics 2006;24(1):1-19.

41. Fenwick E, Claxton K, Sculpher M. The value of implementation and the value of information: combined and uneven development. Med Decis Making 2008; 28(1):21-32.

42. Hoomans T, Fenwick E, et al. Value of information and value of implementation: application of an analytic framework to. Value Health (in press). 


\section{Appendix 5.1}

Data extraction for meta-analysis of effectiveness of audit and feedback

\begin{tabular}{|c|c|c|c|c|}
\hline Study & Details & Comparison & Outcomes & \\
\hline$[31]$ & $\begin{array}{l}\text { Design: cluster RCT } \\
\text { Unit of allocation: provider } \\
\text { Follow-up: } 6 \text { months } \\
\text { Country: USA } \\
\text { Setting: primary care clinic } \\
\text { Professionals: physicians } \\
\text { Guidance on diabetic care: } \\
\text { general patient management, } \\
\text { including blood glucose } \\
\text { control } \\
\text { Evidence base of guidance: } \\
\text { adapted from the American } \\
\text { Diabetes Association guide- } \\
\text { lines }\end{array}$ & $\begin{array}{l}\text { Group I: audit and feed- } \\
\text { back } \\
\text { Group 2: usual care / no } \\
\text { intervention } \\
\text { Outcome measure: mean } \\
\text { adherence to standards } \\
\text { of care, not measured } \\
\text { specifically for blood } \\
\text { glucose control }\end{array}$ & $\begin{array}{l}\text { Group I: } \\
\text { median: } 35.3 \% \\
25^{\text {th }} \text { percentile: } 25.8 \% \\
75^{\text {th }} \text { percentile: } 56.7 \% \\
\text { Group } 2: \\
\text { median: } 6.1 \% \\
25^{\text {th }} \text { percentile: } 0.0 \% \\
75^{\text {th }} \text { percentile: } 14.0 \% \\
\text { Baseline adherence: } \\
-\end{array}$ & \\
\hline$[32]$ & $\begin{array}{l}\text { Design: cluster RCT } \\
\text { Unit of allocation: groups of } \\
\text { practices or group prac- } \\
\text { tice/site } \\
\text { Follow-up: } 6 \text { and } 12 \text { months } \\
\text { Country: USA } \\
\text { Setting: mixed } \\
\text { Professionals: physicians, } \\
\text { nurses } \\
\text { Guidance on diabetic care: } \\
\text { general patient management, } \\
\text { including blood glucose } \\
\text { control } \\
\text { Evidence base of guidance: } \\
\text { not clear }\end{array}$ & $\begin{array}{l}\text { Group I: audit and feed- } \\
\text { back plus distribution of } \\
\text { education materials and } \\
\text { educational meetings } \\
\text { Group 2: usual care / no } \\
\text { intervention } \\
\text { Outcome measure: Dif- } \\
\text { ference in mean adher- } \\
\text { ence to standards of } \\
\text { care, also measured } \\
\text { specifically regarding } \\
\text { blood glucose control }\end{array}$ & $\begin{array}{l}\text { All guidelines: } \\
\text { For } 6 \text { months follow up } \\
\text { Mean: }+5.2 \% \text {-points } \\
\text { Standard error: } 1.5 \%- \\
\text { points } \\
\text { For } 12 \text { months follow } \\
\text { up } \\
\text { Mean: +4.3\%-points } \\
\text { Standard error: 1.6\%- } \\
\text { points } \\
\text { Baseline adherence: } \\
68.2 \% \text {-points }\end{array}$ & $\begin{array}{l}\text { Blood glucose only: } \\
\text { For } 6 \text { months follow up } \\
\text { Mean: } 6.6 \% \text {-points } \\
\text { Standard error: } 2.9 \%- \\
\text { points } \\
\text { For } 12 \text { months follow } \\
\text { up } \\
\text { Mean: } 7.1 \% \text {-points } \\
\text { Standard error: } 3.3 \% \text { - } \\
\text { points } \\
\text { Baseline adherence: } \\
94-\%-p o i n t s\end{array}$ \\
\hline
\end{tabular}




\section{Appendix 5.2 \\ Model implementation in WinBUGS}

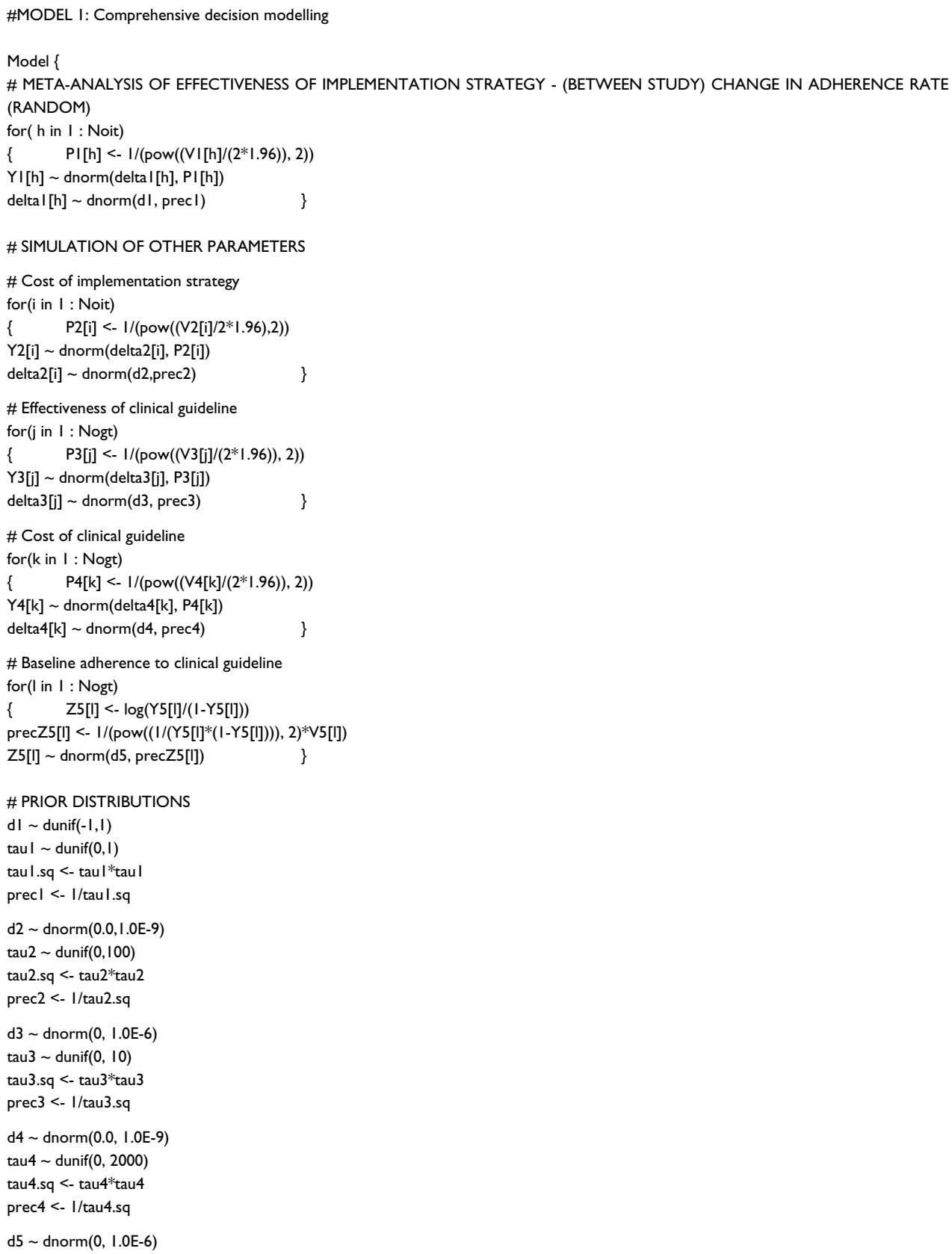




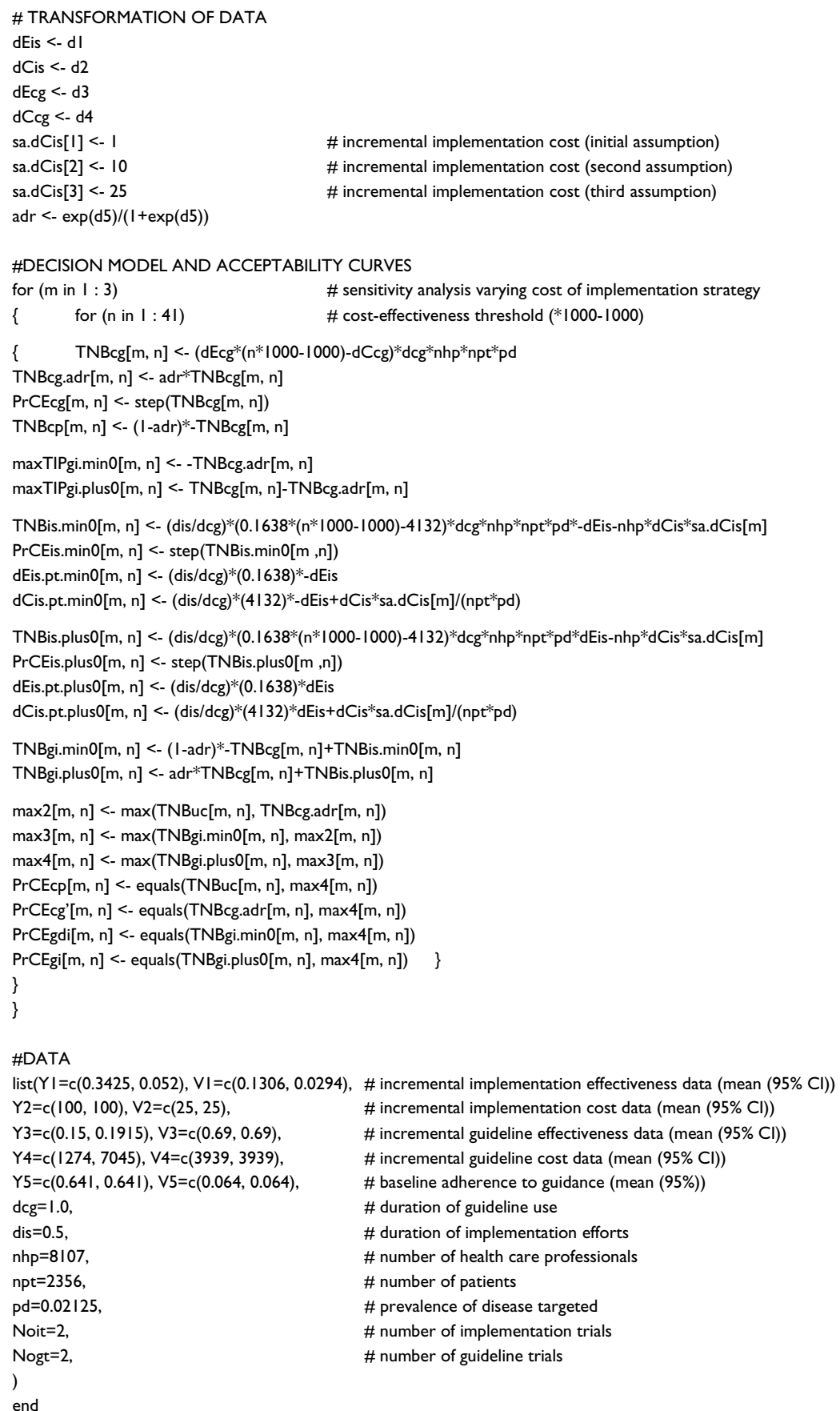

\#INITIAL VALUES

list $(\operatorname{tau} I=0.1$, delta $I=c(0,0), d I=0, \operatorname{tau} 2=20, \operatorname{delta} 2=c(100,100), d 2=0, \operatorname{tau} 3=0.1, \operatorname{delta} 3=c(0.15,0.15), d 3=0, \operatorname{tau} 4=1000, \operatorname{delta} 4=c(1000$, 1000), $d 4=1000, d 5=0)$ 

6 Value of Information and Value of Implementation: Application of an Analytic Framework to Inform Resource Allocation Decisions in Metastatic Hormone-Refractory Prostate Cancer

Ties Hoomans ${ }^{1}$, Elisabeth A.L. Fenwick ${ }^{2}$, Steve Palmer ${ }^{3}$, Karl Claxton ${ }^{3}$

${ }^{1}$ Department of Health Organisation, Policy and Economics, Maastricht University, the Netherlands;

${ }^{2}$ Public Health and Health Policy, Division of Community Based Sciences, University of Glasgow,

United Kingdom; ${ }^{3}$ Centre for Health Economics, University of York, United Kingdom

Value Health (in press) 


\section{Abstract}

In a budget constrained health care system, decisions about investing in strategies to promote implementation have to be made alongside decisions about health care provision and research funding. Using a Bayesian decision-theoretic approach, an analytic framework has been developed to inform these separate but related decisions, establishing the expected value of both perfect information (EVPI) and perfect implementation (EVPIM). We applied this framework to inform decision making about resource allocation to metastatic hormone-refractory prostate cancer (mHRPC) in the United Kingdom.

Based on available evidence on the cost-effectiveness of all plausible treatments for mHRPC, we determined which treatment option(s) were cost-effective and explored the uncertainty surrounding this decision. Given the decision uncertainty and the variation in care provided by health care professionals, we then determined the EVPI and EVPIM. Finally, we performed sensitivity analyses to explore the influence of alternative assumptions regarding various decision parameters on the efficiency of resource allocation.

Depending on the cost-effectiveness threshold $(\lambda)$, we identified mitoxantrone plus prednisone/prednisolone and docetaxel plus prednisone/prednisolone (3 weekly) as the optimal treatments for mHRPC. Given current clinical practice, there appears to be considerable scope for improving the efficiency of health care provision: the EVPI (estimated to be over $£ 13$ million) indicates that acquiring further information could be cost-effective; and the EVPIM (estimated to be over $£ 4$ million) suggests that investing in strategies to implement the treatment regimens being identified as optimal is potentially worthwhile. Through sensitivity analyses, we found that the EVPI and EVPIM are mainly driven by $\lambda$, the number of treatment options being considered, the current level of implementation and the size of the eligible patient population.

The application demonstrates that the framework provides a simple and useful analytic tool for decision makers to address resource allocation problems between health care provision, further research and implementation efforts. 


\section{I Introduction}

Given the growing demand for health care services and the limited resources to deliver them, health care decision makers are increasingly confronted with resource allocation problems. Decision makers commonly rely on economic evaluations to provide evidence about the likely costs, effects, and cost-effectiveness of health care technologies, such as diagnostic instruments, treatment regimens or clinical practice guidelines [1]. The decision whether or not to reimburse a technology is inevitably made in a context of uncertainty surrounding the cost-effectiveness of these technologies [2,3]. In order to reduce uncertainty associated with the reimbursement decision, decision makers could opt to commit resources to collecting additional economic evidence on technologies $[4,5]$. Bayesian value-of-information analysis provides an explicit and rigorous framework within which related decisions regarding technology reimbursement and research funding can be addressed [6-9].

The implicit assumption within decision analyses and value-of-information analyses is that health care technologies automatically get implemented into clinical practice. Nonetheless, irrespective of the rigour of economic evidence on the technologies for which decision makers issue guidance, patients and health care professionals may not adhere to guidance [10-13]. Non-adherence to cost-effective technologies compromises the efficiency of health care provision in terms of the health and resources forgone. Implementation strategies, including education or outreach visits, reminders and financial incentives, aim to change adherence but cost money to enact. In a budget constrained health care system, decisions about investing in strategies to promote implementation have to be made alongside decisions about health care provision and research funding, and decision makers should carefully consider the potential worth of implementation efforts to decide whether to adopt strategies [14-17]. The established methodology for exploring the economics of technology implementation has tended to concentrate on studying the cost-effectiveness of alternative implementation strategies rather than assessing the economic impact of non-adherence, let alone considering the efficiency of investment in health care provision and/or further information collection [17-21].

Recently, an analytic framework was developed to inform the conceptually distinct but related decisions about health care provision, research funding and investments in implementation efforts [22]. Using a Bayesian decision-theoretic approach, the framework establishes cost-effective health care provision and the maximum returns to investment in further research (through the expected value of perfect information) and implementation efforts (through the expected value of perfect implementation). Nonetheless, these upper bounds provide only necessary conditions for collecting additional information and/or ensuring implementation and should be compared to the costs of these activities to determine whether they are potentially worthwhile. The sufficient condition for the worth of research funding requires that the expected value of addi- 
tional or sample information (EVSI) exceeds the costs of the specific research $[7,8,23$ 25]. Similarly, decision makers need to consider the additional benefits and the additional costs of specific implementation strategies to decide whether technology implementation will in fact be worthwhile $[26,27]$.

In this chapter, we aim to demonstrate the use and practicality of this analytic framework by applying it prospectively alongside a technology appraisal to inform the National Institute for Health and Clinical Excellence (NICE), the body providing guidance for the National Health Service (NHS) in England and Wales, about the allocation of health care resources for metastatic hormone-refractory prostate cancer (mHRPC). The chapter starts with an outline of the various decision-theoretic approaches to inform the resource allocation decisions and the analytic framework developed by Fenwick et al. [22]. The application of the framework is then demonstrated, providing a detailed description of the background, the methods and the results of the decision analysis. We conclude with a discussion of the main findings of the analysis and the implications for decision making as well as some comments on the framework and several suggestions for its extension.

\subsection{Methodological background}

\subsection{Resource allocation decisions}

There are three questions which any health care system needs to address in making decisions about the efficient allocation of health care resources: (1) whether it is costeffective to reimburse a health care technology, given available evidence (reimbursement decision); (2) whether it is worthwhile funding further research to collect additional information to inform the reimbursement decision in the future (research decision); and (3) whether it is worthwhile investing in strategies to promote the implementation of the reimbursed technology (implementation decision). In order to inform these conceptually separate but related decisions, various decision-theoretic approaches to health economic evaluation are of use.

Reimbursement decision. If a health care system's objective is to maximise health gain subject to a budget constraint, then the decision about whether to reimburse a health care technology, given currently available information, should be based on the expected cost-effectiveness (or mean net benefits) [23]. Inference and the distribution of the expected cost-effectiveness (or mean net benefits) are irrelevant to the technology choice [7]. For a decision involving $\mathrm{j}$ (mutually exclusive) technologies where the costeffectiveness (or net benefit) is dependent on a set of unknown parameters , the technology with the maximum expected cost-effectiveness (or mean net benefits [ $\max _{j} E_{\theta}$ $\mathrm{NB}(\mathrm{j}, \theta)]$ ) should be chosen [23]. Nonetheless, several authors have recently demonstrated the importance of also considering the value of additional information forgone 
[28] and the (opportunity) costs of reversal or delay [25] when informing decision making about technology reimbursement. More details on the latter are described in the discussion.

Research decision. Although the uncertainty in the expected cost-effectiveness (or mean net benefits) may not be relevant to the reimbursement decision, it is essential for the decision about whether the gathering of additional information is warranted [7,8,23$25]$. Given the uncertainty surrounding the decision to reimburse a technology, there is a probability of making the wrong decision. If the wrong decision about reimbursement is made, there will be costs in terms of health gain and resource savings forgone (i.e. opportunity loss). The expected cost of decision uncertainty is determined by the error probability associated with the reimbursement decision and the opportunity loss of a wrong decision. Value-of-information analysis evaluates the extent to which additional evidence might improve decision making by reducing the chance for error and compares that improvement (in terms of reduced expected costs of uncertainty) with the cost of information. The expected value of perfect information (EVPI) provides a maximum return to investment in further research (i.e. the difference between the expected value of a decision made on the basis of available evidence $\left[\max _{j} E_{\theta} \mathrm{NB}(j, \theta)\right]$ and that on the basis of perfect information $\left.\left[\mathrm{E}_{\theta} \max _{j} \mathrm{NB}(\mathrm{j}, \theta)\right]\right)$, as perfect information eliminates all the possibility of making the wrong decision $[8,23]$. The EVPI can be calculated for individual or various combinations of parameters in order to assess the potential worth of research concerning particular elements of the decision $[3,23]$. If the EVPI exceeds the expected costs of further investigation, then it is potentially costeffective to acquire more information by conducting additional research (i.e. a necessary condition for research funding) [8,23]. Evidently, to establish a sufficient condition for deciding whether further research will be worthwhile and identifying technically efficient research scale and design, the marginal benefits (i.e. EVSI) and the marginal costs of sample information need to be considered, and the expected net benefit of sampling (ENBS) should be estimated [7,8,23-25]. In calculating the EVSI, the expected research cost, and the ENBS of trialling, it is advocated to account for the timing of future research, including time for accrual, follow up and analysis $[7,24,25,29$, 30].

Implementation decision. Health care technologies that are deemed cost-effective (or beneficial) do not automatically or immediately get implemented perfectly into clinical practice [13,31]. Non-adherence to technologies by patients and health care professionals may be caused by multiple factors such as knowledge, attitude or even chance $[32,33]$. Less than perfect implementation of cost-effective technologies reduces the efficiency of the health care system [22]. The expected efficiency losses are determined by the level of implementation, i.e. adherence to technology $j$ (denoted by $\rho_{i}$ ) and by the expected cost-effectiveness (or mean net benefits) of the technologies being considered. 
The expected value of perfect implementation (EVPIM) is simply the difference between the expected value of a decision that is implemented perfectly $\left(\max _{j} E_{\theta} N B(j, \theta)\right)$ and that with implementation at its current level $\left(\sum \rho_{\mathrm{j}} * \mathrm{E}_{\theta} \mathrm{NB}(\mathrm{j}, \theta)\right)$. The EVPIM provides a measure of the upper bound on the value of reimbursing implementation strategies to change adherence to cost-effective health care technologies. If the EVPIM exceeds the expected implementation costs, then it is potentially worthwhile to ensure technology implementation, and a necessary condition for investing in implementation is established. Analogous to the concepts of EVPI, EVSI and ENBS, the sufficient condition for the worth of promoting the implementation of valuable technologies into clinical practice requires that the expected value of specific implementation strategies (EVSIM) exceeds the costs of the implementation efforts [26,27].

\subsection{Decision analytic framework}

The analytic framework developed by Fenwick et al. [22] combines the various (Bayesian) decision-theoretic approaches to explore both the value of information and the value of implementation (see Box 6.1).

Within the framework, the resource allocation decision context is represented by a simple four-state world where both information and implementation can be either at the current level or perfect. The current level of information relates to the rigour of currently available evidence, where a situation of perfect information assumes that there is no uncertainty surrounding the costs and effects of a health care technology. The level of implementation depends on the adherence to the technologies in clinical practice, and varies between $0 \%$ (i.e. perfect implementation where the technology is not cost-effective) and $100 \%$ (i.e. perfect implementation of a cost-effective technology). Each of the states represents a certain expected value of a decision made, in terms of net benefits [34,35].

Through comparison and subtraction of the expected decision values of the different states, we can determine the EVPI (D-C) and the EVPIM (C-A). In addition, the framework allows the determination of the realisable expected value of perfect information (rEVPI = B-A) and the expected value of perfection (EVP = D-A). Assuming a relationship between the availability and rigour of evidence and the level of implementation $\left(\rho_{j}^{\prime}=f(\right.$ level of information $\left.)\right)$, the rEVPI identifies the expected value of research that is realisable without reimbursing implementation strategies to change the adherence to cost-effective technologies in clinical practice. The EVP is a combined measure of the maximum possible return for an investment in research and implementation, and identifies the scope for improving the efficiency of the health care system in terms of the health that can be generated subject to a given budget constraint. 
Box 6.I Framework and derivations of populations EVPI, population realisable EVPI, population EVPIM and population EVP

\begin{tabular}{|c|c|c|c|}
\hline & & \multicolumn{2}{|c|}{ Level of information } \\
\hline & & Current & Perfect \\
\hline \multirow{2}{*}{ Level of implementation } & Current & A & B \\
\hline & Perfect & C & D \\
\hline
\end{tabular}

The framework matrix identifies 4 states (A, B, C and D) that represent a certain expected value of a decision made on the basis the level of information (current or perfect) and level of implementation (current or perfect). Comparison and subtraction of the expected decision values of the different states yields the valuations for EVPI, rEVPI, EVPIM and EVP.

The following equations apply to inform resource allocation decisions involving $\mathrm{j}$ technologies where net benefit (NB) is dependent on a set of unknown parameters $\theta$ :

EVPI $=D-C=E_{\theta} \max _{j} N B(j, \theta)-\max _{j} E_{\theta} N B(j, \theta)$

rEVPI $\left.\quad=B-A=E_{\theta} \sum_{j} \rho_{j}^{\prime} * N B(j, \theta)-\sum_{j} \rho_{j} * E_{\theta} N B(j, \theta)\right)$

EVPIM $\left.\quad=C-A=\max _{j} E_{\theta} N B(j, \theta)-\Sigma \rho_{j} * E_{\theta} N B(j, \theta)\right)$

EVP $\left.\quad=D-A=E_{\theta} \max _{j} N B(j, \theta)-\Sigma \rho_{j} * E_{\theta} N B(j, \theta)\right)$

The population values are determined by multiplying the relevant measure by a scaling factor representing the future population $\sum_{t}^{T} \frac{I_{t}}{(1+r)^{t}}$ (e.g. $\left.p E V P I=E V P I \times \sum_{t}^{T} \frac{I_{t}}{(1+r)^{t}}\right)$

where:

(p)EVPI = (population) expected value of perfect information

$(\mathrm{p}) \mathrm{rEVPI} \quad=$ (population) realisable expected value of perfect information

(p)EVPIM = (population) expected value of perfect implementation

(p)EVP = (population) expected value of perfection

$\rho_{\mathrm{j}} \quad \quad=$ level of implementation, i.e. adherence to technology $\mathrm{j}$, where $\rho_{i}^{\prime}=f\left(\right.$ level of information); with $\rho_{\mathrm{i}}^{\prime} \geq \rho_{\mathrm{i}} \in[0, \mathrm{I}]$

$=$ incidence in period $\mathrm{t}$

$=$ period

$=$ total number of periods for which information from research would be useful

$=$ discount rate

As decisions regarding health care provision, research funding and implementation investments are to the public good, the valuations for EVPI, rEVPI, EVPIM and EVP should be calculated across the population of (future) patients for whom the decisions are relevant. Population level values can be established based on estimates of the incidence of patients $(\mathrm{I})$ in each period $(\mathrm{t})$ discounted at rate $\mathrm{r}$ [23].

On the basis of the expected population values of information and implementation, decision makers can address issues of (1) which technologies to reimburse; (2) whether there is potential worth associated with undertaking further research; and (3) whether it is potentially worthwhile investing in strategies to promote the implementation of cost-effective technologies. Because these values (i.e. pEVPI, prEVPI, pEVPIM and pEVP) place an upper bound on the returns of efficiency improvement through conducting further research and/or ensuring implementation, the framework provides necessary conditions for addressing resource allocation problems between health care pro- 
vision, research funding and implementation investments. Nonetheless, to establish sufficient conditions: decide if further research and/or ensuring implementation will be worthwhile and identify efficient design of specific research and specific implementation strategies, would still require that decision makers estimate the net benefit of sampling (with EVSI > costs of the specific research) [7,8,23-25] and the net benefit of specific implementation strategies (with EVSIM > costs of the implementation efforts) $[26,27]$.

\subsection{Application of framework}

\subsection{Background information}

In the UK, prostate cancer is the second most common male cancer, with agestandardised mortality rates over 27 per 100,000 men [36]. The majority of such deaths are in patients with mHRPC, for whom the disease has become unresponsive to hormone treatment after around 18 months and progressed [37]. Treatment aims to improve symptoms, slow progression of the disease, and prolong life. The UK population of patients with mHRPC is assumed to be 4122 (based on an annual population of 9161 patients, of which $30 \%$ are eligible for $\mathrm{D}+\mathrm{P}$, and a decision time of 1.5 years) [36]; patient survival is not expected to exceed 12 months [38]. Although in some countries (e.g. in the USA, along with other Western countries) a combination of mitoxantrone and prednisolone $(\mathrm{M}+\mathrm{P})$ has come to be accepted as standard care for this group of patients [39], there remains uncertainty about which treatment option is most likely cost-effective under different circumstances. Currently, clinical practice varies considerably among health care professionals, implementing different treatment options, including second-line hormonal therapy, chemotherapy with or without corticosteroids, and best supportive care.

\subsubsection{Methods}

As part of a technology assessment commissioned by NICE to inform its guidance for the NHS concerning mHRPC, an economic model was developed [39] to compare the full range of relevant treatment regimens, comprising:

- $\mathrm{D}+\mathrm{P}$ (3 weekly): docetaxel $(75 \mathrm{mg} / \mathrm{m} 2$ every 3 weeks) plus prednisone/prednisolone (5 mg orally twice daily);

- M + P: mitoxantrone (12 mg/m2 every 3 weeks) plus prednisone/prednisolone (5 mg orally twice daily);

- P: prednisone/prednisolone (5 mg orally twice daily);

- $\mathrm{D}+\mathrm{P}$ (weekly): docetaxel $(30 \mathrm{mg} / \mathrm{m} 2$ on days $1,8,15,22$, and 29 in a 6-week cycle) plus prednisone/prednisolone (5 mg orally twice daily); 
- D + E: docetaxel (60-70 mg/m2 every 3 weeks) plus estramustine (three times daily on days $1-5)$;

- $\mathrm{D}+\mathrm{E}+\mathrm{P}(70)$ : docetaxel $(70 \mathrm{mg} / \mathrm{m} 2$ every 3 weeks) plus estramustine $(840 \mathrm{mg}$ in 3 divided doses on days $1-5$ and $8-12$ ) plus prednisone/prednisolone (5 mg orally twice daily);

- $\mathrm{D}+\mathrm{E}+\mathrm{P}(35)$ : docetaxel ( $35 \mathrm{mg} / \mathrm{m} 2$ twice every 3 weeks) plus estramustine (840 $\mathrm{mg}$ in 3 divided doses on days $1-5$ and $8-12$ ) plus prednisone/prednisolone (5 $\mathrm{mg}$ orally twice daily);

- $\mathrm{M}+\mathrm{P}+\mathrm{C}$ : mitoxantrone (12 mg/m2 every 3 weeks) plus prednisone/prednisolone ( $5 \mathrm{mg}$ orally twice daily) plus clodronate ( $1500 \mathrm{mg}$ over 3 hours every 21 days).

The model provides a framework for the synthesis of clinical effectiveness and economic reviews to develop a single, unified analysis of the main comparators identified, reporting estimates of the incremental costs per life-years gained and quality-adjusted life-years (QALYs). The analysis takes an NHS perspective and uses a lifetime horizon. Further details of the model and the analysis are available in Collins et al. [39].

Table 6.1 summarises the currently available evidence on the costs and effects of the eight potential treatments of mHRPC, and denotes the current implementation of the different treatment options into clinical practice.

Table 6.I Available evidence on the costs, QALYs and ICERs of all eight plausible treatment regimens, and adherence to regimens into clinical practice

\begin{tabular}{|c|c|c|c|c|}
\hline Treatment regimen & Costs* & QALYs* & ICER & Adherence to regimens $^{\dagger}$ \\
\hline$M+P$ & $€ 10,834(2,206)$ & $0.81(0.12)$ & - & $38 \%$ \\
\hline$M+P+C$ & $f \mid I, 008(2,239)$ & $0.79(0.14)$ & Dominated & $2.8 \%$ \\
\hline$P$ & $£ \mid I, 227(3,34 I)$ & $0.81(0,13)$ & Dominated & $18 \%$ \\
\hline$D+E$ & $£ \mid 5,036(1,916)$ & $0.94(0.17)$ & Extended dominated & $1 \%$ \\
\hline$D+P$ (3 weekly) & $£ 15,883(1,926)$ & $0.97(0.15)$ & $£ 32,706$ & $33 \%$ \\
\hline$D+E+P\left(70 \mathrm{mg} / \mathrm{m}^{2}\right)$ & $E 16,260(I, 930)$ & $0.86(0.23)$ & Dominated & $0.9 \%$ \\
\hline$D+E+P\left(35 \mathrm{mg} / \mathrm{m}^{2}\right)$ & $£ \mid 8,460(1,920)$ & $0.90(0.17)$ & Dominated & $0.9 \%$ \\
\hline$D+P$ (weekly) & $£ 26,268(1,945)$ & $0.85(0.13)$ & Dominated & $5 \%$ \\
\hline
\end{tabular}

* Information on the mean (standard deviations) costs and QALYs are based on an existing economic model developed to assess the cost-effectiveness of docetaxel for the treatment of mHRPC' for NICE [39]. ${ }^{\dagger}$ Estimates of the adherence to the different treatment regimens are based on a recent audit on the use of chemotherapy regimens for hormone resistant prostate cancer in 33 centres nationwide undertaken by the British Prostate Group, British Uro-Oncology Group \& British Association of Urological Surgeons [39]. M: mitoxantrone; P: prednisone/prednisolone; C: clodronate; D: docetaxel; E: estramustine; QALYs: quality-adjusted life-years; ICER: incremental cost-effectiveness ratio; NICE: National Institute for Health and Clinical Excellence

To inform the (1) reimbursement decision, we first determined the incremental costeffectiveness ratios (ICERs) for all plausible treatment options, based on the modelled estimates of costs and QALYs [39]. We illustrated the uncertainty surrounding this decision using cost-effectiveness acceptability curves (CEACs) and frontier (CEAF). The CEAC is a plot of the probability that a treatment option is cost-effective as a function 
of the cost-effectiveness threshold $(\lambda)$ [4]. The CEAF presents the same information but only for the range of values for $\lambda$ where the treatment option is deemed to be costeffective (i.e. maximises NB) [40,41]. As such, the CEAF is a disjointed frontier constructed from the individual CEACs of the cost-effective treatment options, with the discontinuities occurring at the point at which the decision switches from one treatment option to another (i.e. ICER). Where a treatment option is not deemed costeffective on the basis of expected values, it will not appear in the CEAF. The CEAF does not, in itself, aid the reimbursement decision; it simply presents the probability that the treatment option deemed cost-effective on the basis of expected values is in fact cost-effective. The complement of the CEAF provides the probability that the decision is incorrect (error probability) and the treatment option deemed cost-effective on the basis of the expected values is in fact not cost-effective [40,41]. It is this error probability that is used within the value-of-information analysis to determine the potential worth of further research.

We then applied the framework [22] to inform both the (2) research and (3) implementation decisions. We explored the pEVPI, pEVPIM and pEVP over a range of values for $\lambda$ and interpreted the values at a $\lambda$ of $£ 30,000$ per QALY with regard to their implications for decision making about resource allocation and priority setting. For simplicity, we assumed no relationship between the level of information and the level of implementation (i.e. the availability and rigour of evidence on different treatment options is assumed to have no influence on the adherence to the treatment regimens into clinical practice $\left[\rho_{j}=\rho_{j}\right]$ ), and therefore did not establish the prEVPI. In effect, under this assumption the prEVPI equals 0 in all analyses and is non-informative for decision making. The implications of this simplification are examined within the discussion.

Finally, we performed univariate sensitivity analyses to examine whether the valuations for pEVPI, pEVPIM and pEVP are sensitive to alternative assumptions related to relevant decision parameters. As decision makers often fail to consider all relevant alternatives for comparison in health economic evaluations [1,2], we varied the number of treatment options being considered, using only the three most routinely used treatment regimens $(\mathrm{D}+\mathrm{P}$ [3 weekly], $\mathrm{M}+\mathrm{P}$ and $\mathrm{P}$ ) rather than all eight potential relevant treatment options. We confined ourselves to briefly discussing the implications of variation in other parameters (i.e. the levels of implementation, the resulting uncertainty surrounding the reimbursement decision, the differences in the expected net benefits between treatment options and the size of the eligible patient population) for decision making about resource allocation.

Monte Carlo simulations were used to calculate the CEACs and CEAF, to determine the pEVPI, pEVPIM and pEVP, and to conduct the sensitivity analyses. All model calculations were done in MS Excel. 


\subsubsection{Results}

\section{Base case analysis}

Reimbursement decision: determining the ICER and identifying the optimal treatment of $m H R P C$. An incremental analysis of the expected costs and QALYs of the eight potential treatments of $\mathrm{mHRPC}$ revealed that the ICER of D + P (3 weekly) compared to $\mathrm{M}+\mathrm{P}$ is $£ 32,706$ per QALY and the other six treatment options were (extended) dominated (see Table 6.1). Thus, depending on $\lambda$, decision makers should reimburse either $\mathrm{M}+\mathrm{P}$ or $\mathrm{D}+\mathrm{P}$ (3 weekly) as standard treatment for mHRPC patients. Nonetheless, this reimbursement decision is uncertain as illustrated by the CEACs showing that the treatment options identified as cost-effective do not necessarily have the highest probability of being optimal (see Figure 6.1a). Figure 6.1b illustrates the CEAF for the reimbursement decision. As noted above, the discontinuity on the frontier corresponds to the ICER between the two treatment options, here $\mathrm{M}+\mathrm{P}$ and $\mathrm{D}+\mathrm{P}$ ( 3 weekly). It is important to note that the comparison of numerous treatment options results in a relative large extent of uncertainty regarding the decision about treatment reimbursement.

Research decision and implementation decision: exploring the pEVPI, pEVPIM and $p E V P$. Figure 6.2 illustrates the relationship between $\lambda$ and the pEVPI, pEVPIM and pEVP for all eight plausible treatment options for mHRPC patients.

The extent of uncertainty regarding the treatment reimbursement decision is formally quantified in the pEVPI curve. This curve increases over the full range of values for $\lambda$, with a local maximum occurring at the value that corresponds to the ICER $(£ 32,706$ per QALY). In effect, the relative high error probability (illustrated by the relatively low CEAF [values]) associated with the reimbursement decision in combination with the substantial opportunity losses of erroneous decision making, results in a considerable maximum return to acquiring more precise estimates of the incremental costs and effects across the range of plausible treatment options.

Indicating the maximum return to investments in implementation, the pEVPIM curve initially falls as $\lambda$ rises, with a local minimum occurring at the value that corresponds to the ICER. At this value for $\lambda$, decision makers are indifferent about which of the cost-effective treatment regimens $(\mathrm{M}+\mathrm{P}$ and $\mathrm{D}+\mathrm{P}$ [3 weekly]) are implemented by health care professionals. Nevertheless, the pEVPIM at this value does not reach zero because there is value to be gained from reducing the current adherence to other treatment options identified as non-optimal, i.e. $\mathrm{D}+\mathrm{E}, \mathrm{M}+\mathrm{P}+\mathrm{C}, \mathrm{D}+\mathrm{E}+\mathrm{P}(70)$ and $\mathrm{D}+$ $\mathrm{E}+\mathrm{P}(35)$. For $\lambda$ s larger than the ICER ( $£ 32,706)$, the pEVPIM rises as a result of the increasing value to be gained from implementing D + P ( 3 weekly), which is identified (with increasing certainty) as the optimal treatment option.

By summing pEVPI and pEVPIM, we derive the pEVP curve, which forms a ' $u$ shape'. Over the range of values for $\lambda$, there is alternately more, equal or less potential 
value associated with research funding than with investments in implementation for improving the efficiency of mHRPC health care services delivery.

Figure 6. Ia Cost-effectiveness acceptability curves for the eight plausible treatment regimens for mHRPC (mHRPC: metastatic hormone-refractory prostate cancer)

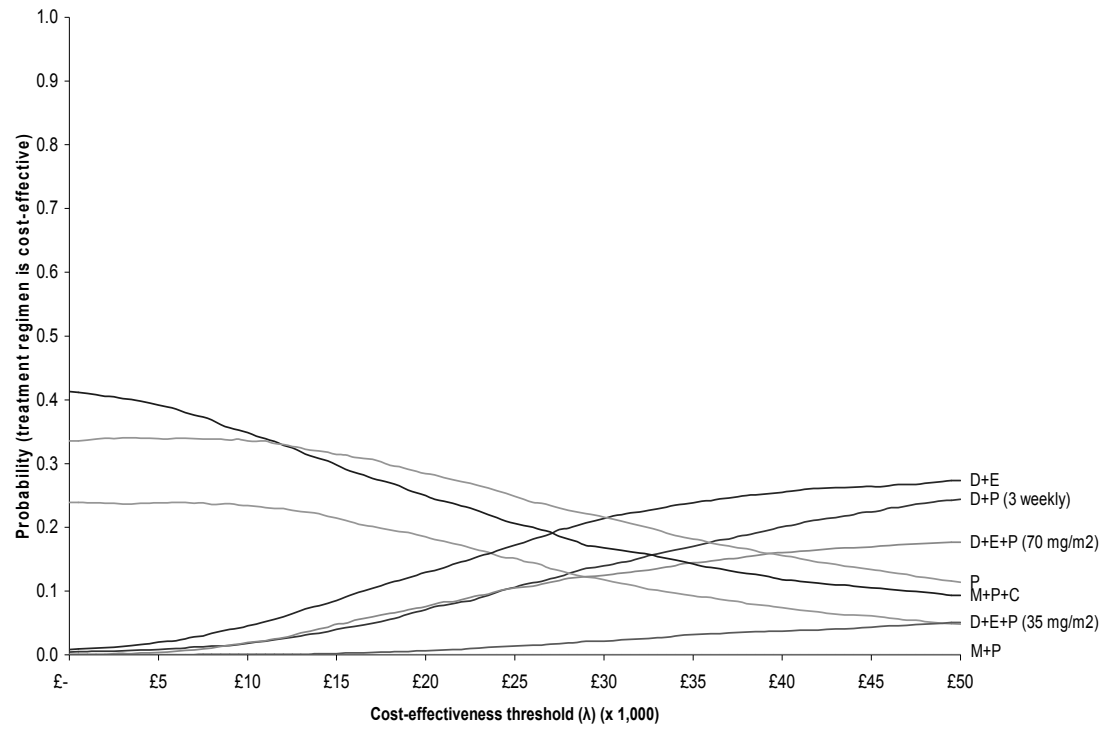

Figure 6.Ib Cost-effectiveness acceptability frontier (CEAF) for the reimbursement decision involving the eight plausible treatment options for mHRPC (mHRPC: metastatic hormone-refractory prostate cancer)

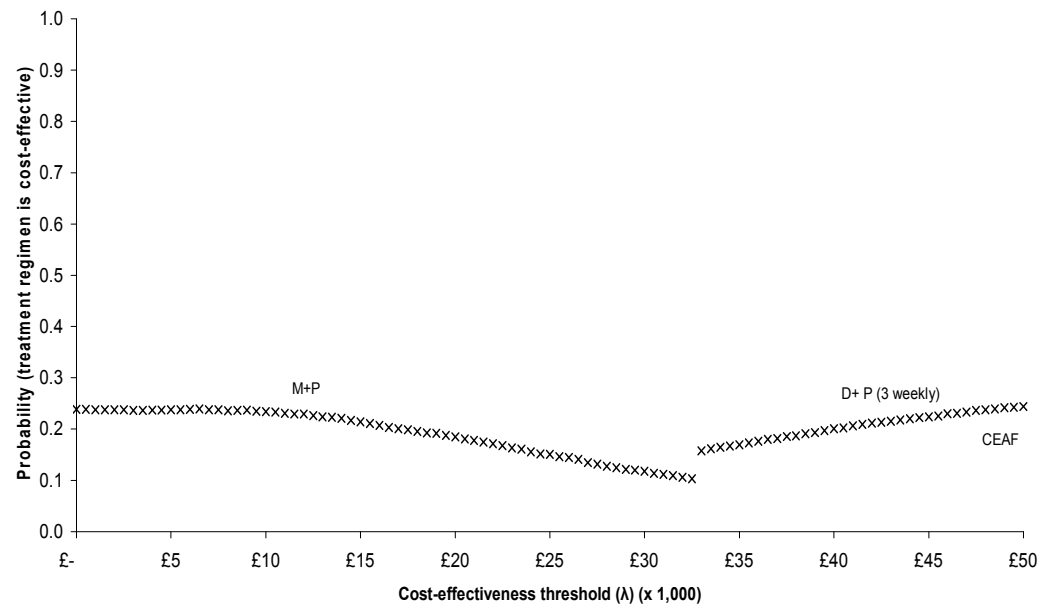


Figure 6.2 Cost-effectiveness acceptability frontier (CEAF) (primary axis), and population expected values of perfect information (pEVPI), perfect implementation ( $p E V P I M)$ and perfection ( $p E V P$ ) (secondary axis) for the adoption decision between the eight plausible treatment regimens for mHRPC (mHRPC: metastatic hormonerefractory prostate cancer)

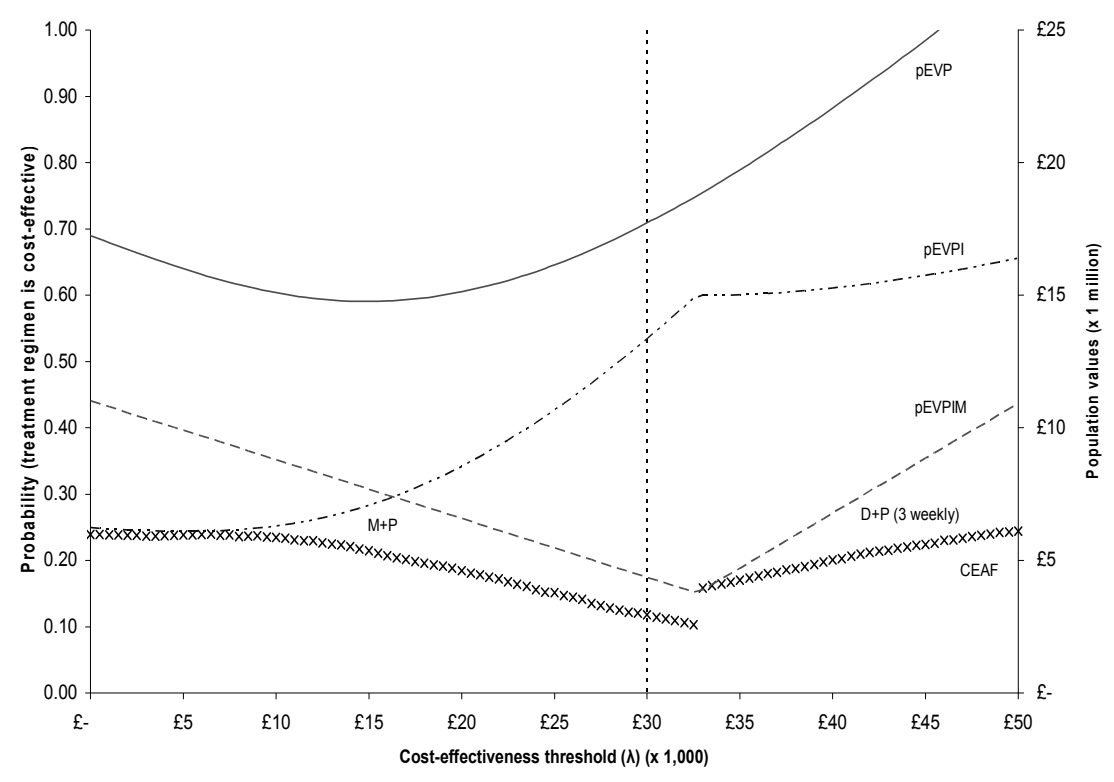

Interpreting the ICER, pEPVI, pEVPIM and $p E V P$ for a $\lambda$ of $£ 30,000$ per QALY: implications for decision making about resource allocation. Given a $\lambda$ of $£ 30,000$ per QALY, M + P is identified as the cost-effective treatment of mHRPC. Assuming perfect implementation, the expected value of the decision to reimburse $\mathrm{M}+\mathrm{P}$, based purely on current information, is $£ 13,575$ per patient, while the expected value of a decision based on perfect information is $£ 16,817$ per patient. With a UK population of 4122 mHRPC patients, the pEPVI is estimated to be $£ 13.4$ million. Considering the variation in clinical practice and current adherence to $\mathrm{M}+\mathrm{P}(38 \%)$, the expected value of reimbursing $\mathrm{M}+\mathrm{P}$ without ensuring its implementation is $£ 12,517$ per patient (i.e. the sum of the proportionate expected values of all eight treatment regimens currently utilised by health care professionals). As a result, there is an estimated worth of $£ 1058$ (= $£ 13,575$ - $£ 12,517$ ) per patient in investing in strategies to promote perfect implementation of $M+P$. Translated to population values, the pEVPIM and pEVP are $£ 4.4$ million and $£ 17.7$ million, respectively. In effect, at this value of $\lambda$ there appears to be considerable scope for improving the efficiency of health care provision for mHRPC patients; there is considerably more value associated with conducting further research than investing in implementation strategies but both are potentially worthwhile. 


\section{Sensitivity analysis}

Implications of varying the (number of) treatments being compared. Figure 6.3 shows the CEAF, pEVPI, pEVPIM and pEVP as a function of $\lambda$, considering only the three most routinely used treatments of mHRCP: D + P ( 3 weekly), M + P and P. Compared with a plausible range of eight treatment options (see Figure 6.2), there is less uncertainty, with the same decision switch point, associated with identifying the optimal option from three treatment regimens. Consequently, the maximum expected return to further research (pEVPI) is less. As we consider the most routinely used treatment regimens and assume no change in their implementation into clinical practice, the pEVPIM remains relatively constant and hence the combined measure of the expected maximum return to resources committed to further research and/or implementation strategies (pEVP) is also reduced. Given a $\lambda$ of $£ 30,000$ per QALY, the pEVPI, pEVPIM and pEVP are $£ 6.8$ million, $£ 1.6$ million and $£ 8.4$ million, respectively. Evidently, by limiting their decision options, decision makers might underestimate the uncertainty surrounding the decision about which treatment to reimburse. The formal quantification of the reduction in decision uncertainty in terms of diminished expected value of acquiring additional information might be misleading, veiling that there is a clear risk of omitting cost-effective treatments options and making inappropriate decisions about the use of health care resources.

Implications of varying other decision parameters. In addition, we performed various sensitivity analyses, not reported here, to examine the influence of the levels of implementation, the resulting uncertainty surrounding the reimbursement decision, the differences in the expected net benefits between treatment options, and the size of the eligible patient population on the expected population values of information and implementation. Evidently, varying the levels of implementation did not change the expectations regarding the decision about which treatment to reimburse or the question of whether to gather more information to inform this decision. Nevertheless, a reduction or increase in the level of adherence to the cost-effective treatment options $(\mathrm{M}+\mathrm{P}$ or $\mathrm{D}+\mathrm{P}$ [3 weekly]) implied larger or lower monetary payoffs from investments in implementation strategies to change clinical practice, respectively. Changes in the degree of uncertainty surrounding the reimbursement decision only impacted on the maximum expected return to further research - the pEVPI increased or decreased dependent on the set of unknown parameters $\theta$; the decision about which treatment regimen to reimburse remained unchanged. Varying the extent of the expected incremental net benefits of the different options to treat mHRPC altered the amplitude of all curves and shifted the decision switch point (i.e. the ICER). Variations in the size of the eligible patient population affected only the altitude of the curves, i.e. the larger the population for whom decisions are relevant, the larger the values of pEPVI, pEVPIM and pEVP. 
Figure 6.3 Cost-effectiveness acceptability frontier (CEAF) (primary axis), and population expected values of perfect information (pEVPI), perfect implementation ( $p E V P I M)$ and perfection ( $p E V P$ ) (secondary axis) for the adoption decision between the three most routinely used treatment regimens for mHRPC (mHRPC: metastatic hormone-refractory prostate cancer)

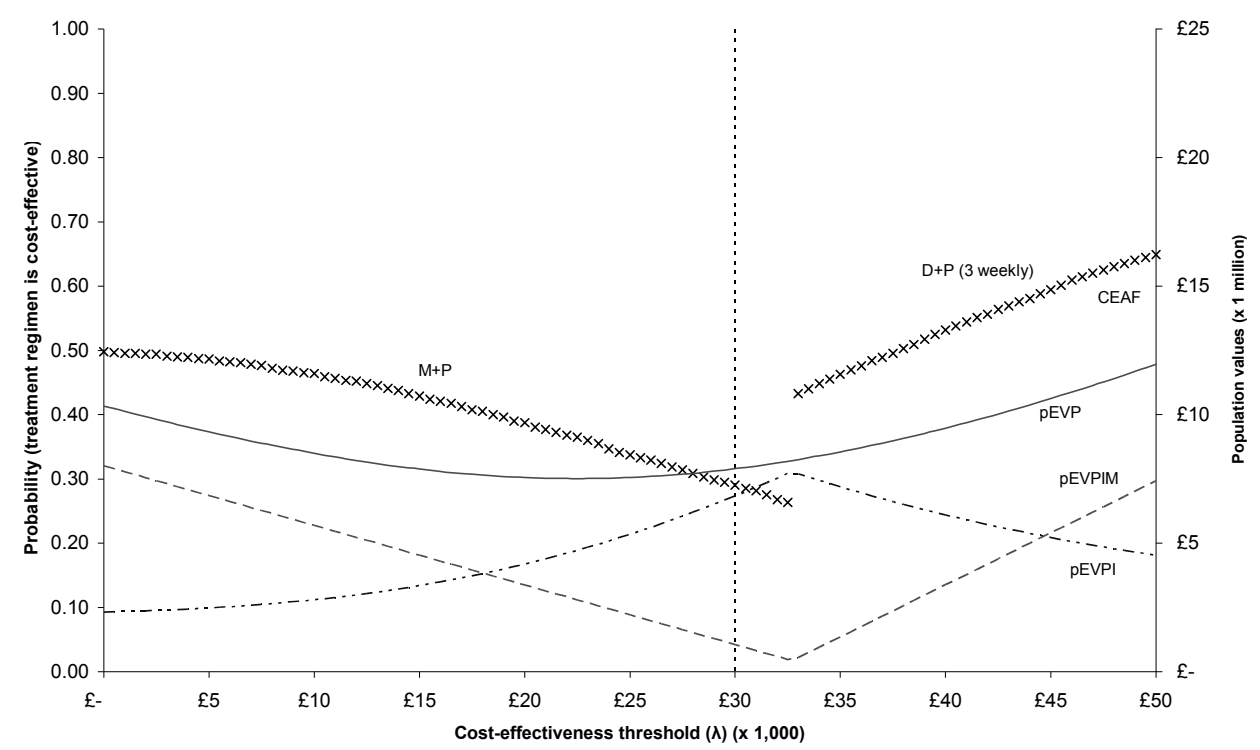

In general, the results of the sensitivity analyses indicated that it is important for decision makers to consider uncertainty and variation in decision parameters when making resource allocation decisions and to include all possible treatment alternatives, even those that are not expected to be cost-effective.

\subsection{Discussion}

Main findings of the analysis. In order to provide an efficient allocation of health care resources for mHRPC in the UK, we applied an analytic framework [22], which informs the separate but related decisions about: (1) treatment reimbursement; (2) research funding; and (3) implementation investment. Depending on the cost-effectiveness threshold $(\lambda)$, we identified mitoxantrone plus prednisone/prednisolone $(\mathrm{M}+\mathrm{P})$ and docetaxel plus prednisone/prednisolone ( $\mathrm{D}+\mathrm{P}$ [3 weekly]) (for a $\lambda$ of $£ 32,706$ per QALY) as the optimal treatments for mHRPC patients. The use of the six other chemotherapy and non-chemotherapy treatment options considered are found not to be costeffective. As illustrated in the CEACs and CEAF, the reimbursement decision is associated with a large degree of uncertainty. This decision uncertainty is formally quantified in the expected population value of perfect information (pEVPI), indicating an esti- 
mated maximum return to acquiring additional economic evidence on the range of plausible treatment options of $£ 13.4$ million (given a $\lambda$ of $£ 30,000$ per QALY). Considering the current variation in clinical practice and a $\lambda$ of $£ 30,000$ per QALY, there is potentially additional value associated with enhancing adherence by health care professionals to the cost-effective treatment regimen(s) $(\mathrm{M}+\mathrm{P}$ or $\mathrm{D}+\mathrm{P}$ [3 weekly]), with the expected population value of perfect implementation (pEVPIM) estimated to be $£ 4.4$ million. Providing a combined measured of the total opportunity losses due to inefficiencies in health care services delivery, the expected value of perfection (pEVP) of $£ 17.7$ million underlines that there is considerable scope for improvement.

Use and interpretation of the main findings. Although the pEVPI and pEVPIM indicate that there is substantially more value associated with acquiring additional information than with ensuring the implementation of optimal treatment regimens for mHRPC, the costs of further research and that of specific implementation strategies need to be taken into account when deciding about the allocation of scarce health care resources for research and/or implementation purposes. That is, to establish the potential worth of research funding and/or investments in implementation, the total research and implementation costs need to be estimated and balanced against the pEVPI and pEVPIM, respectively. Assuming that research costs do not exceed the pEVPI (estimated to be over $£ 13$ million), it is potentially cost-effective to fund further research to reduce uncertainty surrounding the decision about mHRPC treatment reimbursement. In addition, if the expected costs of implementation strategies to change guidance adherence by health care professionals are less than the pEVPIM (estimated to be over $£ 4$ million), then it is potentially cost-effective to ensure the implementation of cost-effective health care technologies into clinical practice. Given a $\lambda$ of $£ 30,000$ per QALY, we would recommend reimbursement of $\mathrm{M}+\mathrm{P}$ alongside commissioning of further research and investment in implementation efforts for improving the efficiency of health care services delivery for mHRPC patients.

Through sensitivity analyses, we found that the valuations for the pEVPI, pEVPIM and pEVP are mainly driven by $\lambda$, the number of (plausible) treatment options being considered, the current level of implementation and the size of the eligible patient population. Consequently, resource allocations decisions will be substantially different for different health care technology decisions.

Use and practicality of the framework. The application demonstrates that the framework provides a simple and useful decision analytic tool for decision makers to address resource allocation problems between health care provision, further research and adopting implementation strategies. It allows decision makers to establish the potential worth (quantified in terms of value of information and value of implementation) of alternative uses of health care resources in an explicit and transparent way. By altering the framework parameters and/or assumptions, the analytic framework will be appli- 
cable to different localities, involving varying settings, patient populations, and health care technologies, costs and effects data, and implementation levels. Of course, in applying the framework to appropriately inform resource allocation decisions, it remains important that decision makers follow methodological guidelines for health economic evaluation, including economic evaluation design, data collection, and data analysis and interpretation of results $[1,2,5]$. Although the analytic framework might aid any decision maker facing problems concerning resource allocation, its most valuable application seems to be in informing policy decisions about the efficient use of health care resources at a health care system level for (national) decision making bodies such as NICE or even (international) pharmaceutical companies.

Limitations of the framework. Notwithstanding the practical significance and merits of the framework, some comments have to be made when using it and interpreting the results for resource allocation decision making. First, controversy exists about whether reimbursement decisions should be based only on the mean net benefits, irrespective of whether differences are statistically significant or fall outside a Bayesian range of equivalence [23]. Eckermann and Willan [25] have recently demonstrated that the EVSI is reduced by the costs of reversal with technology reimbursement and trialling. Consequently, they argue that optimal trial design and decision making in a common case of interest (where there is evidence of positive but uncertain net benefit of a health care technology) requires consideration of the option to delay decisions about reimbursement and trial as well as reimbursing and trial, despite opportunity costs of delay. Second, it is reiterated that the framework establishes only the necessary conditions for deciding on acquiring more information and/or ensuring implementation, providing an indication of whether such investments have the potential to be worthwhile. The sufficient condition for efficient resource allocation requires the valuation and comparison of the expected benefits (i.e. EVSI and EVSIM) and expected costs associated with specific investments in further research [7,8,23-25] and/or implementation strategies $[26,27]$. Finally, within the framework, it is assumed that the current level of implementation (i.e. adherence to guidance) is fixed and known and that no relationship exists between the level of information and that of implementation. This is clearly an oversimplification for the purposes of introducing the framework. More realistically, it is likely that the level of implementation is a function of the level of information and that the provision of information would alter the adherence to health care technology guidance, for instance through publication of research evidence. It is important to notice that this is not necessarily a straightforward relationship where more information leads to better levels of implementation. Situations could be envisaged where more information could lead to less implementation, for example when health care professionals react to new information that suggests a treatment option is effective while ignoring the information that the treatment is not cost-effective. 
Suggestions for framework extension. There are several ways in which the framework could be extended to account for its limitations. First of all, decision making could potentially be improved by allowing for the cost of reversal within the framework and incorporating an explicit ordering of preferences for technology reimbursement between the viable options: (1) to delay and research; (2) to reimburse and research; and (3) to reimburse with no research. This approach has been described in more detail by Eckermann and Willan [25]. Second, it is also possible that technology reimbursement has an impact on the prospects of acquiring certain types of evidence to support its use in the future, because the incentives to conduct evaluative research are removed and even if public resources are made available, further experimental research may be regarded as unethical. Therefore, the decision to reimburse a technology ought to take account of both the value of reimbursing the technology (i.e. its mean net benefit) and the value of the type of evidence (e.g. evidence of the relative effect that would require experimental design) that may be forgone [28]. A third suggestion for extension would be for the framework to set out both the necessary and sufficient conditions for informing the research and implementation decision. That is, the EVPI could be calculated for individual or various combinations of parameters to assess the potential worth of research concerning particular elements of the decision (so called partial EVPI or EVPPI) $[3,23]$. Moreover, the value of information framework could be extended to establish the EVSI in order to identify whether specific research is cost-effective and/or to aid in efficient research design. In the same manner, the value of implementation framework could be extended to determine the expected worth of specific implementation strategies (through EVSIM) and/or to aid in the design of efficient strategies to improve implementation. Finally, the framework could be adapted to incorporate the functional and dynamic relationship between the level of information and the level of implementation of health care technologies and to include the uncertainty about the adherence to technology guidance. For the suggested extensions to be included within the framework, it would need to be expanded beyond the simple four-state world presented here, to allow for post-information and post-implementation states which are less than "perfect”.

Conclusions. In a budget constrained health care system, decisions regarding investment in implementation strategies must be made alongside those regarding investment in health care provision and further research. We demonstrate that the application of the framework developed by Fenwick et al. [22] could aid decision makers in addressing complex issues of priority setting and resource allocation. 


\section{References}

1. Drummond M, Sculpher M. Common methodological flaws in economic evaluations. Med Care 2005;43(7 Suppl):5-14.

2. Sculpher MJ, Claxton $\mathrm{K}$, et al. Whither trial-based economic evaluation for health care decision making? Health Econ 2006;15(7):677-87.

3. Fenwick E, Palmer S, et al. An iterative Bayesian approach to health technology assessment: application to a policy of preoperative optimization for patients undergoing major elective surgery. Med Decis Making 2006;26(5):480-96.

4. Willan A, Briggs A. Statistical analysis of cost-effectiveness data. West Sussex, England: John Wiley \& Sons Ltd; 2006.

5. Drummond MF, Sculpher MJ, et al. Methods for the economic evaluation of health care programmes. 3rd edition ed. Oxford: Oxford University Press; 2005.

6. Claxton K, Posnett J. An economic approach to clinical trial design and research priority-setting. Health Econ 1996;5(6):513-24.

7. Claxton K. The irrelevance of inference: a decision-making approach to the stochastic evaluation of health care technologies. J Health Econ 1999;18(3):341-64.

8. Claxton K, Neumann PJ, et al. Bayesian value-of-information analysis. An application to a policy model of Alzheimer's disease. Int J Technol Assess Health Care 2001;17(1):38-55.

9. Sculpher M, Claxton K. Establishing the Cost-Effectiveness of New Pharmaceuticalsunder Conditions of Uncertainty-When Is There Sufficient Evidence? Value Health 2005;8(4):433-446.

10. Grol R, Grimshaw J. From best evidence to best practice: effective implementation of change in patients' care. Lancet 2003;362(9391):1225-30.

11. Cabana MD, Rand CS, et al. Why don't physicians follow clinical practice guidelines? A framework for improvement. JAMA 1999;282(15):1458-65.

12. Eccles M, Grimshaw J, et al. Changing the behavior of healthcare professionals: the use of theory in promoting the uptake of research findings. J Clin Epidemiol 2005;58(2):107-12.

13. Drummond $M$, Weatherly $H$. Implementing the findings of health technology assessments. If the CAT got out of the bag, can the TAIL wag the dog? Int J Technol Assess Health Care 2000;16(1):112.

14. Freemantle N. Implementation strategies. Fam Pract 2000;17 Suppl 1:S7-10.

15. Severens JL. Value for money of changing healthcare services? Economic evaluation of quality improvement. Qual Saf Health Care 2003;12(5):366-71.

16. Mason J, Wood J, Freemantle N. Designing evaluations of interventions to change professional practice. J Health Serv Res Policy 1999;4(2):106-11.

17. Sculpher M. Evaluating the cost-effectiveness of interventions designed to increase the utilization of evidence-based guidelines. Fam Pract 2000;17 Suppl 1:S26-31.

18. Mason J, Freemantle N, Nazareth I, et al. When is it cost-effective to change the behavior of health professionals? JAMA 2001;286:2988-92.

19. Gandjour A, Lauterbach KW. When is it worth introducing a quality improvement program? A mathematical model. Med Decis Making. 2003;23:518-25.

20. Grimshaw JM, Thomas RE, et al. Effectiveness and efficiency of guideline dissemination and implementation strategies. Health Technol Assess 2004;8:iii-iv, 1-72.

21. Hoomans T, Evers SMAA, et al. The methodological quality of economic evaluations of guideline implementation into clinical practice: a systematic review of empiric studies. Value Health 2007;10(4):305-16.

22. Fenwick E, Claxton K, Sculpher M. The value of implementation and the value of information: combined and uneven development. Med Decis Making 2008;28(1):21-32. 
23. Claxton K, Fenwick E, Sculpher M. Decision-making with uncertainty: the value of information. In: Jones AM, editor. Elgar Companion to Health Economics. Cheltenham: Elgar Publishing; 2006. p. 514-25.

24. Willan AR, Pinto EM. The value of information and optimal clinical trial design. Stat Med 2005;24(12):1791-806.

25. Eckermann S, Willan AR. Expected value of information and decision making in HTA. Health Econ 2007;16(2):195-209.

26. Hoomans T, Ament AJHA, et al. Worthwhile implementation of evidence-based guidelines into clinical practice: how to determine the investment potential for guideline implementation and value for money of implementation strategies? (Abstract). Presented at the International Health Economics Association 6th World Congress, Copenhagen, Denmark, 2007.

27. Hoomans T, Ament AJHA, et al. Stochastic application of model for informing resource allocation decision making about the implementation of clinical practice guidelines in diabetes care (Paper). Presented at the Health Economics Study Group, Norwich, UK, 2008.

28. Griffin S, Claxton K, et al. Dangerous omissions: the consequences of ignoring decision uncertainty (Abstract). Presented at the International Health Economics Association 6th World Congress, Copenhagen, Denmark, 2007.

29. Ades AE, Lu G, Claxton K. Expected value of sample information calculations in medical decision modeling. Med Decis Making. 2004;24(2):207-27.

30. Eckermann S, Willan AR. Time and Expected Value of Sample Information Wait for No Patient. Value Health 2008;11:522-526.

31. Grol R, Buchan H. Clinical guidelines: what can we do to increase their use? Med J Aust 2006; 185(6):301-2.

32. Foy R, Eccles MP, et al. What do we know about how to do audit and feedback? Pitfalls in applying evidence from a systematic review. BMC Health Serv Res 2005;5:50.

33. Shekelle P, Eccles MP, et al. When should clinical guidelines be updated? BMJ 2001;323(7305): 155-7.

34. Willan AR. Analysis, sample size, and power for estimating incremental net health benefit from clinical trial data. Control Clin Trials 2001;22(3):228-37.

35. Stinnett AA, Mullahy J. Net health benefits: a new framework for the analysis of uncertainty in cost-effectiveness analysis. Med Decis Making 1998;18(2 Suppl):S68-80.

36. Cancer Research UK. CancerStats. Available from http://info.cancerresearchuk.org/cancerstats/types/prostate/ [Accessed July, 2008].

37. Eisenberger MA, Blumenstein BA, et al. Bilateral orchiectomy with or without flutamide for metastatic prostate cancer. N Engl J Med 1998;339(15):1036-42.

38. Petrylak DP. Chemotherapy for androgen-independent prostate cancer. Semin Urol Oncol 2002; 20(3 Suppl 1):31-5.

39. Collins R, Fenwick E, et al. A systematic review and economic model of the clinical effectiveness and cost-effectiveness of docetaxel in combination with prednisone or prednisolone for the treatment of hormone-refractory metastatic prostate cancer. Health Technol Assess 2007;11(2):1-198.

40. Fenwick E, Claxton K, Sculpher M. Representing uncertainty: the role of cost-effectiveness acceptability curves. Health Econ 2001;10(8):779-87.

41. Eckermann S, Briggs A, et al. Health technology assessment in the cost-disutility plane. Med Decis Making. 2008;28(2):172-81. 
7 General Discussion 


\section{I Introduction}

Given the limited resources available for health care services delivery, decision makers need to use considerable judgement about whether guideline implementation to change clinical practice is likely to be worthwhile. Considering the importance of rigorous evaluations and sound evidence as a basis for resource allocation decision making under conditions of uncertainty, this thesis explored the economics of clinical practice change, and advanced methods for economic evaluation of implementing clinical guidelines.

In summary, it is advocated that when deciding about whether and how to change clinical practice, decision makers should not only consider evidence on the likely costeffectiveness of clinical guidelines but also provide careful estimates of the size of the patient population targeted, baseline guideline adherence, and resources needed to implement the guidance. Decisions about the adoption of clinical guidelines and that of implementation strategies should be made simultaneously rather than sequentially, based on the overall value for money of clinical practice change. As both adoption decisions are inevitably undertaken in a context of uncertainty concerning the economic data on the guidance and its implementation, it is also relevant to decide whether it is worthwhile collecting additional information to reduce decision uncertainty. A set of analytic methods was developed that allows decision makers to establish the economic impact of non-adherence to evidence-based guidance, the investment potential for its implementation, the value for money of implementation strategies and that of guidance implementation, and the value of information. The advanced economic methodology aids in generating valuable information to inform the separate but related decisions about health care provision, investments in implementation and research funding in a unified, comprehensive and transparent manner.

This chapter first outlines the main findings of the thesis and its contribution to science and decision making. Next, some considerations related to the research are addressed. Finally, recommendations for further research and implications for decision making are offered and some concluding remarks are drawn.

\subsection{Main findings}

As a possible reflection of the growing importance of the value for money of providing health care, a systematic review revealed an increase in economic evaluations of implementing guidance to change clinical practice (see Chapter 2). Nonetheless, the economic appraisals were judged to lack methodological rigour, partly resulting from biases in guidance for guideline implementation evaluation, particularly related to data collection and decision analysis. Because of the heterogeneity and poor methodological 
quality of the empiric studies, the resulting evidence is found to be of limited use in decision making about resource allocation.

Chapter 3 comprehensively illustrated that, in most cases, an integral approach to deciding about clinical practice change (i.e. choosing guidelines and strategies simultaneously on the basis of the overall value for money of guideline implementation) is preferred over a sequential approach, providing an efficient use of resources. To establish consistent estimates of the combined worth of changing clinical practice, information is needed on the costs and effects of clinical guidance, the baseline adherence to the guideline, the impact of implementation efforts on guidance adherence and resource utilisation, and the scale factors specific to the clinical context.

In Chapter 4, a model is presented for exploring the scope of cost-effective practice change, establishing: (a) the economics of suboptimal practice; (b) the resources available and necessary for implementing clinical guidance; (c) the value for money of changing clinical practice. Adopting a total net benefit approach in which monetary values are assigned to health outcomes and economic evidence on guidelines and their implementation is combined with information on clinical practice, the model allows priority setting in multiple instances of suboptimal practice, and overcomes problems with ratio statistics [1-4], e.g. when comparing multiple guidelines and multiple strategies across different clinical settings or when analysing decision uncertainty concerning the implementation of clinical guidance. Whether investing in clinical practice change makes economic sense appeared to be affected by the cost-effectiveness threshold $\lambda$, the guideline adherence at baseline, the size of the patient population and the cost of implementation.

In Chapter 5, its stochastic application in diabetes care demonstrated that the model provides a simple and useful tool for quantifying and exploring the (combined) uncertainty associated with decision making about adopting guidelines and implementation strategies and, therefore, for informing decisions about the efficient allocation of resources to change clinical practice under conditions of uncertainty. In addition to costeffectiveness planes, cost-effectiveness acceptability curves and frontiers showed to be useful in representing and interpreting decision uncertainty. In effect, decision uncertainty about guideline implementation appeared to increase by simultaneously incorporating uncertain evidence on the efficiency of both guidance (including information about baseline guideline adherence) and implementation strategies, and comparing multiple options to change practice.

Alongside exploring the economics of clinical practice change and deciding about the adoption of guidance and/or implementation strategies, decision makers should carefully consider the (potential) worth of further research to reduce decision uncertainty. Chapter 6 illustrated the use and practicality of an analytic framework [5] to establish both the expected value of implementation (i.e. the maximum total investment potential for guideline implementation) and that of information (i.e. the upper bound on the value of collecting additional evidence) in allocating resources to prostate 
cancer in the United Kingdom. The sum of both measures provides an indication of the total opportunity losses due to inefficiencies in health care services delivery, and the potential scope for efficiency improvement. As such, the framework demonstrated to have the potential to address the separate but related decision problems between health care provision, implementation investment and research funding in a unified, comprehensive and transparent manner.

\subsection{Contribution to science and decision making}

The core value of this research is two-fold. First, the work contributes to advancing methodology for exploring the economics of changing clinical practice, addressing some important methodological issues raised in implementation research concerning data collection, decision analysis and handling decision uncertainty (see Chapter 1). A set of analytic methods is established that may aid in designing plus conducting implementation research, and analysing plus interpreting research findings. Second, this thesis addresses the importance and relevance of both considering economic implications and conducting rigorous evaluations when deriving recommendations for clinical practice change. In effect, sound comprehensive economic analysis, incorporating emerging evidence and applying advanced methodology, may help decision makers to justify the widespread use of clinical guidelines and/or implementation strategies for improving suboptimal practice.

By adopting a broadly based decision analytic approach, the use of the advanced methods seems not necessarily restricted to economic evaluations of implementing clinical guidelines. That is, the methods are likely to apply to economic appraisals of any intervention or programme being considered to improve health care but requiring implementation-related activities or technologies. Although it is becoming widely accepted to consider efficiency of health care services delivery, particularly in an implementation-related context, from a wider viewpoint of society, any perspective of analysis (e.g. that of a health care provider, a health care institution or a third-party payer) can be adopted, and the methods are easily applicable to different health care areas and localities. The scope of economic analysis (e.g. local, regional, national or international) can be varied to project a particular decision maker's jurisdiction, population and information needs. Moreover, the methods seem to fit in and/or combined with existing methods and guidelines for health economic evaluation [6-11] and implementation research $[12,13]$. 


\subsection{Some considerations}

Besides the contributions to advancing economic methodology and aiding decision making, there are several comments to be made to this research and its main findings, which concern: (i) the collection of economic evidence on guidance and strategies to change clinical practice; (ii) the use of theory and knowledge of behavioural change in decision modelling; and (iii) the methodological issues related to implementation design and empiric research.

\subsection{Economic evidence on clinical guidelines and/or implementation strategies}

Notwithstanding the increased prominence for comprehensive decision modelling as a vehicle for economic analysis of clinical practice change, trial-based studies remain the primary source for generating unbiased estimates of the relative effects and costs of the guidelines and implementation strategies being compared [6,14,15]. As this thesis concentrated on advancing economic methodology, particularly related to decision modelling and evidence synthesis, no attempt was made to collect data contributing to the evidence base to inform decision making. Overall, empiric findings [16-18] suggest that implementing clinical guidance could lead to (modest) changes in clinical behaviour and (moderate) improvements in processes of care, with guidelines being more likely to be effective if they are adapted to the local clinical context and implemented by means of educational activities and patient specific reminders. Nonetheless, it has been shown that there is a paucity of data on the cost and efficiency of the different methods of guideline implementation $[16,19,20]$. In effect, for many areas of clinical care, robust evidence on the cost-effectiveness of clinical interventions is not available and few guidelines have incorporated economic considerations when deriving recommendations $[16,21]$. The collection of more useful and reliable economic data on both guidelines and strategies, preferably using rigorous evaluative designs tailored to specific decision problems (i.e. concerning specific clinical settings and target groups), is definitely required prior to any substantive investment in changing clinical practice [22].

\subsubsection{Theory and knowledge of behavioural change}

Decision makers could be better informed about the economic consequences of change in clinical practice if it were possible to understand whether and how the costs and effects of implementation efforts vary across type of targeted behaviour, type of health care professional or patient, and clinical context $[12,16]$. The various modelling exercises in this thesis did not account for (non-)modifiable factors [23-28], like the characteristics of the guideline, the attitude and knowledge of professionals and patients or the organisational characteristics of the implementation setting, that influence the efficiency of implementing clinical guidance. More evidence and a better theoretical under- 
standing of these factors and their influence on patient, health care professional and organisational behaviour and change therein would allow the models to have more predictive value and establish the expected worth of intervening in instances of suboptimal practice, e.g. through extrapolation of economic data, linking intermediates to end points or adapting economic data from one setting to another.

\subsubsection{Implementation design and empiric research}

Given that both theories and research findings show that any simple approach to changing clinical practice is not consistently cost-effective, successful implementation of clinical guidance needs well developed, well executed and sustained implementation programmes $[12,16,18,19]$. Several authors proposed an integrated approach to such comprehensive programmes, linking the different phases of the implementation process (i.e. problem analysis, programme design and evaluation), and integrating theories and scientific evidence in this process $[18,29]$. With different methods being used in each phase, this thesis did not address (methodological) issues related to the phases other than (long term) programme evaluation. Such issues include: the structuring of a considered judgment process in formulating guideline recommendations [30]; the structuring and formalising of the process of evaluation (including the development of accurate and acceptable measures) [31]; and the design, conduct and analysis of implementation trials [29,32-35]. Nonetheless, it seems valuable to fit in the advanced methodology in the (proposed) integrated approach to design and evaluation of clinical practice change, and further elaborate on the complementary use of trial-based studies and modelling in implementation research.

\subsection{Recommendations for further research}

In order to extend the use of the methodological advancements for evaluating and deciding about guideline implementation to change clinical practice, there remain several research-specific issues to be solved. These issues relate to: (1) the potential advances in modelling (i.e. concerning the impact of patterns in guidance adherence, the effect of combined strategies, and the rigour and transferability of evidence); (2) the handling of decision uncertainty and value-of-information analysis; and (3) the assessment of the validity, quality and practicality of the analytic methods.

\subsection{Advanced modelling: impact of patterns in guidance adherence}

Within current models for exploring the economics of change in clinical practice [1$4,36,37]$, the level of guideline adherence and patterns therein are assumed to have no impact on the expected value for money of implementation strategies and that of guide- 
line implementation. As such, the models do no justice to the complex reality of the implementation process.

More realistically, it is likely that it will bring increasing implementation cost with increasing adherence to clinical guidance, and that there will be a maximum (or ceiling) rate to (change in) adherence by health care professionals and patients [16]. Moreover, the models do not allow for changes and trends in the adherence to clinical guidelines, caused by factors such as the durability of implementation effects and the shape of any learning curves. Given the plausible patterns in guidance adherence and the varying scope of guideline implementation (also dependent on the number of practices, professionals and patients targeted), it is also debatable whether the (marginally variable) costs for developing guidelines and strategies, often involving a considerable sum, are to be considered sunk rather than relevant in economic analyses of practice change.

The modelling of a more realistic process of changing clinical practice, taking account of the impact of both patterns (i.e. initial, maximum, change and trends) in guidance adherence and scope of activities on the costs and effects of implementing clinical guidelines, requires further investigation in behaviour and behavioural change by patients, health care professionals and organisations. Alongside the use of insights from (multidisciplinary) theories, behavioural patterns could be detected by monitoring behaviour over time, e.g. through continuous, sequential measurements of outcome variables throughout the intervention periods of trials [22].

\subsubsection{Advanced modelling: effect of combinations of implementation strategies}

To address a larger variety of factors that influence the use of guidance in clinical practice, often a combination (or sequence) of implementation strategies (compromising two or more strategies) is adopted. Nonetheless, combined or multifaceted strategies do not necessarily appear to be more cost-effective than single strategies, and the impact of various implementation strategies are not likely to be additive [16]. For the modelling of the economics of implementing clinical guidelines to be of more (predictive) value in informing decision making, it seems important to unravel the synergetic (or nonsynergetic) effects of combining implementation activities. This inevitably requires more evidence and knowledge of the nature and complexity of behaviour and behavioural change, its important moderators, the important modifiable mediators of behaviour, and the size and direction of the impact of the components of implementation strategies to change these.

\subsubsection{Advanced modelling: rigour and transferability of evidence}

Ideally, economic analysis of clinical practice change is based on all available evidence on the guidance and its implementation [15]. In the face of the design and statistical issues in implementation research $[29,32,33,35]$, it is advocated to use information 
from other sources than randomised controlled trials (e.g. non-randomised, quasiexperimental designs, observational studies or expert opinions) and different clinical settings (i.e. varying localities, evidence-based messages, treatments or diseases). To minimise potential systematic biases and maximise applicability of data to address specific decision problems for defined populations (i.e. patients and professionals) and contexts, considerations need to be made for the rigour and transferability of evidence [38]. Such considerations have not explicitly been made within the advanced methods of this thesis.

Imperfections in the design and conduct of research, and generalisation to other decision contexts may be approached by adopting more complex models and/or the explicit modelling of bias [38]. The transferability of economic findings requires careful exploration of variations in resource implications, unit prices and health outcomes, adjustments for baseline risks and potentially (statistical) hierarchical or multilevel data modelling [39-41]. It has also been suggested adjusting for differences between study and target populations [1].

It seems evident that handling non-robust and heterogeneous data would fit most comfortably in a Bayesian decision analytic framework [6,38], with analysis of sensitivity to modelling and other assumptions being a useful technique. Nonetheless, it seems worth to explore the use of advanced Bayesian methods that permit the adjustment for baseline adherence rates, the modelling of intermediate or surrogate outcomes (e.g. guidance adherence), and the incorporation of meta-regression or subgroup analysis (see also Chapter 5).

\subsubsection{Decision uncertainty and value of information}

Although the decisions about whether to adopt guidelines and/or implementation strategies are central to most decision makers, they also ought to consider to role of uncertainty in the decision process: adoption decisions are inevitably made under conditions of uncertainty, and there is potential worth in collecting additional information to reduce decision uncertainty [7]. It seems valuable to provide an integral approach to deciding about adoption and setting research priorities in an implementation-related context using Bayesian decision theory and value-of-information analysis.

The analytic model developed in Chapter 5 and that by Fenwick et al. [5] seem complementary, and could be merged into one single, unified framework to establish the investment potential for implementing clinical guidance, the value for money of implementation strategies and that of guidance implementation, and the value of information. For the advanced framework to better inform resource allocation decisions, however, there remain several methodological challenges (see also Chapter 6), among others things, relating to (i) the interaction between the adoption decisions and research decisions (i.e. allowing for technology reversal costs and disincentives for further research); (ii) the impact of information provision on the adherence to guidance (e.g. 
through publication of research findings); and (iii) the calculation of the expected value of partial perfect information (EVPPI), the expected value of sample information (EVSI) and the expected net benefit of sampling (ENBS).

In prioritising research opportunities, a clear distinction should be made between investing in guideline research and that in implementation research. In Chapter 5, a first attempt was made to conduct (partial) analyses of the construct and extent of decision uncertainty and the value of information for the different sources of evidence. This is done by providing comprehensive overviews of cost-effectiveness acceptability curves for the (individual and combined) components of practice change (i.e. guidance, implementation strategies and guideline implementation). The quantification and exploration of uncertainty in economic evaluation, and its use in decision making, is likely to continue to be an area of methodological interest in the future, especially in the context of implementation research.

\subsubsection{Validity, quality and practical use of analytic methods}

While advanced methodology can provide a valuable framework for economic evaluation of guideline implementation to change clinical practice, it is important to underline that the different evaluative methods are concerned with informing specific decision problems and their analytic findings are conditional on data (e.g. concerning the rigour and transferability of evidence) and structural assumptions (e.g. relating to the use of cost-effectiveness thresholds and the relationship between costs and effects) [9]. In order to promote their use in decision making processes, it is important that the methods and models are formally assessed against standards for structure, data and consistency [42-46]. The different evaluative methods in this thesis were merely comprehensively tested, primarily using hypothetical or stylised examples, and their practical significance and merits in informing actual decisions are not yet fully demonstrated. Ideally, the quality, use and practicality of the advanced methods are demonstrated using realworld, prospective empirical case studies. The citing of actual, real-world examples is believed to illustrate the arguments for the use of the methodology in a more compelling and tangible manner, underlining their importance for decision makers in decision making practice.

\subsection{Implications for decision making}

Notwithstanding the advances in economic methodology for evaluating change in clinical practice, the analytic methods have yet to be widely adopted within the field of economic evaluation and decision making in health care. Dissemination and implementation efforts should not only be targeted at decision making bodies and policy makers but also at research institutes and researchers, the academic community and students, 
health care institutions, health care professionals and patients, and maybe even the general public. An important aim is to educate the targeted audience when and how to use the methods and methodological guidance, emphasising that the economic methodology is of use in conducting evaluations, judging evidence, and commissioning research.

A first step in the 'implementation' process is the publication of this thesis and the separate articles, the presentation of the methods at (international) conferences, and the communication of their potential use through various media. Besides disseminating the methods, further steps to ensure their implementation might include the distribution of educational materials, the uptake of material in (academic) courses (or curricula) and workshops, and the organisation of outreach visits and invitational seminars or stakeholder meetings. A promising idea seems to develop a (standardised) manual for evaluating and deciding on clinical practice change, incorporating the advanced methodology with existing methods and guidelines on health economic evaluation (e.g. [6$11,38])$. The scope of this manual should be kept as broad as possible, and the methods need to be transparent, comprehensible and adaptable to local circumstances and specific decision problems.

In most legalisations, the financing of care provision, investing in implementation and commissioning of research is done by separate institutional bodies. The complete integration of the advanced methodology, providing guidance on these three separate but related issues in a unified way, in decision making practice might therefore require reorganising the infrastructure for health care, policy analysis and research at system level [47]. Health ministries, governmental agencies and other institutional bodies involved should be encouraged to structure and formalise the use of the evaluative methods as part of the formal process of assessment and reimbursement of health care technologies.

\subsection{In conclusion}

In a budget constrained health care system, decision makers need to carefully decide about resource allocation between the adoption of guidelines, the adoption of implementation strategies and the funding of research to change clinical practice. This thesis provides a set of analytic methods, complementary to the established economic methodology, which could serve as a guide in the design, analysis and interpretation, and funding of economic evaluations to inform these separate but related decisions. The advanced methodology allows decision makers to explore: (a) the economic impact of suboptimal practice; (b) the resources available and necessary for implementing clinical guidance; (c) the value for money of clinical practice change; and (d) the uncertainty associated with deciding about guideline implementation and the expected value of collecting additional evidence. To fully exploit the value of the advanced methods for economic evaluation of clinical practice change, it is important that the methodology becomes widely accepted and routine in the actual decision making processes. 


\section{References}

1. Gandjour A, Lauterbach KW. When is it worth introducing a quality improvement program? A mathematical model. Med Decis Making 2003;23(6):518-25.

2. Gandjour A, Lauterbach KW. How much does it cost to change the behavior of health professionals? A mathematical model and an application to academic detailing. Med Decis Making 2005; 25(3):341-7.

3. Mason J, Freemantle N, et al. When is it cost-effective to change the behavior of health professionals? JAMA 2001;286(23):2988-92.

4. Mason JM, Freemantle N, et al. Specialist nurse-led clinics to improve control of hypertension and hyperlipidemia in diabetes: economic analysis of the SPLINT trial. Diabetes Care 2005;28(1):40-6.

5. Fenwick E, Claxton K, et al. The value of implementation and the value of information: combined and uneven development. Med Decis Making 2008;28(1):21-32.

6. Briggs A, Sculpher M, Claxton K. Decision modelling for health economic evaluation. Oxford: Oxford University Outcomes; 2006.

7. Claxton K, Fenwick E, et al. Decision-making with uncertainty: the value of information. In: Jones AM, editor. Elgar Companion to Health Economics. Cheltenham: Elgar Publishing; 2006. p. 51425.

8. Drummond M, McGuire A. Economic evaluation in health care: merging theory with practice. Oxford: Oxford University Press; 2001.

9. Drummond MF, Sculpher MJ, et al. Methods for the economic evaluation of health care programmes. 3rd edition ed. Oxford: Oxford University Press; 2005.

10. Gold MR, Siegel JE, et al. Cost-effectiveness in health and medicine. Oxford: Oxford University Press; 1996.

11. Hunink MGM, Glasziou PP, et al. Decision making in health and medicine : integrating evidence and values. Cambridge etc.: Cambridge University Press; 2001.

12. Grol R, Wensing M, et al. Improving patient care: the implementation of change in clinical practice. London: Elsevier Limited; 2005.

13. Thorsen T, Makela M. Changing professional practice. Theory and practice of clinical guidelines implementation. Copenhagen: Danish Institute for Health Services Research; 1999.

14. Sculpher M, Claxton K. Establishing the cost-effectiveness of new pharmaceuticals under conditions of uncertainty--when is there sufficient evidence? Value Health 2005;8(4):433-46.

15. Sculpher MJ, Claxton $\mathrm{K}$, et al. Whither trial-based economic evaluation for health care decision making? Health Econ 2006;15(7):677-87.

16. Grimshaw JM, Thomas RE, et al. Effectiveness and efficiency of guideline dissemination and implementation strategies. Health Technol Assess 2004;8(6):iii-iv, 1-72.

17. Grol R, Grimshaw J. Evidence-based implementation of evidence-based medicine. Jt Comm J Qual Improv 1999;25(10):503-13.

18. Grol R, Grimshaw J. From best evidence to best practice: effective implementation of change in patients' care. Lancet 2003;362(9391):1225-30.

19. Grol R, Buchan H. Clinical guidelines: what can we do to increase their use? Med J Aust 2006;185 (6):301-2.

20. Hoomans T, Evers SM, et al. The methodological quality of economic evaluations of guideline implementation into clinical practice: a systematic review of empiric studies. Value Health 2007; 10(4):305-16.

21. McIntosh E. Economic evaluations of guideline implementation strategies. In: Thorsen T, Makela M, editors. Changing professional practice: Theory and practice of clinical guidelines implementation. Copenhagen: Danish Institute for Health Services Research and Development; 1999. 
22. Sculpher M. Evaluating the cost-effectiveness of interventions designed to increase the utilization of evidence-based guidelines. Fam Pract 2000;17 Suppl 1:S26-31.

23. Cabana MD, Rand CS, et al. Why don't physicians follow clinical practice guidelines? A framework for improvement. JAMA 1999;282(15):1458-65.

24. Drummond $M$, Weatherly $H$. Implementing the findings of health technology assessments. If the CAT got out of the bag, can the TAIL wag the dog? Int J Technol Assess Health Care 2000;16(1):112.

25. Eccles M, Grimshaw J, et al. Changing the behavior of healthcare professionals: the use of theory in promoting the uptake of research findings. J Clin Epidemiol 2005;58(2):107-12.

26. Foy R, MacLennan G, et al. Attributes of clinical recommendations that influence change in practice following audit and feedback. J Clin Epidemiol 2002;55(7):717-22.

27. Grol R. Improving the quality of medical care: building bridges among professional pride, payer profit, and patient satisfaction. JAMA 2001;286(20):2578-85.

28. Shekelle P, Eccles MP, et al. When should clinical guidelines be updated? BMJ 2001;323(7305): 155-7.

29. Campbell M, Fitzpatrick R, et al. Framework for design and evaluation of complex interventions to improve health. BMJ 2000;321(7262):694-6.

30. Verkerk K, Van Veenendaal H, et al. Considered judgement in evidence-based guideline development. Int J Qual Health Care 2006;18(5):365-9.

31. Sanson Fisher RW, Grimshaw JM, et al. The science of changing providers' behaviour: the missing link in evidence-based practice. Med J Aust 2004;180(5):205-6.

32. Campbell MK, Steen N, et al. Design and statistical issues in implementation research. In: Thorsen $\mathrm{T}$, Makela M, editors. Changing professional practice: Theory and practice of clinical guidelines implementation. Copenhagen: Danish Institute for Health Services Research and Development; 1999.

33. Eccles M, Grimshaw J, et al. Experimental evaluations of change and improvement strategies. In: Grol R, Wensing M, Eccles M, editors. Improving patient care: the implementation of change in clinical practice: Elsevier Limited; 2005.

34. Grimshaw J, Campbell M, et al. Experimental and quasi-experimental designs for evaluating guideline implementation strategies. Fam Pract 2000;17 Suppl 1:S11-6.

35. Mason J, Wood J, et al. Designing evaluations of interventions to change professional practice. J Health Serv Res Policy 1999;4(2):106-11.

36. Hoomans T. Modelling the value for money of clinical practice change: a stochastic application in diabetes care. (submitted for publication).

37. Hoomans T, Evers SM, et al. Whorthwhile implementation of evidence-based guidelines. (submitted for publication).

38. Spiegelhalter DJ, Abrams KR, et al. Bayesian approaches to clinical trials and health-care evaluation. New York: Wiley; 2004.

39. Manca A, Rice N, et al. Assessing generalisability by location in trial-based cost-effectiveness analysis: the use of multilevel models. Health Econ 2005;14(5):471-85.

40. Manca A, Willan AR. 'Lost in translation': accounting for between-country differences in the analysis of multinational cost-effectiveness data. Pharmacoeconomics 2006;24(11):1101-19.

41. Mason JM, Mason AR. The generalisability of pharmacoeconomic studies: issues and challenges ahead. Pharmacoeconomics 2006;24(10):937-45.

42. Anonymous. Decision analytic modelling in the economic evaluation of health technologies. A consensus statement. Consensus Conference on Guidelines on Economic Modelling in Health Technology Assessment. Pharmacoeconomics 2000;17(5):443-4. 
43. Philips Z, Bojke L, et al. Good practice guidelines for decision-analytic modelling in health technology assessment: a review and consolidation of quality assessment. Pharmacoeconomics 2006;24(4):355-71.

44. Philips Z, Ginnelly L, et al. Review of guidelines for good practice in decision-analytic modelling in health technology assessment. Health Technol Assess 2004;8(36):iii-iv, ix-xi, 1-158.

45. Sculpher M, Fenwick E, et al. Assessing quality in decision analytic cost-effectiveness models. A suggested framework and example of application. Pharmacoeconomics 2000;17(5):461-77.

46. Weinstein MC, O'Brien B, et al. Principles of good practice for decision analytic modeling in healthcare evaluation: report of the ISPOR Task Force on Good Research Practices-Modeling Studies. Value Health 2003;6(1):9-17.

47. Claxton K, Cohen JT, et al. When is evidence sufficient? Health Aff 2005;24(1):93-101. 


\section{Summary}

In a budget constrained health care system, decision makers need to carefully decide about resource allocation between the adoption of guidelines, the adoption of implementation strategies and the conduct of research to change clinical practice. This thesis provides a set of analytic methods, complementary to the established economic methodology, which could serve as a guide in the design, analysis, interpretation and funding of economic evaluations to inform these separate but related decisions. Decision making is inevitable undertaken in a context of uncertainty concerning the costs and effects of practice change.

Chapter 2 reviews the use of economic appraisal in evaluations of implementing clinical guidelines, verifying whether the evaluations follow methodological guidance. As a possible reflection of the growing importance of the value for money of providing health care, an increase in economic evaluations was revealed. Nonetheless, the appraisals were judged to lack methodological rigour, partly resulting from biases in guidance for guideline implementation evaluation, particularly related to data collection and decision analysis. The resulting evidence was therefore found to be of limited use in decision making about resource allocation.

Chapter 3 comprehensively illustrates that, in most cases, an integral approach to deciding about change in clinical practice (i.e. choosing guidelines and strategies simultaneously on the basis of the overall value for money of guideline implementation) is preferred over a sequential approach, providing an efficient use of resources. To establish consistent estimates of the combined worth of changing practice, information is needed on the costs and effects of clinical guidance, the baseline adherence to the guideline, the impact of implementation efforts on guidance adherence and resource utilisation, and the scale factors specific to the clinical context.

Chapter 4 presents a model for exploring the scope of cost-effective clinical practice change, establishing (a) the economics of suboptimal practice, (b) the resources available and necessary for guideline implementation and (c) the value for money of implementing clinical guidance. Adopting a total net benefit approach in which monetary values are assigned to health outcomes $(\lambda)$, and economic evidence on guidelines and their implementation is combined with information on clinical practice, the model allows priority setting in multiple instances of suboptimal practice and overcomes problems with ratio statistics, e.g. when comparing a multiplicity of guidelines and strategies across different clinical settings or when analysing decision uncertainty concerning the implementation of guidance. Whether investing in practice change makes economic 
sense appeared to be affected by $\lambda$, the guideline adherence at baseline, the size of the patient population and the cost of implementation.

Chapter 5 demonstrates the stochastic application of the model to inform resource allocation decisions in type 2 diabetes in primary care in the Netherlands. An integrated Bayesian approach to decision modelling and evidence synthesis is adopted for quantifying and exploring the uncertainty associated with decision making. Decisions about whether to adopt the guidance on blood glucose control and whether to adopt audit and feedback for its implementation alter over the range of values for $\lambda$. Through simultaneously incorporating uncertain economic evidence on both guidance and implementation strategy, the decision uncertainty concerning guideline implementation is increased. Using cost-effectiveness plots, curves and frontiers, the model provides a simple and useful tool for quantifying and exploring (combined) uncertainty associated with deciding about adopting guidelines and implementation strategies and, therefore, for informing decisions about efficient resource allocation to change clinical practice.

Chapter 6 illustrates the use and practicality of a Bayesian decision-theoretic analytic framework to establish both the expected value of implementation (i.e. maximum total investment potential for guideline implementation) and that of information (i.e. upper bound on the value of collecting additional evidence) in allocating resources to metastatic hormone-refractory prostate cancer in the United Kingdom. The sum of both measures provides an indication of the total opportunity losses due to inefficiencies in health care services delivery and the potential scope for efficiency improvement of care for patients with prostate cancer. As such, the framework demonstrated to have the potential to address the separate but related decision problems between health care provision, implementation investment and research funding in a unified, comprehensive and transparent manner.

Given constrained health budgets, this thesis addresses the importance and relevance of both considering economic implications and conducting rigorous evaluations when deriving recommendations (concerning guideline adoption, strategy adoption and research funding) for clinical practice change under conditions of uncertainty. Sound comprehensive economic analysis, incorporating emerging evidence and applying advanced methodology, may help decision makers to justify the widespread use of clinical guidelines and/or implementation strategies for improving suboptimal practice. To fully exploit the value of the set of analytic methods for economic evaluation of change in clinical practice, it is important that the methodology becomes widely accepted and routine in actual decision making processes. 


\section{Samenvatting}

In zorgsystemen waarin de financiële middelen beperkt zijn, moeten besluitvormers zorgvuldig beslissen over de verdeling van budget voor verandering van de klinische praktijk. Besluitvorming gebeurt hierbij onder onzekerheid omtrent de kosten en effecten van verandering. Keuzes moeten worden gemaakt over de adoptie van richtlijnen, de adoptie van implementatiestrategieën en het doen van onderzoek. Deze afzonderlijke, maar gerelateerde beslissingen kunnen worden geïnformeerd door economische evaluaties. Dit proefschrift biedt, in aanvulling op bestaande methodologie, een set van analysemethoden dat kan helpen bij het ontwerpen, analyseren, interpreteren en financieren van economische evaluaties van praktijkverandering.

Hoofdstuk 2 beschrijft een systematische review naar economische evaluaties van richtlijnimplementatie, waarbij is beoordeeld of deze aan methodologische richtlijnen voldoen. Als mogelijke afspiegeling van het toenemend belang dat wordt gehecht aan efficiënte zorg, groeit het aantal economische evaluaties. De evaluaties zijn echter vaak methodologisch niet van goede kwaliteit, wat deels wordt veroorzaakt door tekortkomingen in de methoden voor dataverzameling en -analyse. Het resulterend wetenschappelijk bewijs (evidence) is hierdoor beperkt bruikbaar voor besluitvorming over budgetverdeling voor praktijkverandering.

Hoofdstuk 3 laat zien dat een integrale aanpak voor besluitvorming over verandering in de klinische praktijk meestal de voorkeur verdient boven een sequentiële aanpak. Uit oogpunt van doelmatigheid is het beter om gelijktijdig in plaats van sequentieel keuzes te maken over richtlijnen en de daarbij behorende implementatiestrategieën. Integrale besluitvorming gebeurt op basis van de totale waarde van praktijkverandering. Om te komen tot consistente waardeschattingen, is informatie nodig over de kosten en effecten van richtlijnen, de adherentie aan richtlijnaanbevelingen, de kosten en effecten van implementatieactiviteiten en de schaal van de klinische context.

Hoofdstuk 4 presenteert een model waarmee de doelmatigheid van verandering in de klinische praktijk kan worden bestudeerd. Door gezondheidswinst in monetaire waarden uit te drukken en evidence over richtlijnen en implementatiestrategieën te combineren met informatie over de klinische context, geeft het model inzicht in de economische impact van suboptimale richtlijnadherentie, de maximale investeringsruimte voor richtlijnimplementatie en de efficiëntie van implementatiestrategieën en praktijkverandering. Besluitvormers kunnen zo prioriteiten stellen in meerdere gevallen van suboptimale zorg en problemen met ratiostatistiek vermijden. Deze problemen kunnen voorkomen wanneer meerdere richtlijnen en meerdere strategieën met elkaar worden vergeleken of wanneer beslisonzekerheid wordt geanalyseerd. De doelmatigheid van investeringen in verandering hangt onder meer af van de drempelwaarde voor kosteneffectiviteit, de 
baseline adherentie aan richtlijnaanbevelingen, de grootte van de patiëntenpopulatie en de kosten van implementatie.

Hoofdstuk 5 laat de stochastische toepassing zien van het gepresenteerde model bij besluitvorming over de eerstelijnszorg voor type 2 diabetes patiënten in Nederland. Om beslisonzekerheid te kwantificeren en te analyseren, is hierbij een geïntegreerde Bayesiaanse aanpak voor het modelleren en de synthese van evidence gehanteerd. Beslissingen over de adoptie van een richtlijn voor bloedglucosecontrole en het gebruik van audit en feedback om de richtlijn te implementeren, hangen onder meer af van de drempelwaarde voor kosteneffectiviteit. Door onzekere informatie over de richtlijn én de implementatiestrategie te combineren, neemt bovendien de mate van beslisonzekerheid omtrent richtlijnimplementatie toe. Het model biedt, met behulp van kosteneffectiviteitplots en acceptatiecurves, een eenvoudige en bruikbare methode voor de bestudering van (gecombineerde) onzekerheid omtrent beslissingen over richtlijn- en strategieadoptie. Het kan de besluitvorming over een efficiënt middelengebruik voor praktijkverandering ondersteunen.

Hoofdstuk 6 beschrijft de toepassing en het nut van een Bayesiaans model dat inzicht geeft in zowel de waarde van implementatie (dat wil zeggen, maximale investeringsruimte voor implementatieactiviteiten) als ook de verwachte waarde van informatie (oftewel, maximale opbrengst van het verzamelen van additionele evidence). De som van beide waarden geeft hierbij een indicatie van de totale opportuniteitsverliezen door inefficiënte zorg. Het model is toegepast bij de verdeling van middelen ten behoeve van metastatische hormoon-refractaire prostaatkanker in Groot-Brittannië. Het model biedt de mogelijkheid om de afzonderlijke, maar gerelateerde beslissingen ten aanzien van zorgvoorziening, investering in implementatie en onderzoeksfinanciering op eenduidige en transparante wijze te informeren.

Dit proefschrift benadrukt het belang van het meenemen van economische consequenties én het doen van methodologisch correct onderzoek bij besluitvorming over praktijkverandering onder onzekerheid. Gedegen economische analyses kunnen besluitvormers helpen om het gebruik van richtlijnen en implementatiestrategieën voor verandering van de klinische praktijk te rechtvaardigen. Volledige benutting van de verschillende methoden voor economische evaluaties vereist brede acceptatie en routinematig gebruik in besluitvormingsprocessen. 


\section{Acknowledgements}

Alongside my personal input, this $\mathrm{PhD}$ thesis has been made possible through the help of many others. Therefore, I would like to thank everyone being closely involved. First of all, I am particularly grateful to Hans Severens, Silvia Evers and Andre Ament as members of the research project team. Special thanks are also due to Liz Fenwick, Mariëtte Hubben, Karl Claxton, Steve Palmer, Jeremy Grimshaw, Trudy van der Weijden and Keith Abrams for contributing to my papers, and Mark Sculpher and Andrew Briggs for hosting my visits to the United Kingdom. Finally, I thank all my colleagues, and my friends and family for their (moral) support.

'In sharp contrast to the (scientific) contents of my thesis, a warm and well meant note of thanks can seemingly be brief'

Maastricht, August 2008

Ties Hoomans 


\section{Curriculum Vitae}

Ties Hoomans (1976 in Enschede, the Netherlands) studied Industrial Engineering and Management (MSc) at the University of Twente, the Netherlands, specialising in health care and management. He graduated in 2002, and subsequently worked as a project worker (2003) at the Academic Medical Center, the Netherlands.

From 2004 till 2008, he conducted his PhD research on methods for economic evaluation of change in clinical practice at the Department of Health, Organisation, Policy and Economics at Maastricht University, the Netherlands. During this period, he paid a long-term working visit to the Centre for Health Economics at the University of York, United Kingdom (funded with a travel grant from the Netherlands Organisation for Scientific Research (NWO)), and one to the Department of Public Health and Health Policy at the University of Glasgow, United Kingdom.

Currently, Ties Hoomans is a post-doctoral research fellow based in the Health Technology Assessment research programme at the School for Public Health and Primary Care (CAPHRI), Maastricht University. He is also appointed as an advisor at the Dutch Health Care Insurance Board (CVZ). Awarded with a NWO Rubicon grant (2008), he will be working at the University of Glasgow for a period of 12 months (2009). 
